SERVIÇO DE POS-GRADUAÇÃO DO ICMC-USP'

Data de Depósito: $\quad 29.07 .2002$

Assinatura

\title{
ARCHITECT-R: uma ferramenta para o desenvolvimento de robôs móveis reconfiguráveis
}

\author{
Richard Aderbal Gonçalves \\ Orientador: Prof. Dr. Eduardo Marques
}

Dissertação aprescntada ao Instituto de Ciências Matemáticas c de Computação - ICMC-USP, como parte dos requisitos para obtenção do título de Mestre em Ciências de Computação c Matemática Computacional.

USP - São Carlos

Julho/2002 


\section{A Comissão Julgadora:}

Prof. Dr. Liduardo Marques

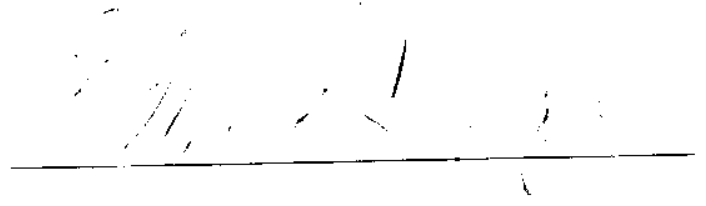

Prof. Dr. Edward David Moreno Ordonez

Prof. Dr. Rafael loueire Lins

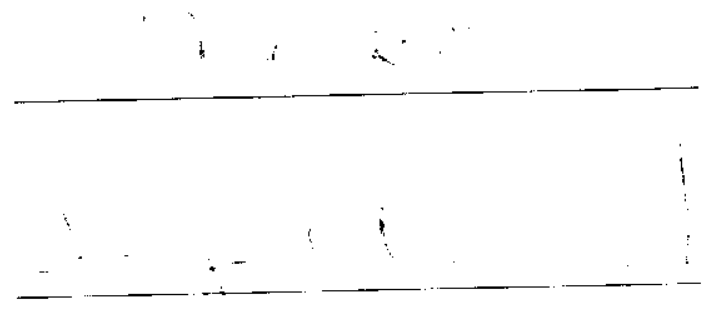


"Se a princípio uma idéia não é absurda, então não existe a menor esperança para ela" -Albert Einstein

Dedico essa monografia ao mell pai e a minha mãe, pois eles me deran as três coisas mais importantes do Inundo: SONHOS, FÉ e AMOR Sell isso seria impossivel viver, OBRIGADO)! 


\section{Agradecimentos}

Primeiramente eu gostaria de agradecer aos mens pais pelo carinho, atconção e, princijalmente, pelo anor que eles dedicaram na minha criação. Som cles nakla serja possivel;

Gostaria de agradecer imensamente ao neu oricntador, Prof. Eduardo Marques, por me tratar náo neramente cono un orientado mas quasc cono se fosse um filho;

Agradego tanbón ao Dr. Márcio Merino licmades da Siroyan-Londres: que colaboron con dieas preciosas e foi a semente que deu origen a todo esse trabalho o no traballo que esta por vir:

Agradeço a minha namorada pela sua compronsão, afeto, amor e ajuda quaso que irrestrita, sem os quais cu nào teria terminado essa monografiá;

Agradeço a Profa. Dra. Maria Carolina Monard pelas conversas que tivemos ao longo desses anos que en estive aqui no ICMC e que sempre contribuíran de alguma forma para cu me tormar una pessoa melhor fgostaria eu de ter mais conversab com essa pessoa maravilhosa!):

Gostaria também de agradecer a Beth o as demais meninas da seção de pósgraduaçào as quais sempre foram compreensivas e me trataram con o maior respeito mesmo cm momentos que el não fiz por merecer;

Além disso, não poderia deixar de agradecer a atual coordenadora da pósgraduaçio, Dra. Solange Oliveira Rozende, a qual no auxilion muito em dois monentos decisivos para a realização dessin monografia;

E não poderia deixar de agradecer aos mous amigos (em especial an Luciano e ao Bonaldo) e ao pessoal do LCli. 


\section{Resumo}

Nos últinnos anos o intercsse por robós: en especial por robos móveis, tem crescido muitu. Grandes avanços foran obticlos nessa área. Contudo a tarefa de programar unn robô móvel ainda se mostra uma tarefa extrenamente árdua tanto em termos da complexidade quanto do tempo desprendido. Algumas novas linguagens próprias para a progranação de robôs tèm sido propostas pelo meio acadêmico, tais como a CES desenvolvida pelo Institute of Robotics da CMU-USA. Outra tarefa essencial para que os robos móveis tenhan un futuro ainda mais promissor é a criaçäo de hardware dedicado para acelerar a execuçáo des algoritmos que controlann o robo de forma que ole possa tomar decisōes mais complexas de maneira mais rápida. Fssa warefa envolve o conbecinento profundo dos algoritmos utilizados pelos mosmos a lém de conhecimentos sólidos no projeto e desenvolvimento de lardware especializado. Na tentativa de amenizar essas dificuldades, será proposta neste trabalho una ferramenta para o desenvolvimento de robos móveis reconfiguráveis, clenominada ARCHI'J'ECI'-R. O objetivo do ARCHITECT-R é a geraçào autonática de hardware especializado para robos móveis através do algoritnos descritos na linguagen CES. A proposta do ARCHTECT-R é bastante arrojada e praticanente impossível de ser descnvolvida por uma só pessoa em um prograna de mestrado. Por isso o trabalho que será realizado no decorrer desse mestrado scrá apenas a criação de uma parte dessa ferramenta. Mais especificamente, serão tratados a criação de blocos arquiteturais (hardwares reconfiguráveis) para redes neurais artificiais ulilizados pela linguagem CES e a especificaçäo do sistema. 


\begin{abstract}
In the last few years, the interest in robotics (specially in mobile rohots) has grown up and many advances have been obtained in this area. But the task of programming a mobile robot still a very difficult task, both in terms of complexity and time spent. Some new languages specially designed for programming robots have been proposed by researchers. The CES language is a example of such a language. It was developed in the Institute of Robotics, CML-LSA, and will be used as the basic robot programming language for this work. Another important task for the future of mobile robots is the design of dedicated hardware to accelerate the execintion of robot's algorithms. This way, the robot will be able to take better and faster decisions. This task involves deep knowledge of the algorithms used and the design of dedicated hardware. An attempt to diminish this difficulties is proposed in this work. This attempt is the development of a reconfigurable robot hardware design tool. This tool is called ARCHITECT-R. The objective of the ARCHITECT-R is the automatic design of dedicated hardware for mobile robots using algorithms' descriptions in the CES language. This is a very ambitious purpose and would be impossible to be achieved by a rescarcher alone. This way, just a very small part of the tool is treated in this work. Specifically, the generation of dedicated reconfigurable hardware for neural networks and the UML specification of the tool. Many future works, which will have to be done for the complete development of this tool, is proposed in the last chapter of this dissertation.
\end{abstract}


2 Computaçāo Reconfigurável $\quad 7$

2.1 Paralelisno en Nível de Hotruçăo . . . . . . . . . . . . . . 10

2.2 ILP e Computaçòo Reconfigurável . . . . . . . . . . . . . 13

2.3 Sistemas Reconfiguráveis . . . . . . . . . . . . . 15

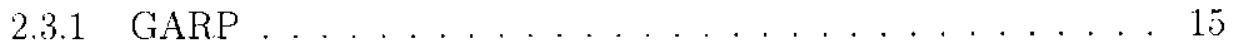

$2.3 .2 \quad \mathrm{RAW} \ldots \ldots \ldots \ldots \ldots \ldots \ldots$

2.3 .3 Chinaera . . . . . . . . . . . . . . 21

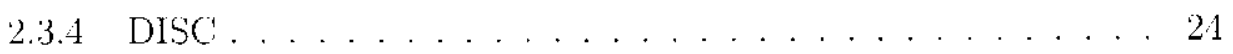

2.3 .5 PRISC . . . . . . . . . . . . . . . . . . 26

2.3 .6 Piprench . . . . . . . . . . . . . . . . 27

2.4 Perspectivals da Computação Reconfigurável . . . . . . . . . 30

3 Geração Automática de Arquiteturas de Computadores 32

3.1 PICO-Program In, Chip Out . . . . . . . . . . . 33

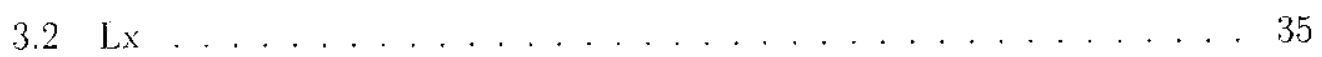

3.3 Considerações Finais . . . . . . . . . . . . . . . . . . . 40 
4 Robótica 41

4.1 Paradignalas da Robótica . . . . . . . . . . . . . . . . . . 42

1.1.1 Paradigna Deliberativo . . . . . . . . . . . . 43

4.1 .2 Paradigma Reativo . . . . . . . . . . . . . . . 44

4.1 .3 Paradigná Híbrido . . . . . . . . . . . . . . . . . 46

4.2 Arquiteturas de Robòs . . . . . . . . . . . . . . . . . . . 47

4.2.1 Exemplo de una Arquitetura Hicrárquica: Nested Hierarchical Controller . . . . . . . . . . . . . . . . . . . 49

4.2.2 Exemplo de una Arquiteura Raativa: Subsumption . . . . 50

1.2.3 Exemplo de una Arquiteura Ilíbrida: Autonomous Robot Architecture . . . . . . . . . . . . . . . 52

4.3 Robôs Probabilísticos . . . . . . . . . . . . . . . . . . 52

4.4 Robos Reconliguráveis . . . . . . . . . . . . . . . . . . 53

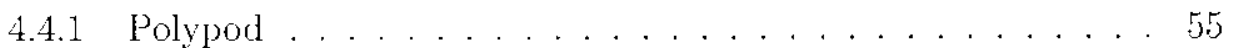

4.4 .2 I-Cubes . . . . . . . . . . . . . . . . 57

$4.4 .3 \quad$ Crystalline . . . . . . . . . . . . . . . . . 59

4.5 Linguagens para a Programaçào de Robôs . . . . . . . . . . . 62

4.5.1 Excmplo de una Linguagem Visual de Programaçào de Rolous:

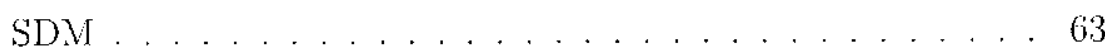

4.6 Alguns Problemas em Aberto na Robótica . . . . . . . . . . . . 64

5 A Linguagem de Programação de Robôs CES 68

5.1 Progrannação Probahilística na CES . . . . . . . . . . . . . . . 69

5.1 .1 Tipos de Dados Probabilísticos . . . . . . . . . . . 69

5.1 .2 Operadores Aritnéticos . . . . . . . . . . . . 70

5.1 .3 Conversäo de lïpos. . . . . . . . . . . . . 71

5.2 Principais Funçòs . . . . . . . . . . . . . . . . 72

5.3 o Comando probloop . . . . . . . . . . . . . . . 72

5.4 Aprendizado de Máquina na Linguagen CTS . . . . . . . . . . 72 
6 Descrição e Especificação do Sistema ARCHI'TECI-R 74

6.1 O Compilador do ARCIITLCT-R . . . . . . . . . . . . . 75

6.2 Hardware do Sistena ARCHITECT-R . . . . . . . . . . . 70

6.3 LEGUS system . . . . . . . . . . . . . . . . . . . 76

6.4 Sistema Operacional do AlRCHITECT'-R . . . . . . . . 78

6.5 Simulador do ARCHITECT-R . . . . . . . . . . . . . . 79

6.6 Diagrama de Blocos do Sistema

ARCHITECT-R . . . . . . . . . . . . . . 80

6.7 Especilicaçáo do ARCHITECT-R: UnL . . . . . . . . . . 81

6.7 .1 Principais Técnicas . . . . . . . . . . . . . 83

6.7 .2 Formentas para Especifieaçäo . . . . . . . . . 84

6.7.3 Fscolha da Ferramenta para a Espccificação do

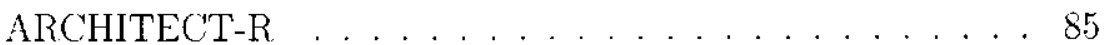

7 Compilador do ARCHITECT-R $\quad 87$

7.1 GNU Pro . . . . . . . . . . . . . . . . . . . . . 88

7.2 SUIF2 . . . . . . . . . . . . . . . . . . . . 89

7.3 Elcor . . . . . . . . . . . . . . . . . . . . . . . . . . . 89

7.4 Nenya/Galadriel . . . . . . . . . . . . . . . . . . . . . . 90 90

7.5 Consideracoes Finais . . . . . . . . . . . . . . . . . . 92

8 Construindo RPUs para o ARCHITECT-R 93

8.1 Rodes Neurais Multi-Camadas . . . . . . . . . . . . . . . . 94

8.2 Rodes Nenrais MLP on Hardware . . . . . . . . . . . . . . . . 97

8.2.1 Hardwares Concrciais . . . . . . . . . . . . . . . 98

8.2 .2 Hardwares Científicos . . . . . . . . . . . . . 100

8.3 Dispositivos Lógico Programáveis c Ferramentas de Desenvolvimento

de Hardware Utilizadas . . . . . . . . . . . . . . . . . 106

8.3.1 Famílias APEX e APEX II de Dispositivos Lógico Progranálveis 106

8.3.2 Família Stratix de Dispositivos Lógico I'rogramáveis . . . . . 110 
8.3.3 Excalibur ........................11

8.3.4 Sinulador de Lingıngens de Descriçào de Ifardware ModelSim 114

8.4 Implementacäo do Gerador de Rodes Neurais Multi-Camadas . . . . . 115

8.4 .1 Tratamentos para a Multiplicaño . . . . . . . . . . . 115

8.4 .2 Tratamentos para a Acumulação . . . . . . . . . . . . . 119

8.4.3 Tratamentos para a Função de Ativaçấo . . . . . . . . . . 121

8.4.4 Implementação do Hardware da Fase Forward cla Rede . . . 128

8.4 .5 Consideragoes Finais . . . . . . . . . . . . . . 130

9 Trabalhos Futuros e Conclusão 132

9.1 Traballos Futuros . . . . . . . . . . . . . . . . . . . . . . . . . . . 132

0.1 .1 Geradores de RPUs . . . . . . . . . . . . . . . . 132

9.1 .2 Criaçăo do Compilador . . . . . . . . . . . . . . . 133

9.1 .3 Eletrónica Evolutiva . . . . . . . . . . . . . . . . . 134

9.1 .4 Reconfigurabilidade Dinânica . . . . . . . . . . . 135

9.1 .5 Compilaçăo Dinânica . . . . . . . . . . . . 135

9.1 .6 Extensão da Linguagen CES . . . . . . . . . . . . . 136

9.1 .7 Construção do LEGUS System . . . . . . . . . . . 137

9.1.8 Criação de Robôs Miniatura para Jogos de Futebol de Robós . 138

9.2 Conchusão . . . . . . . . . . . . . . . . . . . .39

$\begin{array}{ll}\text { Referências Bibliográficas } & 140\end{array}$ 
1.1 Objetivos do Projeto $\Lambda$ rchitect-R . . . . . . . . . . . . 1

2.1 Fomas de acoplanento de um hardware reconfigurível $145_{j} \ldots \ldots 8$

2.2 Fomas de Reconfiguração $[145] \ldots \ldots \ldots$. . . . . . . . 10

2.3 Diagrana de Blocos do GARP $[82] \ldots \ldots \ldots$

2.1 Bloco Lónico do Hardware Reconfigurável do GARP [137]. . . . . 17

2.5) Arquitctura dos Computadores RAW [10]. . . . . . . . . . . . . 19

2.6 Arquitetura do Sistema Chimaera 125]. . . . . . . . . . . 22

2.7 Arquitetura do Blocos Lógicos do Sistema Chinacra [152] . . . . . 22

2.8 Diagrama de Blocos do Sistema DISC $[97 \ldots \ldots \ldots \ldots . \ldots . \ldots . . \ldots 24$

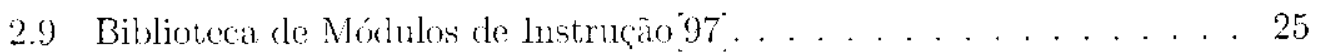

2.10 Arquitctura dos Computadores PRISC [47]. . . . . . . . . 26

2.11 Ganho de Desempentıo utilizando o PRISC [46] . . . . . . . . . 27

2.12 a)Estágios Virtuais do Pipeline. b) Estágios Reais do P'ipeline [135]. . 28

2.13 Arquitetura do PipeRench [135] . . . . . . . . . . . . . . . 29

2.14 Arquitetura dos Elcmentos de Processamento [135] . . . . . . . . . 29

2.15 Gunho de Desempenho do PjpeRench com Relação a un Computador

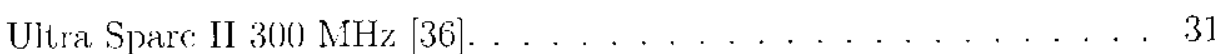


3.1 Ciclo de Desenvolvinento no PICO 156$] \ldots \ldots . \ldots . \ldots 33$

3.2 Sistenta de Desenvolvinento do PICO-VLIW [129] . . . . . . . . 34

3.3 Sistema de Desenvolvimento do PICO-NPA[63] . . . . . . . . 35

3.4 Arquitetura do Hardware do $\operatorname{Lx}[56 \ldots \ldots . \ldots . \ldots . \ldots 36$

3.5 Ciclo de Desenvolvimento no $\mathrm{Lx}[56] \ldots \ldots . \ldots . \ldots . \ldots 37$

3.6 Ciclo Detalhado de Desenvolvimento do Lx [56] . . . . . . . . . . 38

3.7 Possibilidades de Customizaçâo dentro dos Geradores de Arquiteturas. 56]. 39

4.1 Decomposição Horizontal. . . . . . . . . . . . . . . . . . . . 44

4.2 Decomposição Vertical. . . . . . . . . . . . . . . . . . 44

4.3 Exemplo de Descrição dos Comportanentos de min Robó Móvel em Subsumption $[130] \ldots \ldots \ldots \ldots \ldots \ldots \ldots \ldots \ldots \ldots \ldots \ldots \ldots$

4.4 Módulo Segmento do Polypod 127]. . . . . . . . . . . . . 56

4.5 Módulo Nó do Polypod $[127] . \ldots \ldots \ldots$

4.6 Módulos do Polypod Configurados cm Forma de Lagarta $[110$ ’ . . . 56

4.7 Possiveis Movimentos dos Elementos de Ligação dos I-Cubes [119] . . 57

4.8 Interface Gráfica de Programação dos I-Cubes $[119] \ldots \ldots . . .5 .58$

4.9 I-Chbes Escalando mu Objeto $[119] \ldots \ldots \ldots \ldots$

4.10 I-Cubes P'osicionando um Cubo para Monitoranento de nua Região

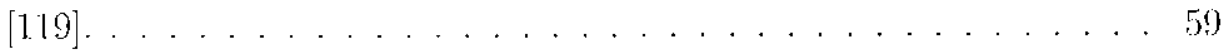

4.11 Átomo Crystalline Expandido e Contraído [107] . . . . . . . . . . 60

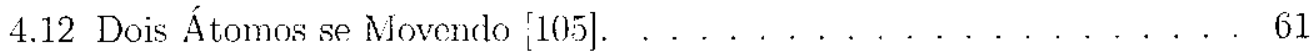

4.13 Metamorfose de um Robó Crystalline em Forma de Cachorro para a Forma de $11 n$ Sofá $[119]$. . . . . . . . . . . . . . . 61 61

4.14 Un Átomo Defeituoso (Mais Escuro) sendo Eliminado do Sistema o Substituído por un Átomo que estava Contraílo [99]. . . . . . . . . 61

4.15 Tela de Criaçäo de Camadas 120]. . . . . . . . . . . . 63

4.16 Camada 1 (Layer 1) Inibindo (S) a Camada 0 (Level 0) 120]. . . . . 64

4.17 Associando a saída Lm ao Motor da Roda Esquerda do Robô [120]. . 65 
4.18 Comportamento Sondo Criado Através do Editor de Máquinas de Estado $[120] . \ldots \ldots \ldots \ldots \ldots \ldots \ldots$

6.1 Diagrana de Blocos do LEGUS System. . . . . . . . . . . . . 77

6.2 Diagrama de Blocos do Projeto ARCHITECT-R. . . . . . . . . . 82

8.1 Descrição de um Ncurônio Compucacional [150] . . . . . . . . . . . 94

8.2 Possíveis funçöes de Ativação de um Ncuronio [150]. . . . . . . . . 9.95

8.3 Una Rede Nenral NLP con muna Canada Intennediária. . . . . . . 95

8.4 Avioes Utilizando o $\mathrm{NN}^{3}$ (Acima e Abaixo it Dircita) e Placa com Chips NNP (Abaixo à Esquerda) [41] . . . . . . . . . . . . . . 99

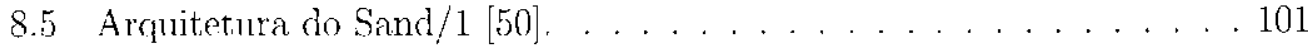

8.6 Arquitetura do RRAN [93]. . . . . . . . . . . . . . . 102

8.7 Diagrama de Blocos do Hardware de Propagação para Frente [94] . . . 103

8.8 Diagrana de Blocos do Hardware de Propagação para Trás [94. . . . 104

8.9 Diagrama de Blocos do Hardware de Atualizacão dos Pesos [94. . . . 105

8.10 Arruitetura MultiCore ${ }^{T M}[19] \ldots \ldots \ldots \ldots$. . . . . . . . . 108

8.11 Estrutura MegaLab [19] . . . . . . . . . . . . . . . . 108

8.12 Estrutura de um Eilemento Lógico (LE) [19] . . . . . . . . . . . 109

8.13 Bloco DSP da Stratix no Moclo Multiplica e Acumula [2:3] . . . . . . 111

8.14 Placa de Desenvolvimento do Kit Excalibur com Processador Nios '20],112

8.15 Diagrana de Blocos do Processador Nios [16] . . . . . . . . . 113

8.16 Flexibilidade e Esscalabilidade dos Processadores Embutidos NIOS [16].113

8.17 Diagrama de Blocos do Cirenito que Calcula o Logaritmo de um Número Multiplicado por $2^{16}[109 \ldots \ldots \ldots$. . . . . . . . . 117

8.18 Diagrana de Blocos do Circuito que Calcula a Exponencial de Númcro Dividido por $2^{2 * 16}[109] . \ldots \ldots \ldots \ldots \ldots \ldots \ldots$

8.19 Diagrama de Blocos do Cirenito que Calcula a Aproxinnação da Funçấo

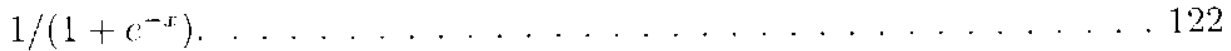


8.20 Diagrama de Blocos do Circuito que Calcula a Aproximaçāo da Função

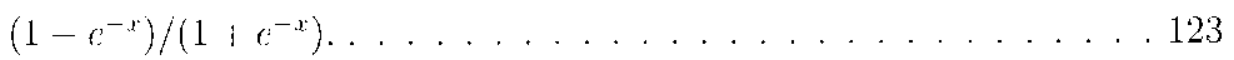

8.21 Diagrama de Blocos de $10 n$ Veuronio em Hardware. . . . . . . . . . 128 
2.1 Treho de Programa Escrito em Linguagem de Baixo Nível . . . . . 12

2.2 Conjunto de Instruẹões de uma Máquina VLIW Hipotética . . . . . . 12

2.3 Execução do Código na Máquina VLIW Hipotética . . . . . . . . . 12

2.1 Ganho de Desempenlıo do GARP sobre o SPARC utilizando-se Código Gerado na Mão. . . . . . . . . . . . . . . . . . . . . . . . . 18

2.5) Ganlo de Desempenlo do RAW sobre o SPARC 20/71 utilizando-se Código Gerado na Mão. . . . . . . . . . . . . . . . . . . . . 21

2.6 Desempenho do Sistema Chimaera . . . . . . . . . . . . 24

8.1 Dados sobre Multiplicadores nas Famílias Apex e Stratix da Altera . 116

8.2 Dados sobre Inplementação do Multiplicador em Aritmética Logarítmica nas Famílias Apex e Stratix da Altera . . . . . . . . . . . . 118

8.3 Dados sobre Acumuladores nas Famílias Apex e Stratix da Altera . . 120

8.4 Análise das Aproximaçōes Cordic-like paráa as Funçòes de Ativaçäo. . 124

8.5 Análise das Aproximaçoes J líbridas com Multiplicadores para as Funções de Ativação. . . . . . . . . . . . . . . . . . . . . . 125

8.6 Análise das Aproxinaçoes Híbridas sem Multiplicadores para as Funçoes de $\Lambda$ tivação (8 Intervalos) . . . . . . . . . . . . . 126 
8.7 Análise das Aproximações Híbridas sem Multiplicadores para as Funções de Ativaçào (16 Intervalos). . . . . . . . . . . . . . . . 127 


\section{Introdução, Justificativa e Objetivos}

Robôs móveis têm sido alvo de inúmeras pesquisas nos últimos anos. Essas pesquisas proporcionaram grandes avanços na área, especialmente no que diz respeito aos algoritmos de aprendizado de máquina e ao uso de técnicas de probabilidade para lidar com as incertezas do ambiente com o qual o robò irá interagir e com a imprecisão dos dados obtidos pelos sensores do mesmo.

Contudo, a tarefa de se programar un robó ainda ó bastálute complexa e exige o desprendinento de muito tempo. Para lentar solucionar esse problema algunas linguagens inovadoras e próprias para a programação dos mesmos tëm sido propostas [27] [120]:148] [57. 91]. Nesse traballıo scrá abordada umla dessas linguagens, denominada CES (C for Embedded System) [158: [161] que foi desenvolvida pelo Doutor Sebastian Thrun do IR-CMU (Institute of Robotics - Carnegie Mellon University). Essa linghagem visa principalnente diminuir a complexidade de se programar robos móveis o o tempo gasto em tal programação. 
Outra tarefa de suma importância para o desenvolvinento da robótica é a criação de hardware especializado para a execução dos algoritmos utilizados nos robôs. Esse descnvolvinento ten se mostrado mua tarefa extremamente árdua e cue cxige mintos conhecinentos por parte do desenvolvedor conhecimentos tanto da área de algoritmos de aprendizarlo de máquinas quanto de técnicas de projeto e de desenvolvinento de hardware. Além de complexa, hoje, essa tarefa se mostra extremamente lenta devido ì falta de ferramentas próprias para a criação de liardwares para robótica (as ferramentas utilizadas sào para o desenvolvinento de hardware geral, com algumas excegós [120j [131]). Alón disso, os poucos hardwarcs criados especialnente para robôs costuman ser ASICs (Application Specific Integrated Crrail), os quais são extremanente caros. O custo de desenvolvinento de um ASIC é da ordem de 1 milhão de dólares, o que é proibitivo para a maioria dos grupos de pesquisa ou desenvolvimento cm robótica [77].

Outra desvantagem dos ASICs é que eles não poden ser modificados park se adaptarem a mudanças tanto de curto prazo (por exemplo, mudança na intensidade da iluninaşo) quanto de longo prazo (por exomplo, mudanga de utilização do robó). Para ilustrar melhor esta questão suponhan que exista un ASIC para o controle de navegarào de un robô nóvel utilizando un algoritmo $X$ e que em pesquisas futuras tenla sido descoberto que o algoritmo Y é mais eficiente. O projetista do robô teria que tomar una importante decisâo: reconstruir (do zero) todo o hardware de navegação do robó para que ele incorpore esse novo algoritno, on manter o hardware antigo.

Una techologia que tem se mostrado nuilo interessante do ponto de vista comercial, que vem sendo utilizada com una frepuiència ascendonte e que pode resolver esse problema, é a Computação Reconfigurável. Sistcmas de Computação Reconfigurável [84] são plataformas de hardware cujas arquiteturas podem ser modificadas pelo software, em tempo de execução, para melhor adequar-se à aplicação executada naquele instante. O termo, geralnente, reforesc à habilidade do reconfigurar um circuito FPGA (Field Programmuble Gate. Amoy) bascado na tocologia SRAM 
(Slalic Rundom Access Memory). Lintào, através desta tconologia obtêm-se chips extremamente eficientes e totalmente rcaproveitáveis, pois estes podem ser reprogramados o rentilizados quantas vezes foren necessárias. É importante ressaltar que é o hardware reconfigurével que se adlapta à aplicação e não o contrário. Por isso, seria multo interessante a existência de una ferranenta que automatizasse a criação desse hardware reconfigurável para o robô a partir de um programa fonte da aplicação e que ao mesmo tempo otinizasse a geraçäo do código objeto do programa para csse determinado lardware.

Dentro deste contexto foi criado o Projeto ARCHITECT-IR 52] [4] [51]que visá a criaçâo cle mua ferramenta como a mencionalda, explurando as técnicas de Computação Reconfigurável.

O objetivo do Projeto ARCHITECT-R (Fïg. 1.1) é tornar-sc una ferramenta avançada de desenvolvimento de hardware para robótica. A partir de una dada aplicação, escrita em linguagem CES, cla deverá gerar automaticanente (através de técnicas avançadas de ILP - Paralelisno em Nível de Instrução, computação reconfigurável, compilaçăo e intcligência artificial) una arquitetura reconfigurável para a execução desta aplicação específica e un conjunto otinizado de instruções de máquina para essa dada arquitetura. A arquitetura proposta será especificada por blocos lógicos arquiteturais escritos na linguagem de descrição de hardware VHDL (VHSIC Hardware Description Language, onde VISIC é a sigla de Very High Speed Integraled Circuit) [76] [162] ou Verilog [43. [89].

Una das tarefas mais importantes para o desenvolvimento do sistema ARCHIECT$R$ é a construção do compilador para a linguagen CES, atualmente não existe nenhum compilador para essa linguagen. Desse modo, pretende-se cscolher como compilador base do ARCHITECT-12 o GNU Pro [66] 67] [124], on o SUIF [68] ou ainda o Elcor/Impact do sistema trimaran [144. [128] [61], todos para linguagens $\mathrm{C} / \mathrm{C}++$ e extendè-lo con técnicas de compilação para conputação reconfiguráveis, algumas das quais conticlas no compilador Nenya/Galadriel front-cnd o back-end compiler, respectivanuente) $\{122\}[121], 39$;. 


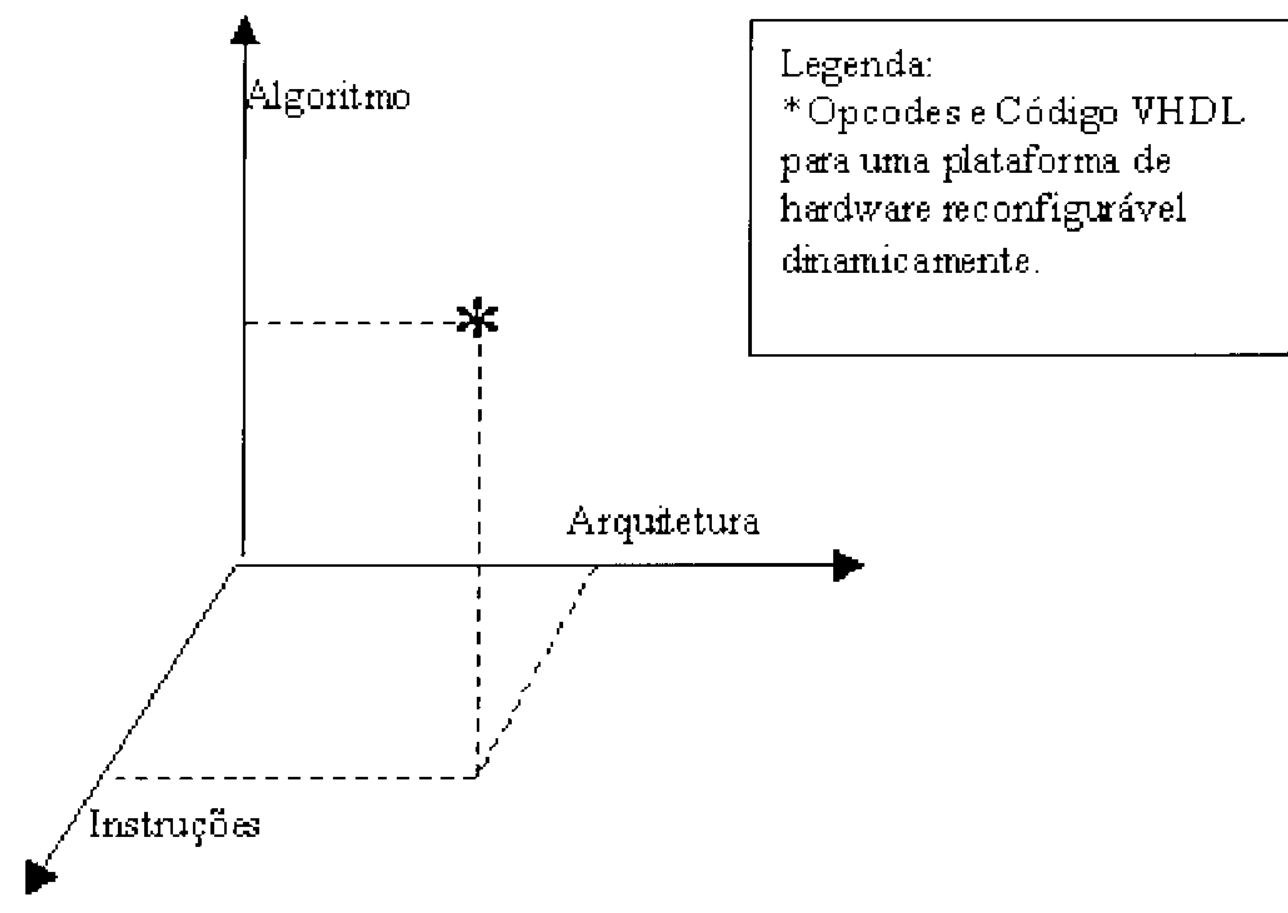

Figura 1.1: Objetivos do Projeto Architect-R

Outra tarefa importantíssima será a construção de RPUs (Reconfigurable Processor Units), as quais são análogas as unidades de processamento dos microprocessadores convencionais, con a diferença de que estas unidades poden ser inseridas ou retiradas do hardware de acordo com a necessidade do utilizaça de destes hardwares'. Essas RPUs serão responsáveis por implementar diretannente no hardware alguns dos algoritmos mais commmente usados na robótica (tais como algoritmos de redes nenrais, algoritmos genéticos c lógica fuzzy), bem como funções especílicas da CES que podem sofrer un ganho muito elevado quando construídas no próprio hardware; cm especial as funçoes gure envolven probabilidade.

Cabe ressaltar que para que o projeto $A R C H I T E C T-R$ obtenla sucesso é necessírio que o sistema conte com o suporte de um sistema opreracional especial. Esse sistema operacional será responsável pela reconfiguração do robò e por prover algumas

\footnotetext{
${ }^{3}$ Alguns autores também chamam esse tipo de hardware de SFUs (Sprcial Functional Units)
} 
utilidades tipicannente associadas a sistemas operacionais (tais como commicação de processos, controle de processos, controle de entrada e saída). Essc sistemal operacional será particularmente complexo porque cle terá que trabalhar num sistema reconfigurável dinànico; ou scja, o sistema pode ser reconfigurado en tempo de execução, utilizando-se múltiplos processaddores. Esse sistema operacional de tempo-real (RTOS) será desenvolvido a partir do eCos (Embbeded Configurable Opcrating System) [72] [73. [61], o qual é un sistema operacional parecido com o Linux especialnente criado para aplicaçoes embarcadas e de tempo-real.

A ferranenta ainda terá que contar com un clemento que integre todos os elcmentos descritos acima da melhor forma possivel. Esso clemento integrador foi denonninado Legus. As funçòes do Legus são: definir quais as RPUs que estarão ativas a carla momento, qual é o conjunto de instruşoes que o compilador pode utilizar a cada momento e qual a tarefa que o sistema opcracional terá que desempenlar.

O AlRCHI'LEC'I-R não seria completo scm uma forma de validar o programa e o hardware gerado e de testar o desempenho do sistema. Para isso scrá necessário o desenvolvinento de un simulador parametrizável do sistema, semelhante ao utilizado no 'TRIMARAN da HP [144.

A proposta do ARCHITECT-R é bastante arrojada e praticamente impossível de ser desenvolvida por uma só pessoa cm un programa de mestrado. Por isso o trabalho que será realizado no decorrer desse mestrado será apenas a criação de uma parte dessa ferramenta. Mais especificanente, serão tratados a criação de blocos arquiteturais (hardwares reconfiguríveis) para redes neurais artificiais utilizados pela linguagem CES e a modificaçio do compilador GNU Pro para reconlecer e utilizar esses blocos.

É importante ressaltar que o ARCHII'ECT-R é um trabalho conjunto do Laboratório de Computaçāo Reconfigurável (LCR) do ICMC-CSP con o LABIC (Laboratório de Inteligência Computacional), e servirá como ferramenta de apoio ao descnvolvimento do projeto ARMOSH (Aprendizado de Robôs Móveis via Software c Inardware - processo FAPESP nro. 2000/(2959-3) que visa implementar algoritmos 
de robótica en software e hardware reconfigurável [58].

No Capítulo 2 scrá discutida a conputação reconfigurável e serão mostrados alguns exemplos de arquiteuras reconfigmáveis. O Capítulo 3 discute dois dos principais geradores de arquiteturas: o PICO e o Lx, ambos da HP. No Capítulo 4 serão introduzidos os robôs móveis e a sua problemática. O Capítulo 5 descreve a linguagem de programação de robôs CES, a qual será a linguagem utilizada 110 ARCHITECT-R. No Capítulo 6 será descrita a ferramenta para desenvolvimento de robôs móveis ARCHITECT-R c a linguagem UML: a qual está sendo nsada pará a especificação da ferramenta. As opçōes de compiladores para serem utilizadas's no ARCHITECT-R sào discuticlas no Capítulo 7. As etapas para a construção de um gerador de RPL's para redes neurais MIT sĩo comentadas no Capítulo 8. Concluindo a disscrtação, o Capítulu 9 apresenta algumas opções de trabalhos futuros e algumas consideraçós finais sobre o trabalho. 


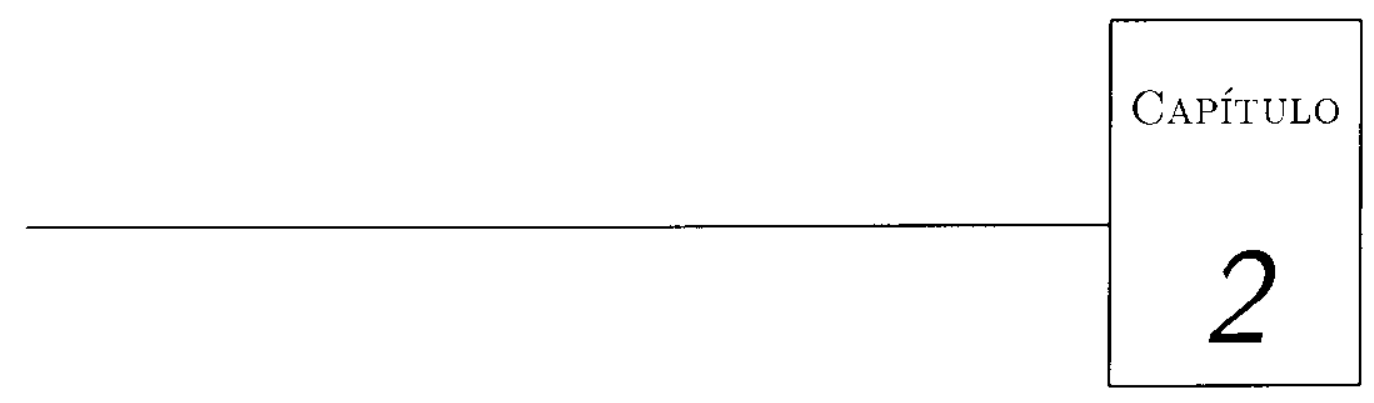

\section{Computação Reconfigurável}

Existem classicamente duas formas de se executar um algoritmo computacional [90]: através de ASICs ou microprocessadores. Cono os ASICs (também chamados de hardware totalmente customizados) são projetados para executarem uma detcrminada operação, eles são extremamente rápidos e eficientes quando estào executando a operaçào para a qual cles foran desenvolvidos. Contudo, apús fabricado o $A$ SIC nâo pole ser alterado. Caso seja necessário modificá-lo, ele tem cue ser desenvolvido e fabricado novanente, o que é unna tarefa bastante onerosa (tanto do ponto de vista do tompo desprendido quanto do dinheiro gasto no processo).

Por outro lado, os microprocessadores são dispositivos bastante flexíveis que podem ser programados para desempenhar qualquer operação digital. Entretanto, ele tem um desempenho menor quando comparado com un ASIC: por causa do tempo ganto na busca e decodificaño de instrugóos e por cansa da sua mão-especialização.

Una nova forma de computaşão que vem ganhando destaque, principahnente. 
nos últinnos anos, é a computaçào reconfigurável [7! [2] [83] [78] ¿146] [149] [145] $[77]$.

Fm tormos mais básicos podenos definit a computação reconfigurável como sendo a capacidade que um sistena (hardware) possui de ser programado e reprogramado (quer seja en tempo de execução ou não) após a sua fabricação.

O hardware reconfigurável introduz um novo conceito que antes não existia: o conceito de hardware virtual. O conceito de hardware virtual é o de que só ć necessário ter ativo $n o$ sistema o liardware dedicado para executar as tarefas que estäo sendo executadas naguele instante. Deste modo, sempre que mua parte do hardware virtual não é mais necessária ela é "eliminada" do chip e sempre que una nova funcionalidade é requerida cla é "inserida" no chip (o que é análogo ao concito de memória virtual). Essa característica de poder possuir hardware virtual faz com que o lardware reconfigurável se adapte as reais necessidades da aplicação (software). Com isso, obtém-se a flexibilidade do soltware com o desempenho do hardware. Alén disso, preenche-se a lacuna que existia anteriormente entre o software (flexivel e lento) e o hardware (inflexível e rápido) [145] [146].

O hardware reconfigurável pode ser clissificado segundo dois critérios [90]: acoplatmento e reconfigurabilidade.

Em relação an acoplamento têm-sc as scguintes possibilidades (Fig.2.1):

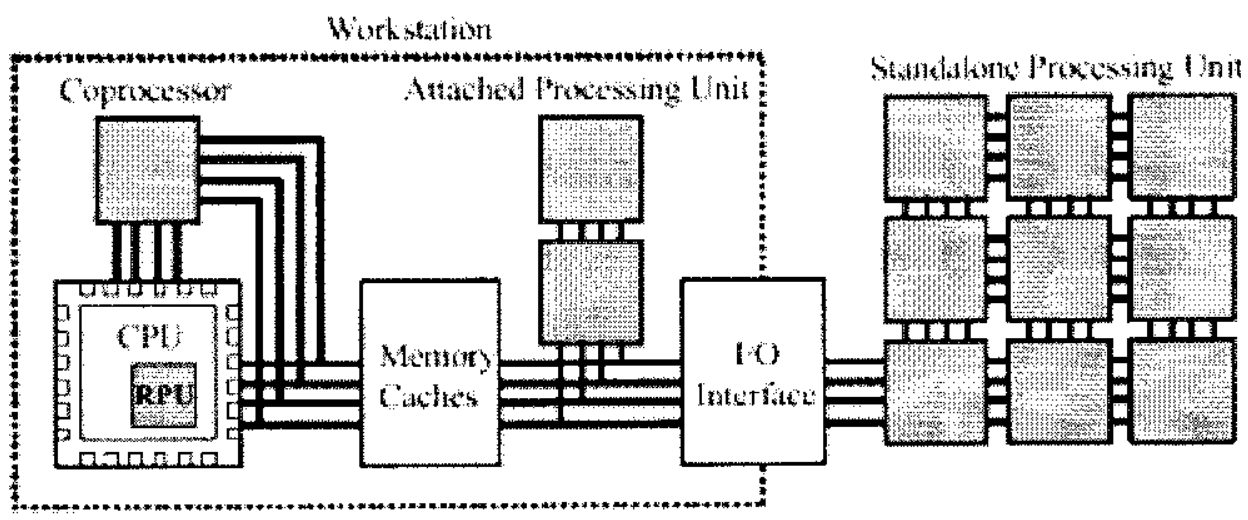

rigura 2.1: Formas de acoplannento de um hardware reconfigurável [145]. 
- Unidades Funcionais Reconfiguráveis (RPUs): neste modelo o hardware reconfigurável é utilizado cono se fosse uma unidade funcional do processador principal, acessando os registradores do próprio processador para armazenar seus dados de cutrada e de saída. Isto permite nun anıbiente de programação tradicional com a adição de algumas instruções especiais que podem nudar com o tempo.

- Coprocessador: neste modelo o coprocessador é inicializado pelo processador principal que diz quais são, ou onde estão, os dados que o coprocessador necessita. () coprocessador efetua as opcraçòes necessárias independente do processador principal e retorna os resultados após o término da sua exccução. Esse modo implica em un overhead maior cle commicação entre o processador e o hardware reconfigurável. Contudo pode aumentar o grau de paralelismo do sistema visto que o coprocessador opera independente do processador. Geralmente os coproccssador reconfiguráveis são maiores do que as unidades funcionais reconfiguráveis.

- Processador: agora o hardware reconfigurável opera como un processador adicional num ambiente multiprocessado. O ovcrhead deste modelo é ainda maior do que no modelo coprocessador. Entretanto, o hardware reconfigurável ganha mais independência do processador, o que possibilita que ainda mais partes do processamento sejam passadas para o hardware reconfigurável.

- Standalone: aqui o hardware reconfigurável opera sozinho, sem a interferência de um processador. Esse modelo é recomendado para casos onde deseja-se processamento de alta capacidade que necessita de unl hardwaro dedicado.

En relaçäo a reconfigurabilidade ten-se os seguintes nodlos (Fig.2.2):

- Total: implica en que todo o hardware tem que reconfigurado de una só vez. 


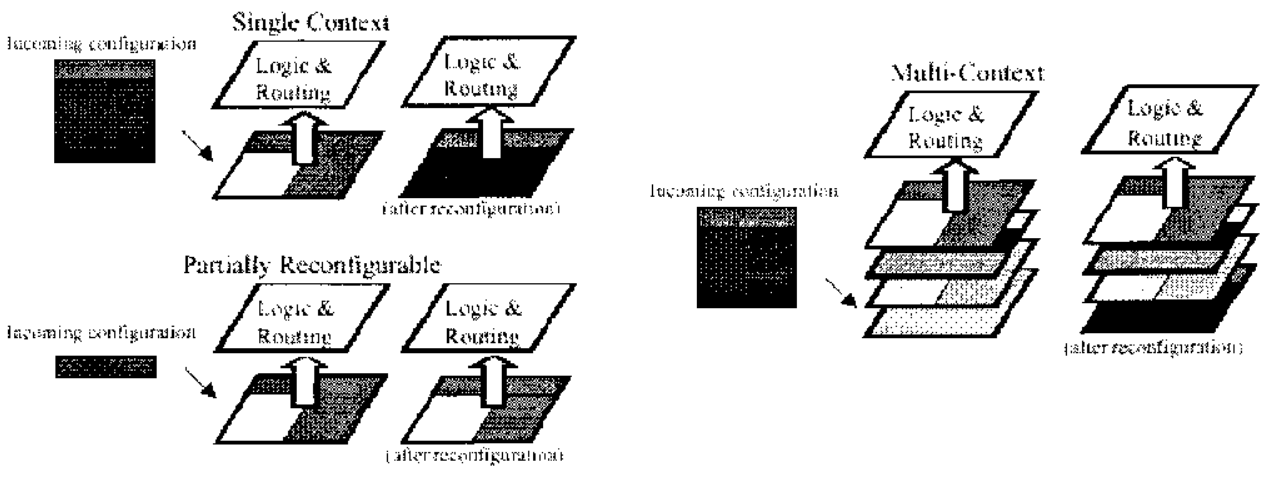

Figura, 2.2: lonmas de Reconfiguraçăio [145].

- Parcial: pernite que apenas alguns trechos do hardware sejann reconfigurados, mantendo-se os demais trechos intactos.

- Estática: o dispositivo necessita ser desligado para ser reconfigurado.

- Dinâmica: o dispositivo pode ser reconfigurado em tempo de execução.

- De contexto único: apenas una configuraşáo é carregada por vez.

- De múltiplos contextos: múltiplas configuraçoes podem estar carregaralas en un deterninado monento. Contudo, apenas una configuração pode estar ativa (sendo executada). Fsse modelo permite uma reconfiguração rápida do dispositivo, a qual ó feila através da troca da confignração ativa pela configuração necessária. Esse conccito é semelhantc ao uso de uma memória cache numa arquitetura convencional, onde as páginas trocadas seriam os arquivos de reconfiguração do hardware a ser programado.

\subsection{Paralelismo em Nível de Instrução}

O paralelismo em nível de instrução (ILP) é uma família de técnicas de desenvolvimento de hardware (en especial, processadores) e compiladores que aumentam o desempenlo dos computadores, farendo com que operaçoos, tais como leitura e 
escrita de mennória, adição de inteiros e multiplicação de ponto flutuante, sejann executadas em paralelo 8] [134].

As operaçoes envolvidas são operaçôes normais no estilo RISC (Roduced Instruction Set) e o prograntador encreve as suas aplicações cono se estivesse escrevendo uma aplicaçāo seqüencial convencional, on seja, utilizando linguagens de alto nível como $\mathrm{C} / \mathrm{C}++$ ou Java. Un fator importante destas técnicas é que elas são transparentes aos usuários e, portanto, podem manter toda a base de software seqücncial instalada e ainda melhorar o seu desempenho.

Arquiteturas VLIW (Very Long Instruction Word) e Superescalares são exemplos de hardwaress que utilizan técnicas de ILP. Software pipelining, previsào de saltos, execuçâo especulativa e execução predicativa [133] [141] [154] são excmplos de técnicas de ILP utilizadas pelo compilador Elcor [128] [154.

Como um excmplo didático de ILP, será apresentado o trecho de programa escrito em linguagem de baixo nível da tabela 2.1 .

Para este exemplo ó utilizada una arquitetura VLIW com 2 unidades de inteiros (IU), 2 unidades gerenciadoras de memória (MNU) e 1 unidade de salto (BR), e possuindo um conjunto de instruçós descrito na tabela 2.2. 'I'onando-se por base a cxecução seqüencial do trecho de código da tabela 2.1 tem-se um tempo de execução de 9 ciclos. Utilizando-se técnicas simples de ILP aplicadas a essa arquitetura o tempo de cxecução caiu para 6 ciclos (Tal. 2.3) e houve un ganlıo de 33,3\%, provando que mesmo aplicando-se apenas técnicas simples de ILP, pode-se tor um ganho considerável de desemponló ${ }^{1}$.

A principal vantagem das técnicas de otimização ILP sobre ontras técnicas (tais ('ono vetorização) é que a ILP pode ser aplicada en código seqüencial convencional o que permite manter a base de software seqüencial instalada e melhorar o scu desempenho.

As técnicas do ILP sào exploradas com nunito sucesso nas ferramentas da IJP'

\footnotetext{
${ }^{1}$ Um ganho ainda mais considerável de desempenho poderia ser obtirlu, visto que a matoria dats unidarles funcionais ficam ociosas a maior parte da execuçäo do trecho.
} 
Tabela 2.1: Trecho de Programa Fscrito en Iinguagem de Baixo Nível

\begin{tabular}{|c|c|c|}
\hline & Instruções & Ciclos \\
\hline \multirow[t]{7}{*}{ Loop: } & I1: 'T1=LOAD X(J) & 2 \\
\hline & $\mathrm{I} 2:{ }^{\prime} \mathrm{I} 2=\mathrm{I}^{\prime} 2+5$ & 1 \\
\hline & $\mathrm{I} 3: \mathrm{T} 3=\mathrm{T} 2 * \mathrm{~T} 4$ & 3 \\
\hline & $\mathrm{I} 4: \mathrm{U}=\mathrm{C}+\mathrm{T} 3$ & 1 \\
\hline & $\mathrm{I} 5: \mathrm{J}=\mathrm{J}+1$ & 1 \\
\hline & I6: If J < 10 GOTO (Loop) & 1 \\
\hline & Total de Ciclos & 9 \\
\hline
\end{tabular}

Tabela 2.2: Conjunto de Instruçòes de uma Máquina VLIW Hipotética

\begin{tabular}{|c|c|c|}
\hline Operação Executada & Unidade Funcional & Ciclos \\
\hline Adição o Sulstração & IU1 e IU2 & 1 \\
Multiplicação & IU1 & 3 \\
Leitura de Memória & MMU1 e MMU2 & 2 \\
Fscrita de Memória & MMU1 e MMU2 & 1 \\
Comparação & BR & 1 \\
Salto Incondicional & BR & 1 \\
Salto Condicional & BR & I \\
\hline
\end{tabular}

Tabela 2.3: Exocução do Código na Máquina VLIW Ilipotética

\begin{tabular}{|c|c|c|c|c|c|}
\hline Ciclo de Execução & IU1 & IU 2 & MMU1 & MMU2 & $\mathrm{BR}$ \\
\hline 1 & $\mathrm{I} 2$ & Ijj & I1 & $\otimes$ & $\otimes$ \\
\hline 2 & $\otimes$ & $\otimes$ & $\otimes$ & $\otimes$ & $\otimes$ \\
\hline 3 & I3 & $\otimes$ & $\otimes$ & $\otimes$ & $\otimes$ \\
\hline 4 & $\otimes$ & $\otimes$ & $\otimes$ & $\otimes$ & $\otimes$ \\
\hline 5 & $\otimes$ & $\otimes$ & $\otimes$ & $\otimes$ & $\otimes$ \\
\hline 6 & I4 & $\otimes$ & $\otimes$ & $\otimes$ & I6 \\
\hline
\end{tabular}


para desenvolvimento de arquiteturas 128] [154] [26].

Existem dois projetos na IIP para a geraçäo de arquiteturas customizadas estilo EPIC [142] :15:3]. As ferramentas são o PICO (Progran-On-Chip-Out) [129]:156i] c Lx [56], os quais possuem objetivos arquiteturais smelhantes ao ARCHITECT-R.

Esses trabalhos scrão analisados, posteriornente, no decorrer do desenvolvimento do ARCHITECT-R.

\subsection{ILP e Computação Reconfigurável}

Computação Reconfigurível são sistemas de computação paralela que exploram paralelismo em nível de instrução possuen o mesmo objetivo: acelerar a cxccução de una dada aplicação e explorar suas peculiaridades.

Para a computação paralela, a melhora no desempcnho ć obtida através da exploração do paralelismo existente nun prograna e en seu mapcantento nas vírias unidades funcionais de uma dada arquitenura. Para a Computação Reconfigurável, a aceleraçäo na execução de una aplicaçào é obtida transferindo-se as partes do programa que sâo computacionalmente mais intensivas (lentas) para as Unidades de Processamento Rcconfigurável (RPUs). Fssas duas técnicas podem ser unidas para a obtenção de melhores rcsultados.

O descrnolvinento de aplicaçöes $11 n$ ambiente de computaçầo reconfi-gurável requer o uso de uma das seguintes metodologias:

1. O uso de objetos de hardware (cores) adquiridos junto a distribuidores ou desenvolvidos por um projetista de hardware, tendo-se en mente una interface específica com a lingnagen de software que está sendo ntilizada. Essa metodologia é apropriada para o desenvolvimento de aplicaçoes que necessitan de funções padrào tais como: redes neurais artificiais, algoritmos genéticos e transformaçâo de Fourier. Contudo, essa metodologia exige que o usuário utilize as funçôes da linguagen que já estão mapcadas no hardware. Sc o usuário não fizer uso dessas funçôes o sistema reconfigurável será mais lento, 
consumirá mais energia e será mais caro do que um sistema convencional com os mesmos recursos de hardware e compilação. On seja, rentilizar os cores prontos agiliza demais as implementacoos mas restringe a flexibilidade.

2. O uso de uma ferramenta para a compilação de un programna em linguagem de alto nível para un código objeto que scrá executado num processador junto com seus arquivos de configuraça usados para progranar as RPUs. Essa aborlagem é mais complexas, porém mais flexívol.

Cada mina das metodologias antoriores possui suas vantagens o suas desvantagens. A mellor forma de obter as melhores RPUs possiveis é ntilizando-se um compilador especial que detecte as mellores partes do código foute para serem excutadas en hardware reconfigurável, e que passe essa informação para nma ferramenta de síntese lógica de alto nível (HLS - High Level Synthesis)², a qual gerará as RPUs necessárias valendo-se de una biblioteca de componentes de hardware. Essa abordagem será utilizad no ARCHITECT-R (Capítulo 6).

Para isso, o compiladur deve empregar técnicas de otimização de forma a expor o máximo possível de paralelismo existente no prograna. As técnicas que são tipicamente minregadas säo: hyperblock e superblock formation, loop unrolling, software pipelining, trace scheduling, strength reduction; commom subexpression elimination c function inlining.

Os componentes que formarào a biblioteca de componentes de hardware clevem ser aqueles que serão mais tipicanente utilizados, os quais produzem o maior ganho de desempenho, e que poden ser identificados em tempo de compilaçâo. l'or exemplo, não adiantaria provermos componentes de hardware que implenentasscm redes neurais multi-camadas se não tivésscmos como iclentificar que un cleterminado trecho da aplicação necessita daqucle componente. Utilizando-se essa técnica obtém-se os benefícios de cada una das metodologias anteriomente citadas, minimizando os seus malefícios.

\footnotetext{
${ }^{2}$ HIS é o processo de trantsformaçäo de uma descriço de hardwate para hardware real.
} 


\subsection{Sistemas Reconfiguráveis}

No passado, a computaça reconfigurável era utilizada apenas para resolver problemas intrinsecanente paralelos, on seja, problentis onde a habilidade do hardware reronfigurável de explorar o paralelismo espacial[49j garantia uma performance muito maior do que a dos dispositivos de propósito geral e, às vezes, até mesmo do que os supcrcomputadores. Contudo, essas tarefas eram bastante específicas e na maioria das vezes poderiam ser melhor solucionadas através do 11so de ASICs.

$\Lambda$ tendência moderna é a de se utilizar a computaçäo reconfigurável para acelerar aplicaçôes de propósito geral ou de uma área específica [54]. Para isso é necessário o desenvolvinento de novas ferranentas que apóien o desenvolvimento das aplicações para esses sistemas, en especial o descnvolvimento de novos compiladores que sejann capazes de tirar o maior proveito possível do hardware reconfigurável. O descuvolvimento dessas ferramentas ainda cstá numa fase bastante inicial, miss os resultados obtidos já são bastante promissores.

Alguns sistenas reconfiguráveis que foram criados con sucesso são descritos 1las seçoes scgnintes.

\subsubsection{GARP}

O GARP 80 [86] 137] [82] [79] é o projeto de um sistema reconfigurável que cstá sendo desenvolvido na Universidade de Berkeley que tem por objetivo investigar a viabilidade de sistemas reconfiguráveis e da compilação para esses sistcmas. O GARP combina um processador escalar MIPS com hardware reconfigurável, o qual é utilizado como un acelerador (Fig. 2.3). O hardware reconfigurável e a interface entre os componentes do sistema foram desenvolvidos tendo-se em mente a sua utilização em aplicaçoes computacionais de propósito geral. O GARP foi projetado para trabalhar $11 m$ ambiente de processamento que inclui programas estruturados, bibliotccas de subrotinas, mudanças de contexto, memória virtual e múltiplos usirários. 


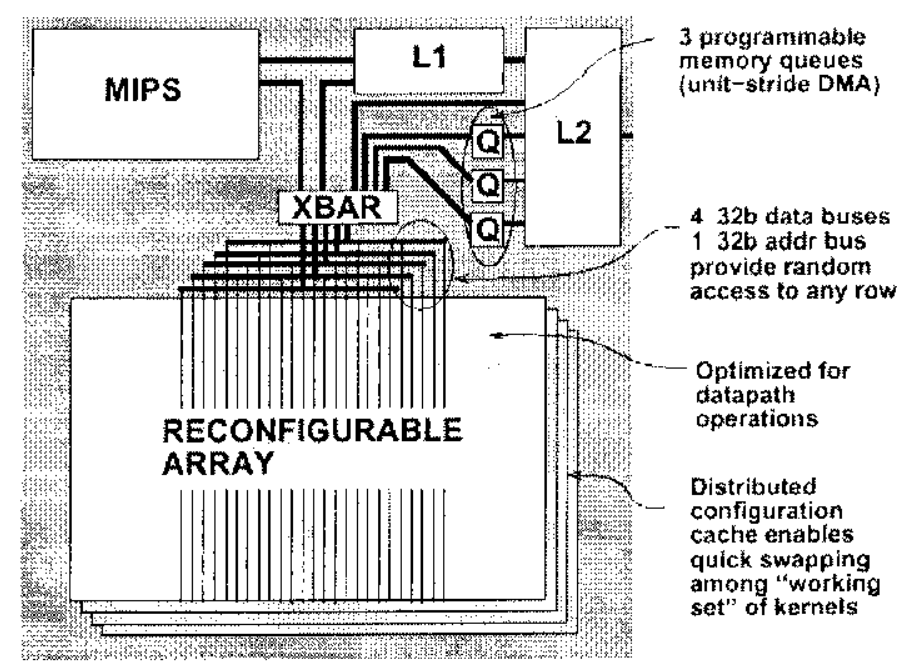

Figura 2.3: Diagrama de Blocos do GARP [82].

O projeto considerou que a parte reconfigurável do GARP seria utilizada para acelerar a execução de loops de aplicaçòes de propósito geral. Dessa forma, a parte reconfigurável foi implementada cono un coprocessador. Foram criadas instruçes especiais no processador para controlar esse coprocessaklor.

As configuraçōes do hardware reconfigurável poden ser armazenadas na memória principal (onde o tempo de reconfiguração é da orden de milhares de ciclos de processamento), na cache do processador (onde o tempo do reconfiguração é da orden de centenas de ciclos de processamento) on muma cache especial de reconfiguração (onde a rcconfiguraçäo leva aproximadamente cinco ciclos).

O processiador possui instruçõos especiais para configurar o coprocessador e carregar os dados necessśrios para iniciar a sla execução; conno por exemplo, a posiçio inicial da memória onde o coprocessador deve ir buscar os dados sobre os quais ele deve executar unla determinada opcraçìo. Quando a configuração é carregada o coprocessador comega a executar a tarefa desejada até terniná-la. Uma nova configuração somente pode ser feita após o término dessa tarefa. Se o proccssador necessitar reconfigurar o hardware, ele é bloqueado até que a tarefa seja completada.

O hardware reconfigurável presente no GARl' (Fig. 2.4) foi especialmente pro- 
jetado e otimizado para executar tarefas numéricas (soma, subtração, multiplicação e divisão).

O GARP conta com un compilador para a linguagen C [82] [80]. Esse compjilador é derivado do SUIF [68]. O compilador é responsável pelas seguintes tarefas:

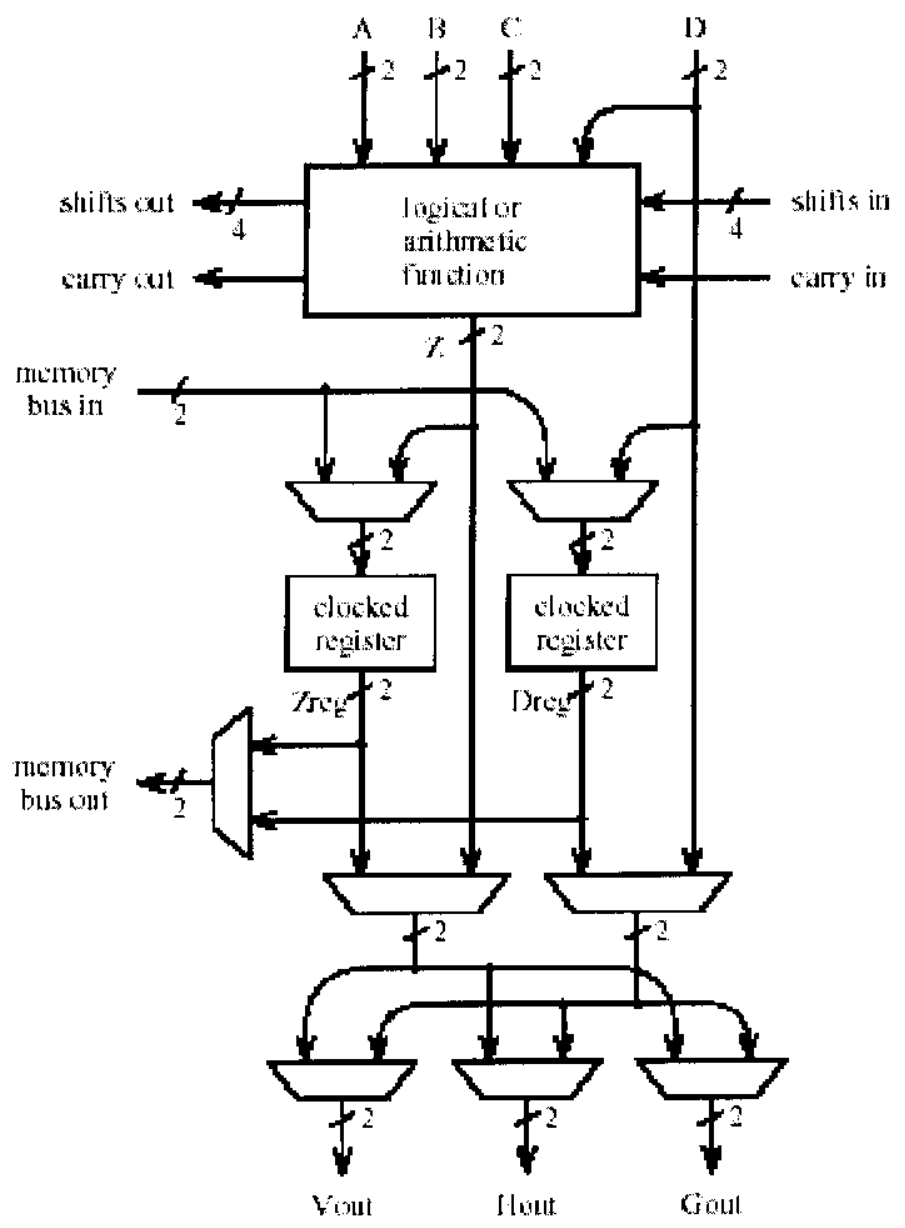

Figura 2.4: I3loco Lógico do Hardware Reconfigurável do GARP [137]. 
Tabela 2.4: Ganho de Desempenho do GARP sobre o SPARC utilizando-se Código Gerado na Mão.

\begin{tabular}{|c|c|c|}
\hline Aplicação & Tamanho dos Dados & Ganho de Desempenho \\
\hline filtro de nédia para inagens & $610 \times 180$ pixels & 43 \\
DES & 1 MByte & 18.7 \\
strlen & 1024 chars & 14.2 \\
strlen & 16 chars & 1.84 \\
sort & 2 MBytess & 2.2 \\
\hline
\end{tabular}

- Traduzir o código-fonte para uma linguagem internediária;

- Particionar o que será computado no hardware reconfigurável e o que será computado no MIPS;

- Mapear, posicionar e fayer o roteanento da parte que será implementa en heurdware:

- Gerar as configuraçoes, gera o código que será rodado no MIPS:

- Inserir algumas instruçōes para a sincronizaçäo entre o coprocessador c o MIPS.

A maioria das técnicas aplicadas por esse proccssador derivam de técnicas de paralelismo em nível de instrução (ILP) 81] 122] 96. [151] [3] [144] [128].

Uma característica marcante do GARP é que a compilação de ma aplicação nesse sistema leva menos tenpo do que a síntese de hardware na maioria dos compiladores de linguagens de descriçao de hardware (HDLs). Isso não ocorre na maioria dos sistcmas reconfiguráveis e é decorrente principahnente da estrutura do hardware reconfigurável $[137]$.

O GARP tem obtido bons resultados quando comparado com processadores de propósito geral (Tab. 2.4). Contudo, o GARP aindà não foi implennentado cm silício c todos os resultados obtidos até agora sào decorrentes de simulação. 


\subsubsection{RAW}

() RAW é um sistema reconfigurável que está sendo desenvolvido no MIT. O princípio pclo qual o $\mathrm{R} \Lambda \mathrm{W}^{3}$ [10] [9] [30] [29] 7] ó o de criar hardwares simples cuja arquitetura esteja totalmente exposta ao compilador (ou ao software). Essá é a mesma premissa de projeto dos processador $V \mathrm{~L} / \mathrm{W}$, com a diferença de que o RAW possui elementos reconfiguráveis.

A arquitetura do RAW (Fig. 2.5) é composta por um conjunto de blocos interconectados, os quais possuem memória de instruções, memória de dados, unidades lógicas e aritméticas (ULAs), hardware reconfigurável e comutadores programálveis (para lidar con roteannento dinâmico e estático). Cada bloco suporta múltiplos níveis de granularidade das operaçöes (bit, bytc e word) o que permite que o programador explore melhor cada un dos blocos. Alćm disso, a parte reconfigurável de cada bloco pernite que o progranador crie operaçoes especiais para aquela aplicação em particular.

A cstrutura do RAW foi criada para explorar o paralelismo em nível de instruçäo (ILP). Em particular, para cxplorar a possibilidade de pipeline entre as operaçóes.

\footnotetext{
${ }^{3} \mathrm{O}$ nome $\mathrm{RAW}$ vem do fato de que a arquitelura é simples - "crua".
}

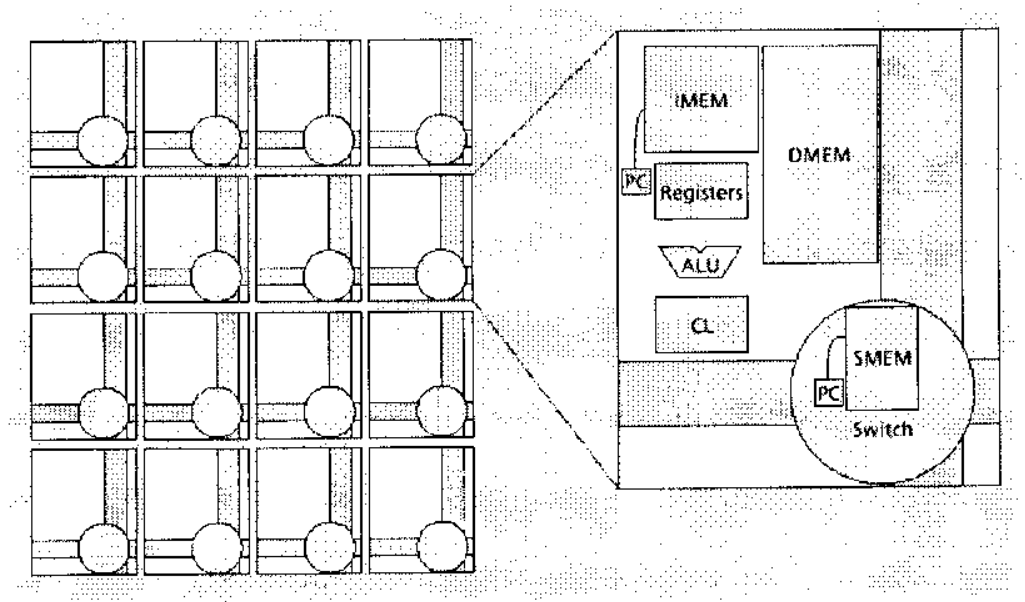

Figura 2.5: Arcuitetura dos Computadores RAW 10]. 
Éntretanto, seu hardware simplista näo permite algums conceitos avançados de ILP, tais como exceução especulativa c renomcancuto de registradores. Os projetistas desenvolveram o hardware de forma a ficar o mais simples possível para assim conseguir colocar mais blocos mum único processador RAW.

O RAW foi desenvolvido de forma a expor o máximo possível da arquitctura do hardware para o compilador e fazer com que o compilador faça o agendamento estático das instruçoes. Devido a esse fato, foi incluído no hardware o mínimo de suporte possível para lidar con elementos dinâmicos, tais como pontciros e desvios. Como o hardware possui pouco suporte a elenentos dinámicos, é de responsabilidade do compilador gerar código para lidar con essa parte da aplicaģão.

Ainda năo existe um compilador para o RAW, nas existem algmmas dirctivas para a sua criação. O compilador para o RAW deverá aceitar um programa escrito numa linguagen de alto nível e mapeá-la numa arquitetura $R A W$ de forma a explorar o máximo de ILP possível. Para isso serão necessários os seguintes passos [10]:

- Particionamento: nessa fase o código é paralelizado (dividido em threads) de forma que todos os blocos da arquitetura estejam ocupados. Durante essa etapa é considerado que todos os blocos podem comunicar-se com todos os demais blocos e que a quantidade de registradores presentes em cada bloco é ilimitada.

- Posicionamento: nessa fasc cada thread é alocado para um bloco de forma a minimizar a latencia de comunicaço entre os blocos.

- Roteamento: durante essa fase os recursos de concxão da arquitetura são alocados.

- Configuração: nessa ctapa são criadas e alocadas as configurações do hardware reconfigurável de cada unn dos blocos. Pretende-se utilizar unna forramenta de síntese lógiea para isso. 
Tabela 2.5: Ganho de Desempenho do RAW sobre o SPARC 20/71 utilizando-sc Código Gerado na Mão.

\begin{tabular}{|c|c|c|}
\hline Aplicação & Tamanho dos Dados & Ganho de Desempenho \\
\hline Bubble Sort & 61 elenentos de 32 bits & 7 \\
Jacobi & 256 elementos de 8 bits & 230 \\
Merge Sort & 14 elementos de 32 bits & 2.6 \\
N Rainhas & 16 elementos de 1 bit & 3.96 \\
Fechamento Transitivo & 512 elementos de 1 bit & 398 \\
\hline
\end{tabular}

Năo existe nenhumia implementação física do RAW; todos os cxperimentos realizados até hoje foram obtidos utilizando-se un simulador. Os resultados iniciais obtidos são promissores (ver Tab. 2.5).

\subsubsection{Chimaera}

O projeto Chimaera [125] [123] [11] [126] [152] foi desenvolvido na Universidade de Washington. O principal objetivo do projeto Chimacra é prover processadores com conjuntos de instrução (ISA) variáveis, de forma que instruçoes nais apropriadas para cadi aplicação possam ser inseridas.

O sistema Chimaera é composto de um processador central e de ume unidade funcional reconfigurável. Como a parte rcconligurável foi inplementada cono uma unidade funcional, o hardware reconfigurável tem acesso aos registradores do processador central.

$\Lambda$ arquitetura do Chimaera (Fig. 2.6) é composta de um array reconfigurável (RA), de $u m$ arquivo de registradores sombra (SRF), unidade de controle de execuçâno (ECU), da unidade de controle de configuração e cache e do processador central (CCCU).

O array reconfigurável é uma coleção de blocos lógicos programávcis organizados em linhas interconectadas (atualnente são 32 colmass). Cada colund possui 32 blocos lógicos (o mesmo número de bits en um registrador do processador central). Cada 


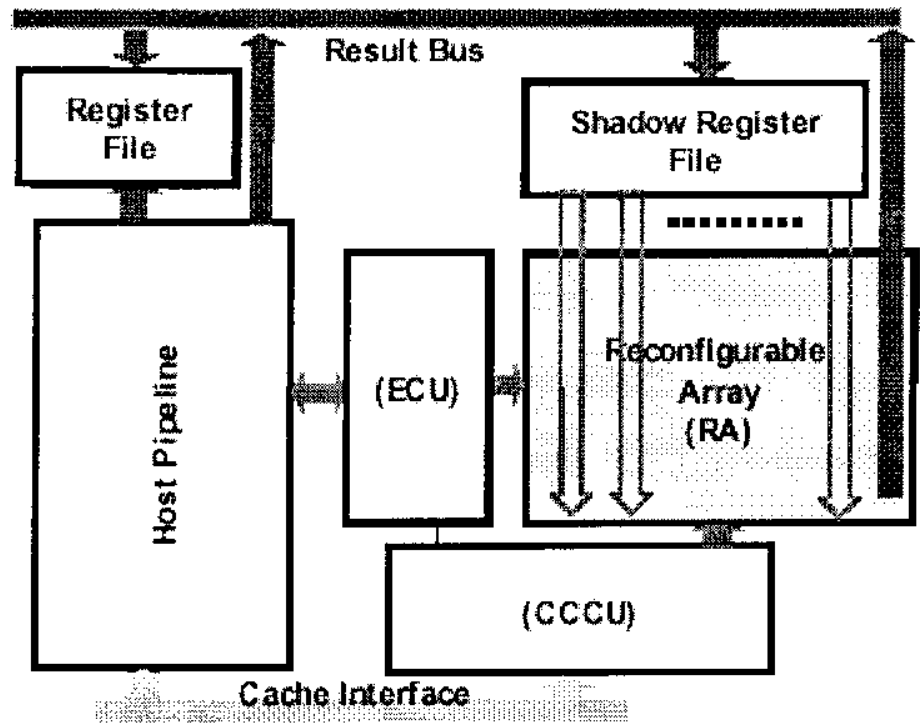

Figura 2.6: Arquitetura do Sistema Chimacra [125].

bloco lógico pode ser configurado para trabalhar como um 4-LUT (LookUp-Table de 4 bits), cono duas 3-LUTs, ou como uma 3-LUT e lógica de computaçán de carry-out. A computaçào do carry-out permite a otimizaçào de operaçóes de soma, subtração, comparação e paridade.

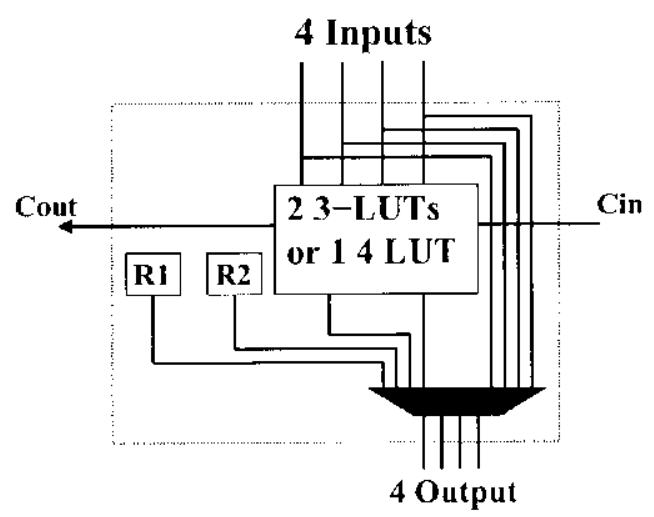

Figura 2.7: Arquitetura do Blocos Lógicos do Sistema Chimaera. [152].

A entrada e sáda de dados do array (RA) reconfigurável é feita através do arquivo de registradores sombra (SRF). 
O R $\Lambda$ pude conter configuraçòs para mais de una operação de RPL. Cada configuraçầo é responsável por uma operaçióo de RPU. As configuraçôes são feitas através da unidade de controle de configuraçäo e cache (CCCU) e da unidade de controle de execucão (ECU). A CCCU é responsável por determinar quais configurações estão ativas e gerenciar a cache de configuração. A FCU é responsável por determinar quando uma operação de RPU é requerida e por ativar a CCCU caso a configuração necessária para aquela operação nessa esteja ativa. Cada operação de RPU possui um opcode, um registrador de destino e un ID para a sua configuraçäo (cada configuração é univocamente identificada pelo seu ID).

As configuraçōes são organizadas em linhas, ou scja, todas as configuraçöes possuem um núnero de bits que é múltiplo do número de bits necessário para confignrar uma linha do RA. Essa estrutura permite que a reconfiguração dinâmica e parcial do $R A$ scja feita de forma simples e rápida.

O compilador do Chimacra 11, 126] foi desenvolvido a partir do GCC 66]. Para liclar con as operaçòs de RPU (unidade funcional reconfigurável) foram introduzidas tres novas otimizaçoes ao gec:

1. SWAR (SIMD Within a Register): otinização que concatena 4 operaçòes de 8 bits en uma única operação de 32 bits. Aplicaçôs multinńdia podon tirar bastante proveito desse tipo de otinizaçâ.

2. Localização de controle: transforma blocos de instruçōes contendo desvios em una única instrução (análogo aos algoritmos de hyperblock e superblock formation [151] [128]). Esse tipo de otimizaçào visa tornar visível para o compilador um nívcl maior de paralelismo em nível de instrução.

3. Combinaçāo de Instruções: combina múltiplas instruções em uma única instruçào da RPU. As operaçôes que serão combinadas devem ser possívcis de ser inplementadas na RA, ou seja, clevem ser operaçós aritméticas ou lógicaus.

O sistema Chimaera já está todo implenentado e obteve bons resultados durante scus experimentos (Tab. 2.6). 
Tabela 2.6: Desempenho do Sistema Chimaera

\begin{tabular}{|c|c|c|}
\hline Benchmark & Descrição & MIPS \\
Mpegenc & Fucoder de MPEG & 1139 \\
Adpon enc & Compressão do Vor & 6.6 \\
Adpcun dec & Descompressão de Vor & 5.6 \\
Comp & Compressão de Imagens & 34.1 \\
Decomp & Decompressão de Innagens & 32.7 \\
\hline
\end{tabular}

\subsubsection{DISC}

O DISC [98] [97] é uma arquitetura reconfigurável implementada pela universidade de Young. Como o próprio nome já diz (I)ISC é a abreviação em inglês para Computador com Conjunto de Instruçốs Dinànico), o DISC foi criado para permitir que o conjunto de instruçoes do processador se adiupte as necessidades da aplicação executada.

O sistema DISC é composto de un processador de propósito geral, um controlador geral e do hardware reconfigurável (Fig. 2.8).

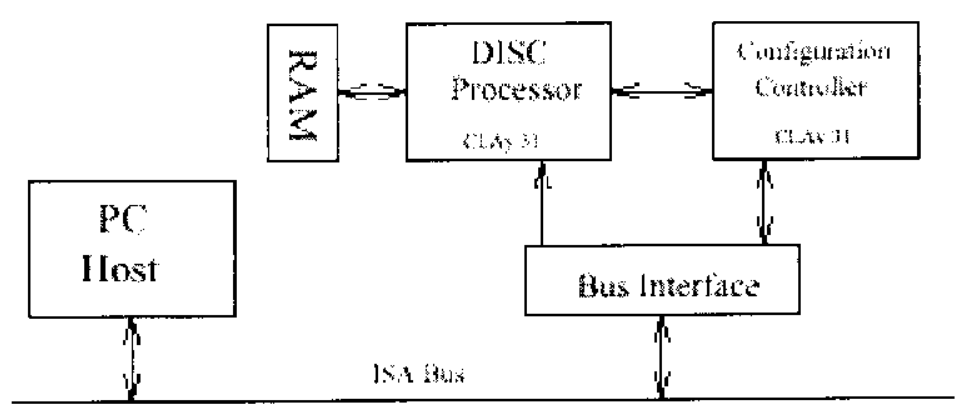

Figura 2.8: Diagrama de Blocos clo Sistema 1)1SC [97].

O hardware reconfigurável é composto de 56 linhas de blocos reconfiguráveis, onde cada uma possui 56 blocos lógicos. A reconfiguraçào do liardware reconfigurável é feita basicannente da nesma forma que no Chinacra: as configuraçốs são divididas 
em linhas e carregadas sempre que for necessário.

O controlador geral é o responsável por fazcr a comunicação com o processador central, com os periféricos e com a memória. Além disso, ele também é o responsável por armazenar as configuraçôes e fazer a reconfiguraşăo do hardware reconfigurável sempre que necessário.

Para se saber quais instruçōes são possiveis durante a execução do sistema é utilizada uma biblioteca de módulos de instrução: as quais possuían as configuraçòes associadas a cada instrução. Essa biblioteca é carregada junto com o controlador geral (Fig. 2.9). Todas as instruçoes (configuraçocs) customizadas devem ser foitas pelo próprio usıário.
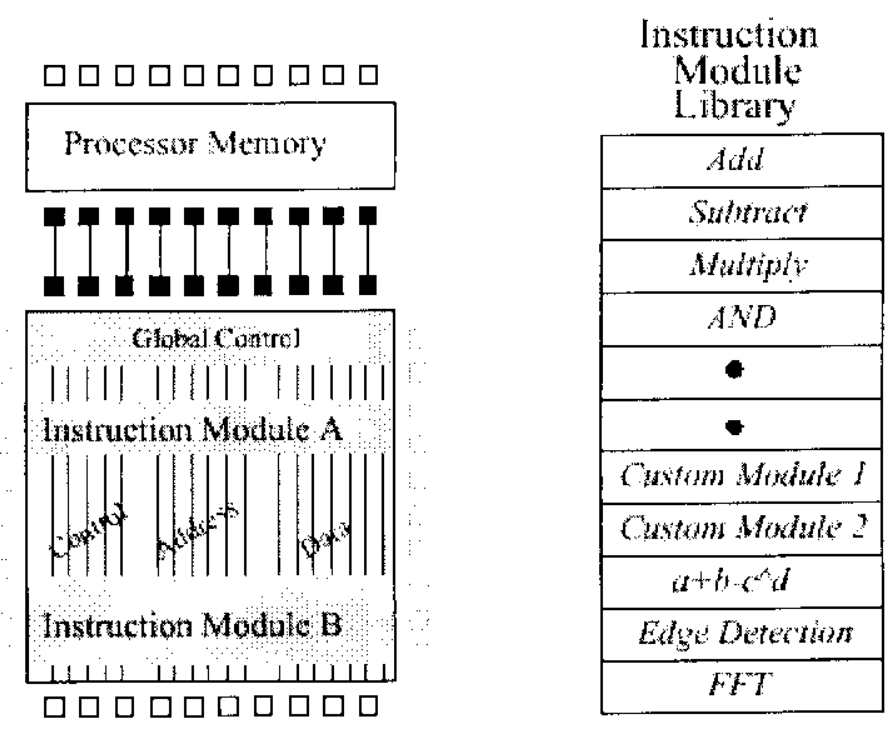

Figura 2.9: Biblioteca de Módulos de Instruçào[97].

O I)ISC é uma arquitetura simples e foi projetada visando a performance do sistema. Os desenvolvedores apenas querem estudar um computador com um conjunto de instruçoes dinâmico c a sua problemática. 


\subsubsection{PRISC}

PRISC (Programmable Instruction Set Computers) [47] [46! é una arquitetura reconfigurável desenvolvida pela. Universidade de Harvard. O PRISC anplia o conjunto de instruções de un processador RISC de forma a introduzir instruções especiais para a aplicação que está sendo exccutada.

Fssas instruçoes especiais introduzidas são excutadas en uman unidade funcional programável (PFUs). Para gerar essas instrucôos cespecíficas de forma automática foram desenvolvidas rotinas espociais de compilaşão que antalisam a complexidade de criação de hardware para cada instrução. Usando essa informaçäo o compilador interage con ferramentas de síntese de hardware para selecionar seqüencias de instruçōes que se benefician da execuçào nas PFUs.

No PRISC o hardware reconligurável foi inserido diretanente na CPU. Dessa forma, de interage diretanchte com os registradores do processador RISC (Fig. 2.10.

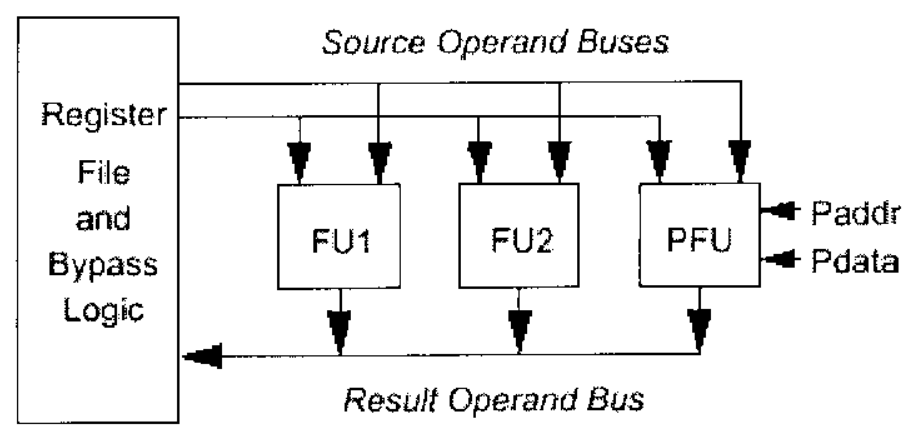

Figura 2.10: Arquitetura dos Computadores PRISC [47].

De maneira geral, o hardware reconfigurável é mais lento do que hardware especializado para uma determinada tarefa. Assim, o PRISC nào permite que una funcionalidade existente nas unidades funcionais convencionais seja replicada na PFC: A P'PC possui duas entradas e mana única saíla, de modo que cla somente. pode inplementar funçós de até duas entradas com una única sáda. Para exe- 
cutar as operaçoés na PFU foi descnvolvida una única instruçäo: expfu (execute a unidade funcional programável). Essa instrução é composta de cinco campos: o opcode, o primeiro registrador fonte, o segundo registrador fonte, o registrador destino e o número da operação especial a ser executada. Durante a fase de compilação foi assinalado un número de operação para cada instrução especial que o compilador designou para ser execulada na Plit.

Apesar de simples, a arquitctura do l'RISC obteve bons resultados cm aplicaçöes $\mathrm{CAD}^{4}$ (Fig. 2.11).

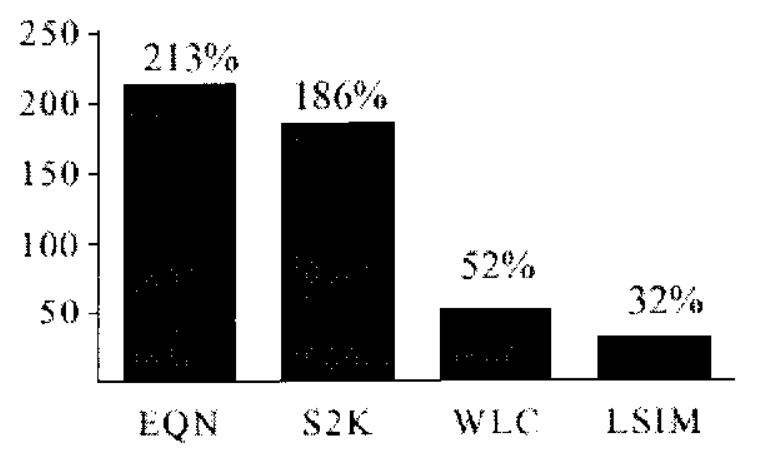

Figura 2.11: Ganho de Desempenho utilizando o PRISC [46].

\subsubsection{PipeRench}

O PipeRench [135] [136] [36] é una arquitetura reconfigurável desenvolvida pela Universidade de Caneggie: Mellon (Fig. 2.12).

O P’ipeRench utiliza una técnica chamada de reconfiguração de pipeline. Essá técnica permite que o hardware execute mais estágios de pipeline do que seria possível utilizando-se as técnicas convencionais. Fla tira proveito da capacidade do hardware reconfigurável criar hardware virtual. Dessa forma, un pipeline de cinco

\footnotetext{
${ }^{1} \mathrm{EQN}$ : transforma una equação lógica em man tabela verdade. S2k: ó parte de una fermmenta de abstraçóno de tramsistores.

WLC: é uma aplicação que testa a conectividade de fios num projeto esquemático.

LSIM1: é um simulador lógico.
} 


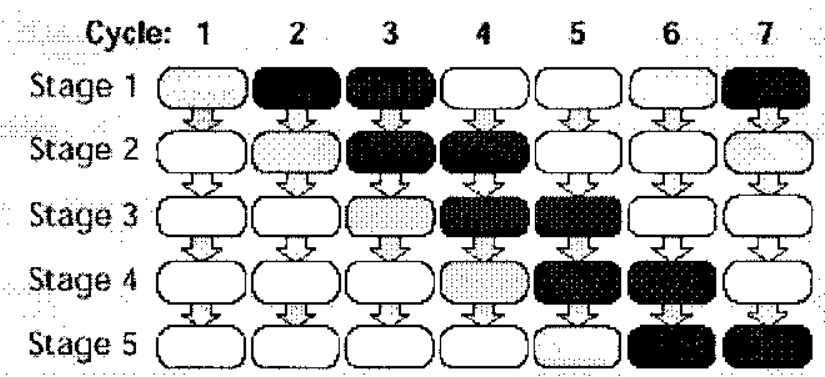

(a)

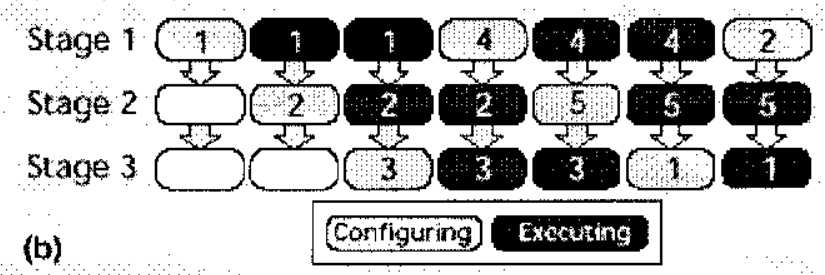

Figura 2.12: a) Estágios Virtuais do Pipeline. b) Estágios Reais do Pipeline [135].

estágios porle ser exccutado num hardware que somente permite que três estágios estcjann ativos a cada instante. A reconfiguração de pipeline innoò uma restrição sobre o tipo de operasoes que podem ser executadas: clas só podem ser dependentes do estágio atual e anterior do pipeline.

Nà sua implementação atual o PipeRench é um processador reconfigurável conectado a um processador convencional. O PipeRench é composto de múltiplas camadas (estágios reais do pipeline), as quais são compostas de inúmeros elementos de procossamento (PLs) (Fig. 2.13).

Cada PE é composto de um arquivo de registradores e de uma unidade lógica aritmética (ULA) (Fig. 2.14). Cada UI.A é composta por LUTs e por uma lógica adicional para permitir a avaliação e propagação rápida de carry-bits. Cada PE pode acessar dados dos PEs do estágio anterior ou dos PEs do mesmo estágio que cle.

O compilador do PipeRench é parametrizável. Ele aceita como parânetros o núnero de estágios reais do pipeline, o número de elementos de processancuto por estágio do pipeline, a largura de dados que cada PE pode processar, entre outras 


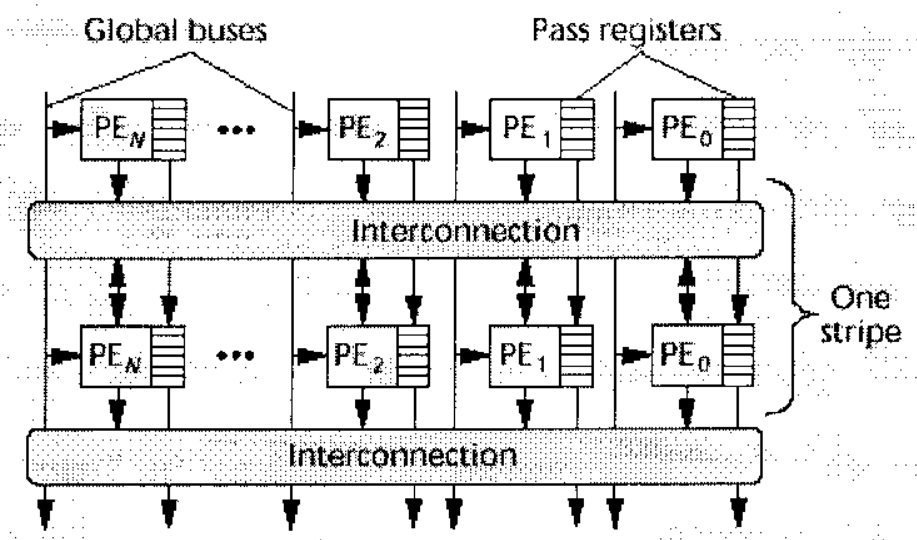

Figura 2.13: Arquitetura do PipeRench [135:

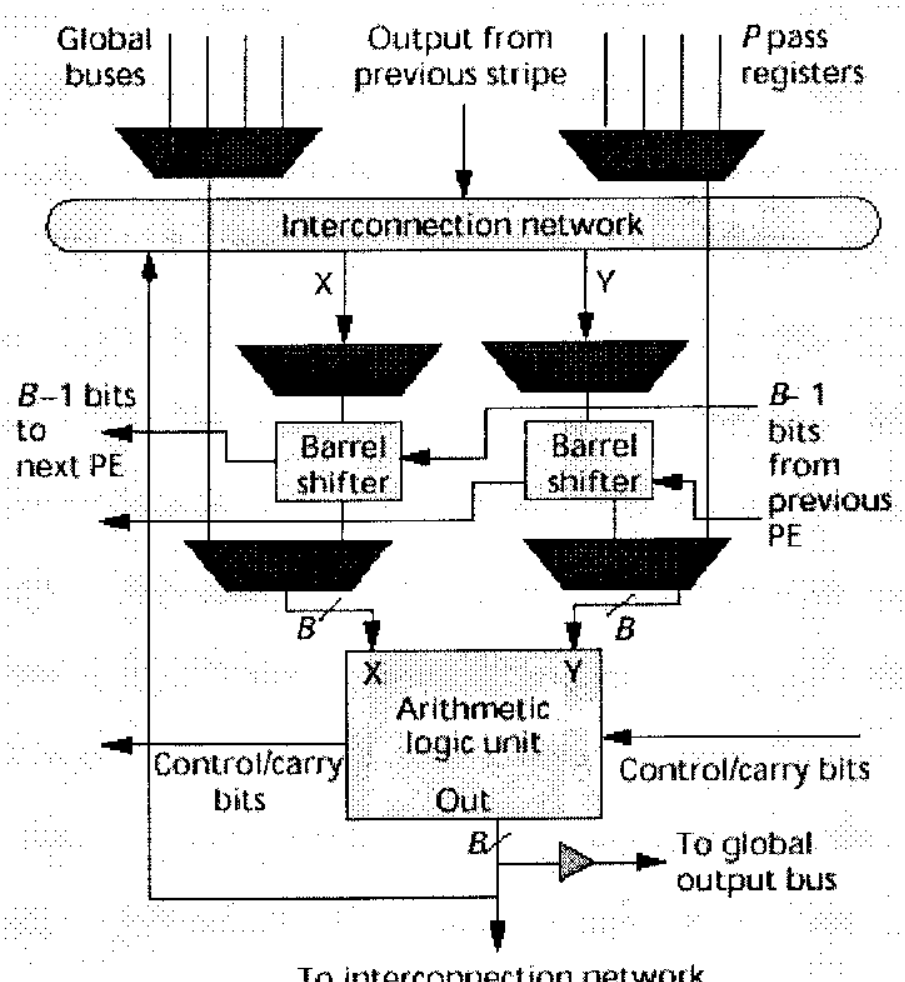

Figura 2.14: Arquitetura dos Elementos de Processamento [135].

coisas.

A linguagem utilizada por esse compilador é a DIL (Dataflow Intermediate: Lan- 
glatge), a qual deriva os operadores da linguagen C. Unla característica importante da DIL é que ela permite que o usuário especifique o tamanho dos dados de forma a utilizar o mínimo de bits possivel (se o nsuário năo especificar o tamamho dos dados, essess são setados para valores default).

Duas otimizações importantes para o PipeRench é a loop unrolling, a cual desenrola loops (transforma o loop em código linear), e a function inlining, a qual substitui chanladas de procedimentos e funções pelo código do procedimento on função requisitada. Essas otinizações são importantes por exporem um maior grau de paralclismo cm nível de instrução para as ctapas seguintes do compilador [122. [128]. Depois dessas otimizaçôes o compilador cfetua mais uma transformaçâo do códigofonce de forma a tonnar operaçöes complexas, tais como multiplicação e divisão, em operacooes mais simples, tais como shifts e somas. Isso é importante porque calda estágio do pipeline deve levar o mesmo tempo para ser cxecutado e essas operações complexas afeterrian a performance do sistema. Após realizar todas as otimizaçóes o compilador cria as configuraçóes para cada um dos estágios do pipeline e gera o cóligo executável que será executado no P’ipeRench.

O PipeRench foi comparado com un computador UltraSpare II de $300 \mathrm{MHz}$. Os resultados obtidos podem ser vistos na figura 2.15

\subsection{Perspectivas da Computação Reconfigurável}

Os chips de computadores estän ficando cada vez mais densos (com mais portals lógicas) e cssa tendencia deverá ser mantida nos próximos anos. Entretanto, esperase que por volta de 2010 este aumento de densidade dos chips não resulte mais cm um aumento da velocidade (clock) ou performance (throughput) dos computadores de propósito geral. Éspera-se que nessa época os chips consigam comportar por volta de um bilhão de portas lógicas. Com isso, o objetivo dos projetistas de hardware scrá descobrir a molhor forma de aproveitar toda essa quantidade de recursos ${ }_{2} 77$ ].

Una possível resposta para esse problema é a introdução de ítens customizados 


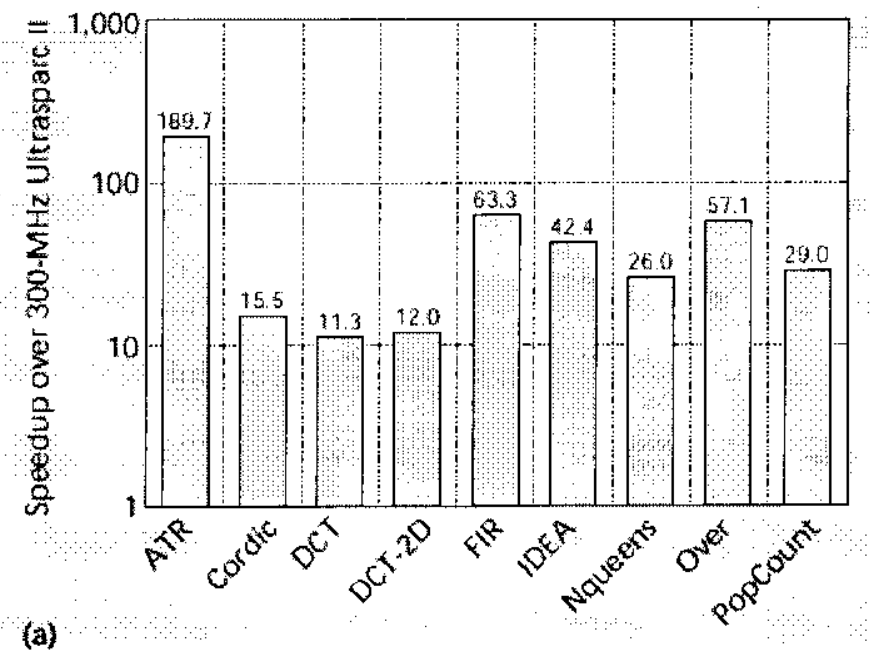

Higura 2.15: Ganho de Desempenho do PipelRench con Rolação a un Computador Ultra Sparc II $300 \mathrm{MHz}[36]$.

nos processadores de propósito geral. A tendência atual é de que a computação reconfigurável seja utilizada para esse finn. Mas antes que isso se torne una realidade, é necessário que a construşão de hardware customizado utilizando conputação reconfigurável se tome uma tarefá mais fácil. De preferĉncia automatizada.

O objetivo do ARCHIIECT-R, c dos sistemas de computação roconfigurável citados anteriormente, é exatamentc o de tornar automática essa construção de ítens customizados. Ao fazerem isso, esses projetos năo visam um impacto na tecnologia modenna de construçào de computadores; mas sim um impacto futuro na computação como un todo. 


\section{Geração Automática de Arquiteturas}

\section{de Computadores}

Devido a constante evolução da tecnologia de integração de circuitos, o mercado de computação está sofrendo una tendệncia de migração dos computadores pessoais para sistenas mbutidos. Conseqüentenente, laverá cada vez nais a necessidado da criagão de novos circuitos eletrônicos. Além dessà demanda por quantidade, a complexidade dos circuitos a serem projetados também está ámentando vertiginosamente. No caminho inverso, o múnoro de profissionais voltadas para o projeto de laardware têm caído ou se mantido constante.

Assin sendo, é inevitável vislumbrar un futuro (bastante próximo) onde não haverá profissionais suficientes para atender a dentanda. Cientes disso, as grandes empresas desenvolvedoras de lardware têm buscado caminhos altemativos. Un desses caminhos alternativos é a criação de geradores automáticos de lardware; en 
particular, geradores antomáticos de arquiteturas de computadores. Geradorcs automáticos de arquiteturas de computadores sào sistemas computacionais capazes de desenvolver o hardware e as ferramentas necessárias para a utilização desse hardware, tais como compiladores e sistemas operacionais. Atualmente somente software é usado, contudo existe a possibilidade de, no futuro, se utilizar hardware para esse fin também.

A empresa que tem investido mais fortemente nesse seguinculo e, por seguinte tem obtido os melhores resultados, é a HP. Ela possui atualmente duas pesquisas distintas nessa área: o PICO c o Lx, as quais serão discutidas nas seções seguintes.

\subsection{PICO - Program In, Chip Out}

Como o próprio nome diz, a intenção desse projeto é gerar toda una arquitetura (incluindo ass ferramentas) à partir do código-fonte de un programa. O ciclo de desenvolvimento do PICO [156] [129: [63] pode ser observado na Figura 3.1.

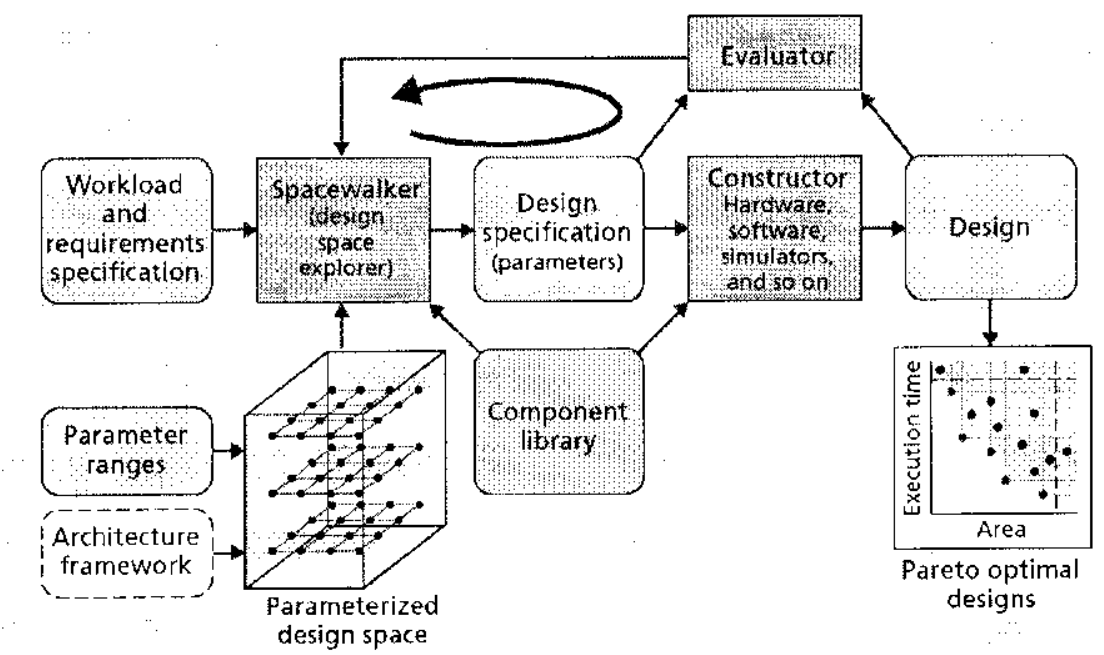

Figura 3.1: Ciclo ale Desenvolvinento no PICO 156].

Além do programa (workloud), o PICO também recebe como entrada alguns parâmetros que especificam algumas neccssidades da aplicaçăo para a qual a arquite- 
tura deverá ser gerada (tais como consumo máximo de energia, tamanlıo máximo do chip de silício, número máximo/mánimo de registradoress, throughput, entre outros). Deprois disso, o sistema efetua una busca no espaço de possiveis arcfuitecturas (atraves do Spacewalker) de forma a concontrar uma arquiteturéc que se constitua. como uma solução (quasi) ótima para a aplicação. O espaço de busca é constituído por arquiteturas estilo EPIC [112] [153] [26] que respeitem os parâmetros de entrada.

Na verdade, o Spacewlaker pode ser dividido en dois programas distintos: um para buscar a arquitetura convencional ótina (PICO-VLIW - Fig. 3.2) e outro para. encontrar arquiteturas sistólicas para otimização de loops (PICO-NPA - Fig. 3.3 ).

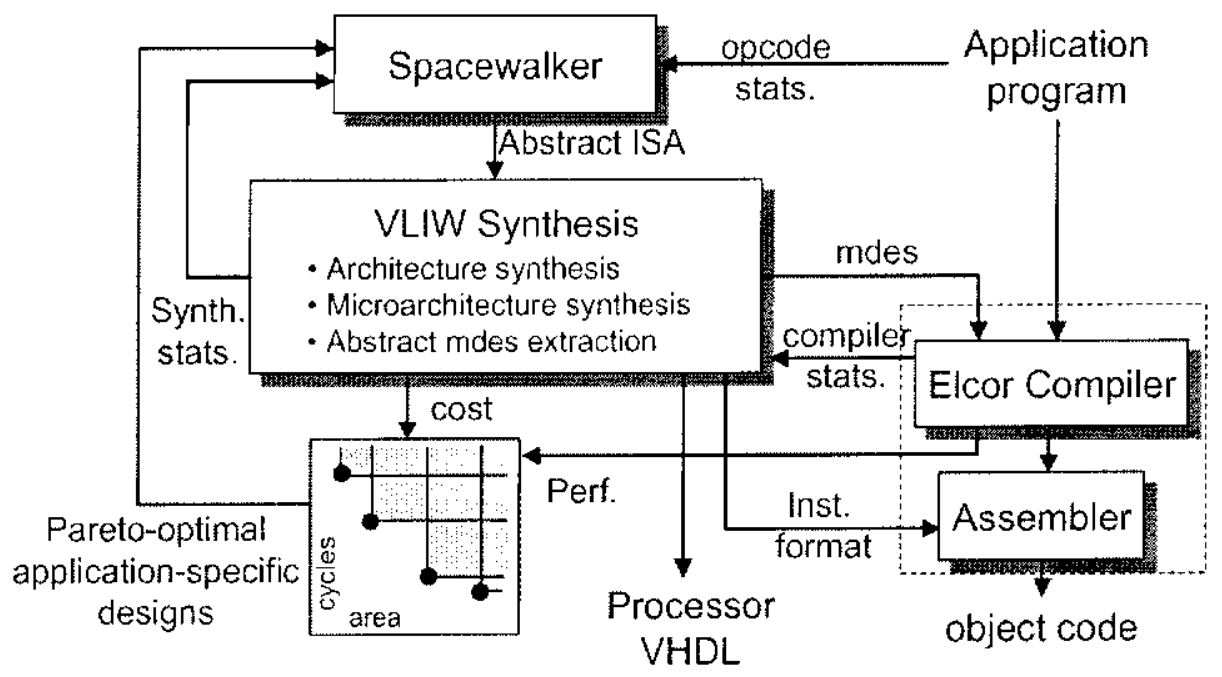

Figura 3.2: Sistema de Desenvolvimento do PICO-VLIW [129.

A pós o Spacewalker determinar a arquitetura ótima: a descrição (em formato undes $\left(155_{\mathrm{j}}\right)$ é utilizada para a geração do hardware da arquitctura, um compilador baseado no Elcor [128] e um simulador [144]. O simulador é, então, utilizado para verificar o sistema e fornecer dados para $1 \mathrm{~m}$ avaliador que analisa se a arquitctura pode ou não ser melhorada. Se houver a possibilidade de melloras, o sistema é reativado à partir do Spacewalker só que com novos parânetros do especificação da arquitetura de forma a guiar o Spacewalkor a ma nova arquitetura mellor. 


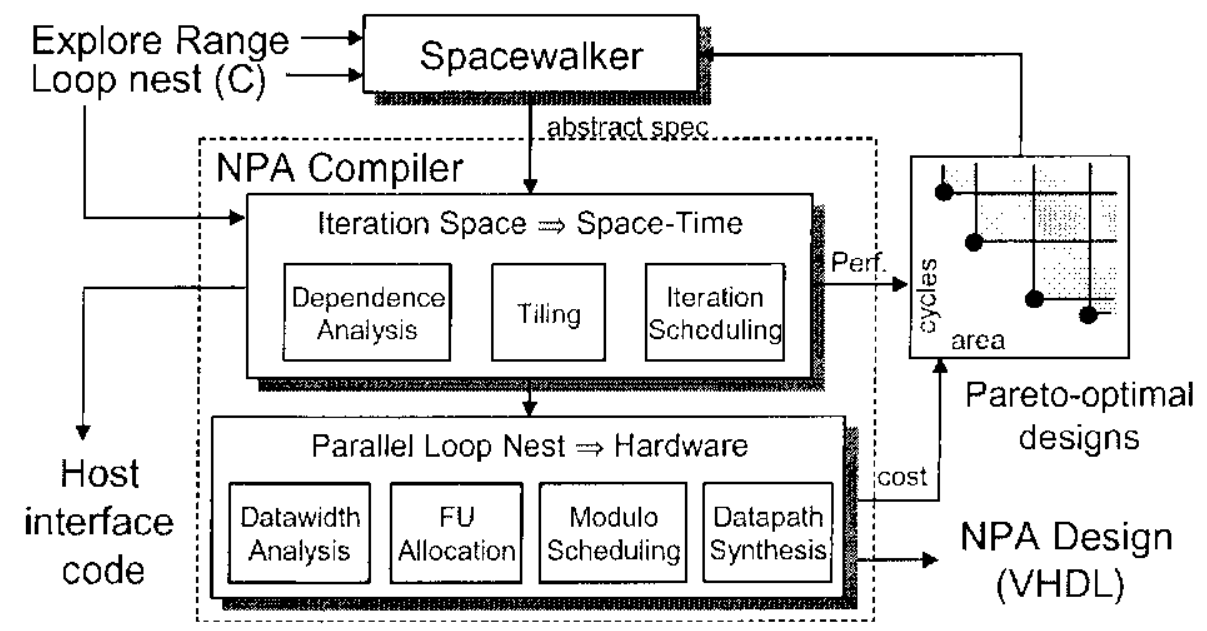

Figura 3.3: Sistema de Desenvolvinnento do PICO-NPA[6.3].

\section{$3.2 \mathrm{Lx}$}

O Lx [56] é um gerador menos volta para pesquisa e mais voltado para o uso comcrcial. Essa característica faz com que ele se utilize de uma arquitetura base menos rebuscada (Fig. 3.4).

Além disso, o sistema en si é monos automatizado: ao invés de esperar que a ferranenta faça todo o traballo, o Lx espera como entrada (além do código-fonte o parainetros de especificaçäo da arquitetura) a arquitetura inicial, a qual deve tor sido gerada por un projetista humano (Fig. 3.5).

As limitações anteriormente citadas fazen con que a ferramenta seja mais rápicla que o PICO. Outra diferença fundamental entre o PICO a o Lx é que no caso do segundo: circuitos específicos para algumas partes da aplicação (geralnnente loops) deven ser criados pelo projetista humano no monento do desenvolvimento da anquitetura inicial (o que pode vir a linitar bastante a utilização desse tipo de recurso).

O ciclo básico de descenvolvinento de ambas as forramentas é basicamente o nesno, só que as ferrannentas geradas e utilizadas são distintas cono pode ser observado na Figura 3.6. 


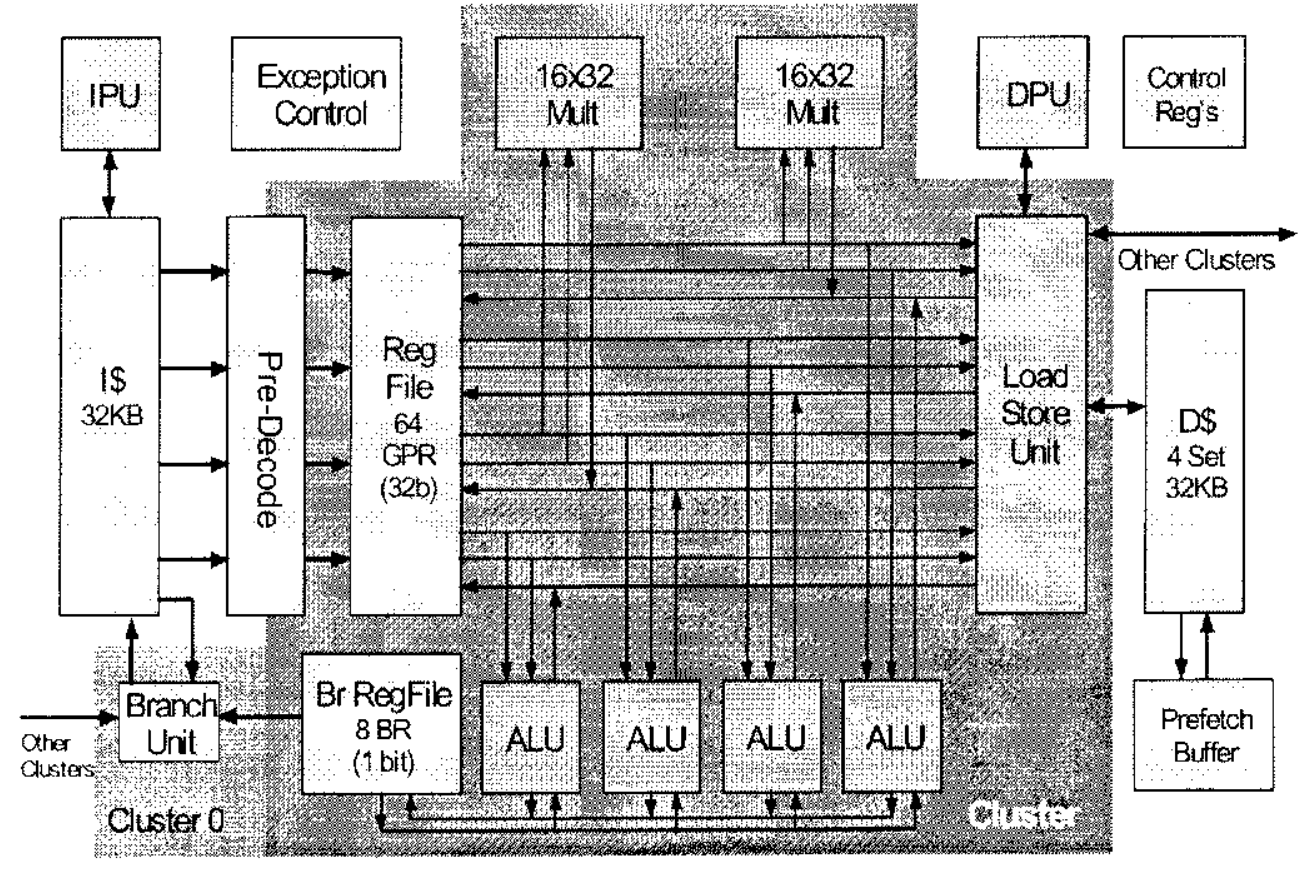

Figura 3.4: Arquitetura do Hardware do Lx [56]. 


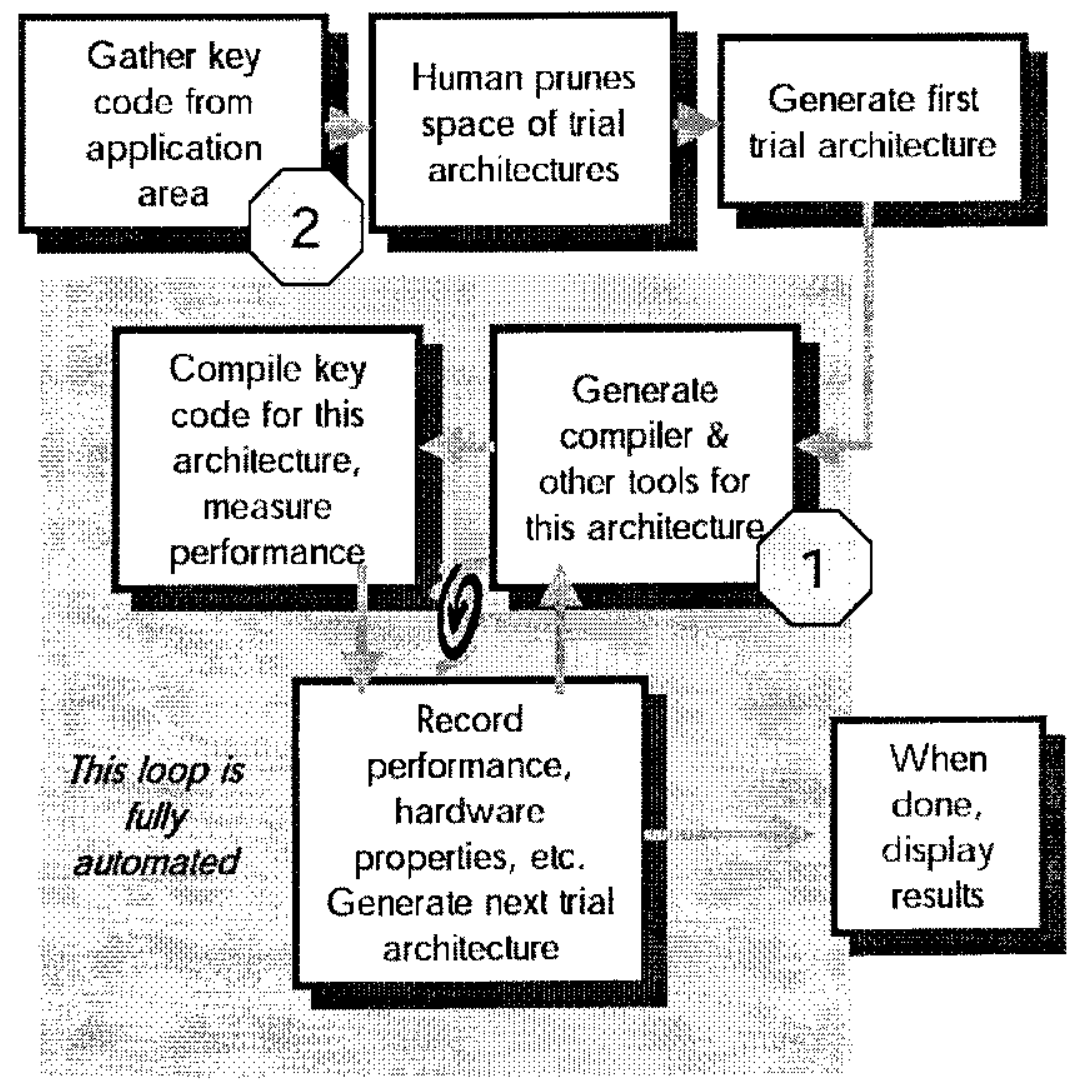

Figura 3.5: Ciclo de Desenvolvimento no $\mathrm{Lx}[56$; 


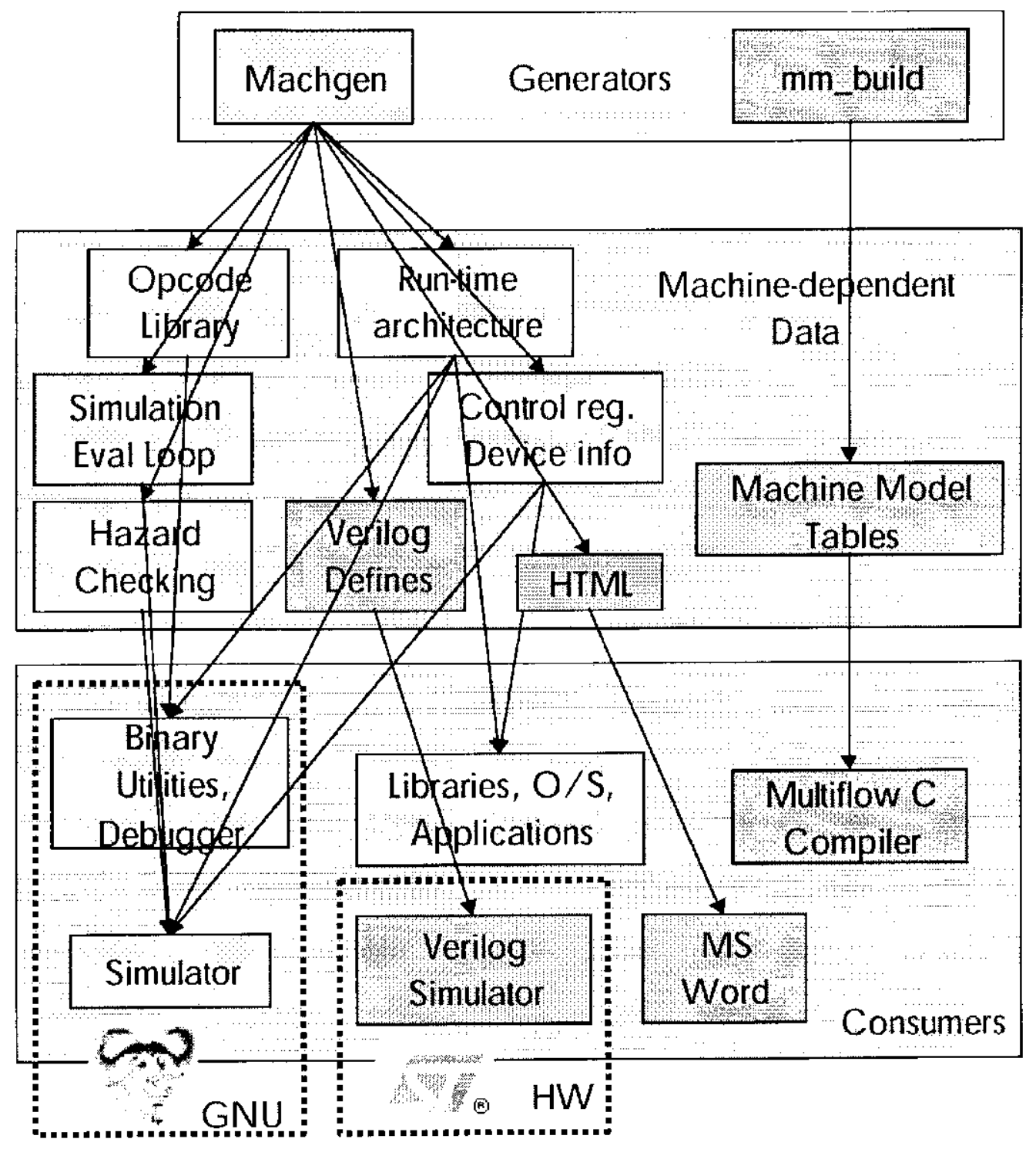

Figura 3.6: Ciclo Detalhado de Desenvolvimento do Lx [56]. 
Uma das características do Lx é que ele desenvolvido visando projetos bastante Hexíveis, on seja, de forma que a arquitetura gerada para ma aplicação possa ser utilizada de forma quasi-ótima por um conjunto de aplicaçós (Fig. - o Ix se encaixa no lado esquerdo da figura.). Na verdade, o fator que tem sido mais pesquisado dentro do Lx é o quão boa uma arquitetura gerada para uma aplicação específica pode ser para o conjunto de aplicações que pertencem a mesma área.

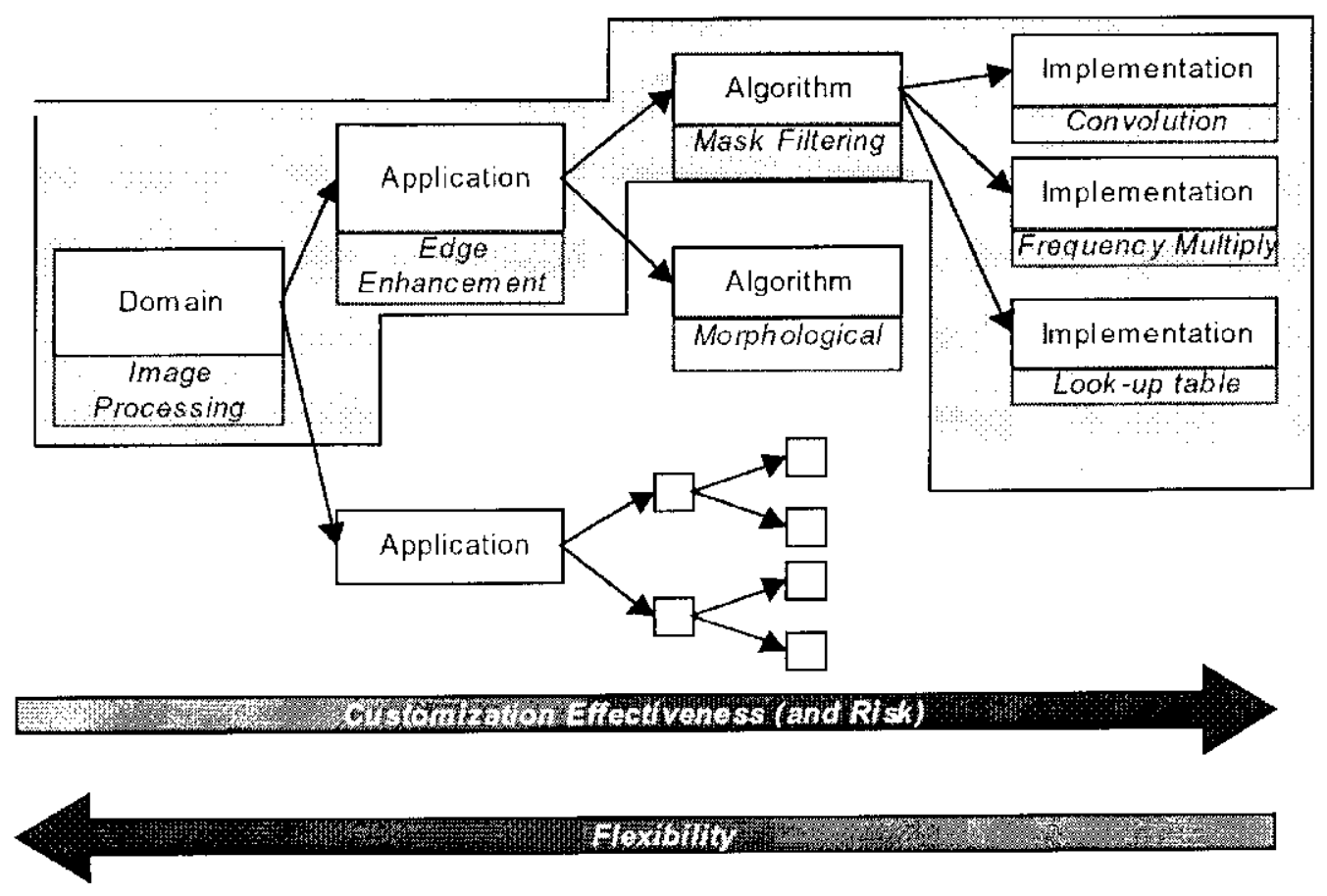

Figura 3.7: Possibilidades de Customização dentro dos Geradores do Arquiteturas. [56]. 


\subsection{Considerações Finais}

Com a demanda crescente por circuitos digitais para sistemas embutidos e a conplexidade também crescente de tais circuitos, algumas empresas de desenvolvinento de hardware ficaram preocupadas com a falta de profissionais para essá área. A maioria das empresas (como a Motorola, por exemplo) adotaram o uso de reuso de componentes de hardware na forma de IPs (sigla em ingless para Propriedade Intelcctual). Outras empresas mais de vanguarda. como é o caso da HP', optaram pela criação de geradores de arquiteturas de computadores. Apesar de mais complexos (e ainda distantes dos desempenhos obtidos por projetistas humanos), esse tipo de forramenta possui grande potencial futuro e muitas clessas ferramentas devem surgir num futuro relativamente próximo. Não espera-se que esse tipo de ferramenta venha a substituir os projetistas humanos, visto que a criaçào dos componentes de hardware que servem como base para a geração do hardware de tais ferramentas aindla será descnvolvido por projetistas humanos, mas, sim, que sirvan como una ferramenta de desenvolvinento inicial dos projetos, os quais deverão ser revistos e melhorados por projetistas humanos experientes.

Ainda é importante salientar que muitas das idéias do ARCHITECT-R foram derivadas do PICO e do Lx. Contudo o ARCHITECT-R ainda mantém suas qualidades devido a algumas idéias próprias e inéditas tais como o uso de compilaçäo dinâninica aliado ao uso de computação reconfigurável. 


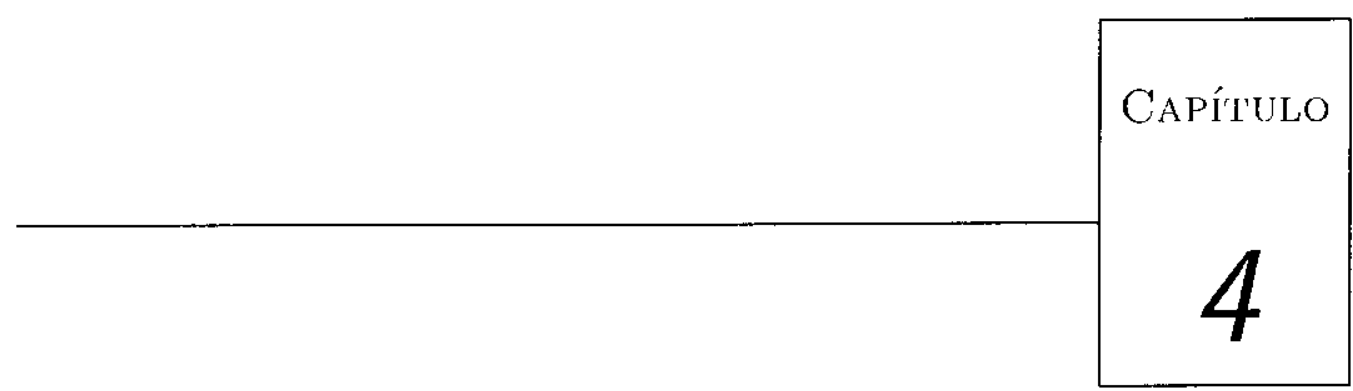

Robótica

Robôs são dispositivos mecànicos versáteis (por exemplo, braços mecânicos articulados, veículos terrestres, aércos ou submarinos, etc.) equipados com sensores e atuadores sob o controle de $u m$ sistema computacional. Eles realizan tarefas executando movimentos num espaço físico. Este espaço é povoado por vários objetos e está sujeito às lcis da natureza [1].

Nuna prineira etapa, houve un grande desenvolvimento na árca de robótica industrial. A implantação no châo de fábrica de robôs industriais trouxe benefícios como al melhoria da eficácia e da qualidade, reduçào da mäo-de-obra, maior confíabilidade e reduçào de custos. Vantagens adicionais incluen a capacidade de realizar tarefas para as quais os humanos teriann grande dificuldade e a remoção de humanos de tarefas em ambientes perigosos. Esses robos eran pouco sofisticados e na maioria das vezes atuavam em anbientes estálicos.

Numa nova etapa de evolução, pesquisadores cun robótica tèm concentrado cs- 
forços na construção de Robôs Móveis. introduzindo as capacidades de mobilidade e antonomia para reagir adequadamente a ambientes dinânicos, o que abre un vasto campo de novas aplicacoes e conseciuientemente novos desafios.

\subsection{Paradigmas da Robótica}

Un paradigma é una filosofia ou um conjunto de suposiçôes e técnicas que caracterizam unna abordagen de resolução de un problema [140]. A aplicação do paradigna correto toma a resolução de un problema mais simples. Portanto, ter conhecinemto dos paradigmas de rolótica é importante para se programar um robô de forma correta para uma determinada aplicação.

Atualmente existem três paradigmas en robótica: deliberativo, reativo e híbrido. Os paradigmas divergem sobre dois aspectos:

1. Pola forma como eles relacionam as três primitivas da robótica: sentir, planejar e agir. Se uma função reccbe dados dos sensores do robò e transforma esses dados cm informaçöes úteis para outras funçòes do robô, essa função é classsificada na categoria de sentir. Se una funçăo recebe informaçoes (quer seja direto dos sensores quer seja de outras funcoues) c produz mua on mais tarefas que o robo deve realizar, essa funçó é classificada na categoria de planejar. Se uma função produz dados para os atuadores do robô, essa função é classificada na categoria de agir.

2. Pela forma como os dados sensoriais sĩo processados e distribuídos pelo sistema. Os dados podem ser processados localnente por cada função ou podem ser processados por uma única função que produz um modelo global do mundo (ambiente onde o robò está atuando) e distribui essa informação para as domais funçües. 


\subsubsection{Paradigma Deliberativo}

O paradigma deliberativo é o mais antigo clos paradigmas. Ele dominou as inplementações do robôs de 1967 até 1980 (quando surgiu o paradigma reativo).

() modelo deliberativo é seqüencial por natureza. Inicialnente o robô "sente"o munclo, o annbiente e constrói un mapa global do ambiente (por ambiente não entendam apenas o mundo exterior ao robô, o sou estado interno também faz partc do seu ambiente). Depois disso, já sem receber daclos dos scus sensoress, o robô planeja a melhor forma de obter os seus objetivos. Finalmente, o robò age de forma a seguir o plano traçado. Essá sequència é seguida de formáa cíclica durante toda a execução do algoritmo do robó.

Como fica claro na seqüencia de açōes do robô, o paradignna cleliberativo recebe todos os clados dos sensores em una elapa e gera a represontaçäo global do ambiente que é utilizada durante as fasses de plancjannento e atıacão.

A principal vantagem desse paradignna é que cle é simples o fácil de ser codificado: cxiste una ordem clara entre as tarclas a serem executadas.

O principal problema desse paradignina é que ele se bascia na suposiçào do mundo fechado, ou scja, ele supõe que todas ás informações que o robô precisa saber ustão contidas no seu modelo de nundo. Isso é ruin por dois motivos: prineiro é muito clifícil especificar e armazenar todas as informacos sobre o ambiente e, se houver o esquecinento de algum detalle, o robô pode ser surprecndido a nào funcionar corretamente. Segundo, para realizar até mesmo tarefas simples o robó precisa lidar corn un conjunto de dados bastante grande no qual a maioria das informações são irrelevantes, o que torna o robô mais lento do que o necessário (por que o robô precisa saber que existe uma porta na sala ao lado se tuclo que ele quer é pegar um objeto que está no neeio (lessa sala??).

Una desvantagem adicional desse sistema é de que o roloô leva muito tempo para reagir a mudanças no sen ambiente. Suponlá que o robô desempenhe suas tarefas numa biblioteca e que uma pratcleira esteja cainclo sobre ele, se ele estiver na sua 
fase de planejamento (que geralmente é demorada) a prateleira irá cair em cima do robô antes que ele receba os dados dos sensores dizendo que a prateleira está caindo.

\subsubsection{Paradigma Reativo}

O paradigma reativo surgiu da insatisfação dos pesquisadores com o paradigna deliberativo e con o aumento do fluxo de idćias etinológicas [140]. Essas idéias sugreriam que a inteligência nos animais era decomposta verticalmente e não horizontalnente como no sistema deliberativo (Figs. 4.1 e 4.2). Desta forma, o paradigma reativo recebe os dados dos sensores e já age, sem nenhum planejannento. Ou seja, o ciclo sentir-plancjar-agir do sistena deliberativo é reduzido para sentir-agir.

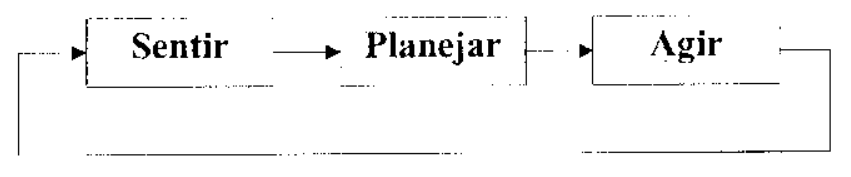

Figura 4.1: Decomposiçăo Horizontal.

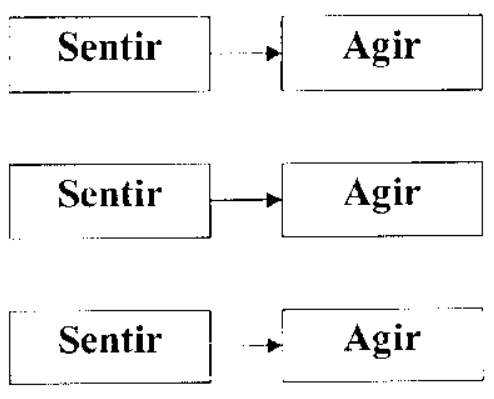

Figura 4.2: Decomposiçào Vertical.

Todo o paradigma reativo é bascado no conceito de comportamentos. Un comportamento é um mapeanonto direto dos dados dos scnsores em padrões de ações, as quais são utilizadas para se obtcr um detcrminado objetivo. Geralmente, um robô possui vários comportanentos. Esses comportamentos são organizados eln camadas de forma que comportanentos en camadas superiores possam inibir comportanen- 
tos cen canladas inferiores'. Un cxemplo disso é um robô que possui o comportamento de ficar andando aleatorianente por una sala numia camada e numa camada superior possui o comportannonto de seguir paredes. Enquanto o robò não identificar uma parede ele irá andar alcatorianente. Assim que ele identificar uma parede ele irá seguíla; e, portanto, irá parar de andar aleatoriamente. Desta forma, o comportamento de seguir paredes inibin o comportamento de andar alcatoriantente.

A forma conno unn robô reativo funciona depende de todos os comportamentos que esse robô possui (isso é chamado de comportamento encrgente). Quase sempre um robó conn nais comportanentos é considerado mais inteligente do que outro. Contudo, na verdade. os robôs reativos não são inteligentes: cles apmas são estinulados c respondem a esse estímulo. A inteligchncia dos robôs reativos está nos ollos do observador [132j. Quem irá dizer que un robò que é capaz de buscar unn objeto e trazè-lo até vocè não possui nenhum tipo de inteligência??

Nas primeiras implementações do robós reativos foi usada a icléia de um sensor e 1 m comportanento 140]. Entretanto, con o passar do tempo e com os resultados de inúneras pesquisas, ficou comprovado que para comportamontos mais avançados ara molhor utilizar os dados de vários sensores ${ }^{2}$, pois isso implicava num anmento da precisào das informaçoes recobidas pelo comportamento.

Uma característica interessantc dos robôs reativos ć que eles não possuem nenhuma represcntação do ambiente; ou seja, "o nundo é a sua melhor representação" [132]. Se por un lado isso é una vantagem sobre o paradigma cleliberativo, yue na maioria das vezes necessita de quantidades cnormes de clispositivos de armazenamento de dados para manter as suas representacóces do ambiente, por outro lado tanubém é una desvantagenn. Como un robô reativo que possui o comportanento de scguir uma parede sabe que cle não está andando cm círculos? Simples, ele não sabe! 140] A principal vantagem do paradignna reativo é que ele permite a criação de robôs mais rápidos, visto que eles não possuem a fase de planejanento. Outra vantagen

\footnotetext{
${ }^{1}$ Geralmente, os comportamentos das camadals de nivel mais alto sajo mais rebuscados.

${ }^{2}$ Essa técnica é denominada fusão de sersores
} 
é que por ser modular (os robòs são decompostos em comportamentos), é mais fácil reaproveitar os componentes utilizados ma criaçấo de unn robô em outro (qual robó nóvel que não precisá se proocupar en evitar colisào?).

\subsubsection{Paradigma Híbrido}

Os paradigmas deliberativo e reativo podent ser vistos como complementares. Conscqüentemente era apenas uma questão de tempo até que pesquisadores cogitassen uní-los. A princípio, acreditou-se que essa mistura apenas traria desvantagens. Os robôs seriam mais lentos do que os reativos c ainda mais complexus de se programar do que os robôs delibcrativos. O consenso na época cra de que se uma detcrminada pesquisa estivesse projetando unn robô para un ambiente suficientemente ben conportado e fácil de representar, ela deveria utilizar o paradigma deliberativo, caso contrário ela deveria utilizar o paradigma reativo.

Contudo, atuahnente, acredita-se que o paradigna híbrido é o molhor de todos os paradigmas. Com a possibilidade de se executar trechos de programas em paralclo, surgiu a oportunidade de se executar o planejancnto e os comportamentos reativos do mesmo tempo. Deste nodo, a perda de desempenho já não é mais tão significativa e cossa arquitetura paralcla permite que a parte deliberativa escollha quais os comportamentos que devem estar presentes no robô a cada instante. Assim, o comportanento do robô pode ser dinamicancute reconfigurado: o que pode trazer um ganho de desempenho ao invés de deteriorização do mesmo.

Enm termos das primitivas básicas da robótica, os robôs lí́bridos possucm uma fase de plancjanento en paralelo com uma fase sentir-agir. Isso é inportante, pois permite, por exemplo, que os rolós tracen a melhor trajetória entre a sua localizacão atual e seu objetivo, sen que ele fique lento ou perca a capacidade de evitar obstáculos. Para que os robôs lúbridos possann plancjar foi necessário reintroduzir uma representação do ambiente. Porém. essa represcntação não precisa mais ser tão precisa: a parte reativa do robó pode lidar com alguns imprevistos rapidamente. Então, concluindo, qual deve ser a proporção entre deliberativo e 
reativo que un robó híbrido deve ter? Essa questão ainda permanece em aberto e muitos acreditam que a sua resposta seja dependente da aplicação do robô.

\subsection{Arquiteturas de Robôs}

Arquiteturas de Robôs são sistemas computacionais e especificações das caractcrísticas desejadas em unı robó, os quais provém linguagens e ferramentas para a construção de sistemas robóticos [33].

A escolla de una arquitetura para o robo afeta todo o projeto e desenvolvinento do mesmo [85]. Assim surgiu a segninte pergunta: como avaliar a utilidade de una determinada arquitetura? Arkin propós os seguintes critérios [33:

- Suporte à Paralelismo: a maioria dos comportamentos de um robó são inerentemente paralelos, pois o robó necessita adquirir dados dos seus sensores, planejar uma forma de obter scu objetivo, evitar colidir com objetos e pessoas e tudo isso deve scr feito ao mosmo tempo. Portanto, ć importante considerar qual o suporte que a arquitetura fornece para a execução paralela de tarefas.

- Portabilidade de IIardware: essc critćrio se refere à capacidade da arquitetura em se adaptar aos atuadores c sensores do robô e de a nuesma ser mapeada diretamente en hardware.

- Portabilidade de Ambiente e Utilidade: testa se a arquitetura possui a capacidade de se adaptar a novos ambientes e a diferentes propósitos de utilizaçào.

- Suporte à Modularidade: diz respeito ao suporte que a arquitetura provê para a re-utilização dos componentes (via cle regra componentes de software) do projeto atual em fiuturos projetos.

- Robustez: é a capacidade da arquitetura en prover tolerância a fallıas. 
- Recursos de Desenvolvimento: quais as fcrramcutas e os ambientes de desenvolvinento que a arquitctura provê para o descuvolvedor de sistemas robóticos.

- Pcrformance: esse critério diz respeito ao tcmpo de execuçäo do sistema, sen consumo de energia c, principalmente, se a tarefa para a qual o robó foi projetado foi realizada com sucesso.

$\Lambda$ s arquiteturas de robôs podem ser classificadas em três categorias:

1. Hierárquicas: adota o estilo top-doun. Esse estilo enfatiza a supremacia do controle de alto nível e tenta inibir as commnicações de baixo núvel. As primeiras arquiteturas utilizavan esse estilo, mas hoje cm dia ela é difícil de ser cmpregadia. Lla é empregadia m robós deliberativos.

2. Comportamentais: adota o estilo bottom-up. Esse estilo faz uso de módulos chamados comportamentos. Essses módulos são executados paralelannente e enfatizan a interação através da commicação e con o anbiente. É empregada em robôs reativos.

3. Híbridas: nistura os dois estilos anteriores. Tenta facilitar a comunicação entre o controle oficiente de baixo nível (reativo) conn o controle kle plancjannento de alto nível (deliberativo), É cmpregada em robòs híbridos.

O maior problema enfrentado pelos desenvolvedores de sistemas robóticos contemporâneos é o fato de que não existe nenhuma arquitetura preponderante en nenhuma das três categorias: na maioria dos casos, al arquitetura é criada para o robó que está scndo desenvolvido [138]. Isso possui sćrias implicações tais como:

1. A dificuldade de re-utilização de código gerado durante o projeto de un robô para o projeto de outros robôs;

2. A dificuldacle de validação de unn sistenna robótico; $\mathrm{e}$ 
3. A dificuldade na especificação e descuvolvinnento do sistema robótico.

O principal motivo pelo qual ainda não surgiu nenhuma arquitetura que seją considera preponderante é o fato de que, na maioria das vezes, cada robò possui características e necessidades muito peculiares.

\subsubsection{Exemplo de uma Arquitetura Hierárquica: Nested Hi- erarchical Controller}

$\Lambda$ arquitetura Nested Hierarchical Controller (NHC) foi criada para a navegação de robós 6]. Ela possui componentes que são facilnente classificados en sensores; planejadores e atuadores. Como dito anteriormente, a parte de controle (planejadores) possui a maior prioridade do sistema.

Os robôs que implementam essa arquitetura, inicialmente, obtém os dados dos seus sensores e geram o mapa do ambiente. Depois disso, o robô deve plancjar a melhor forma de obter o seu objetivo. Una característica marcante da $\mathrm{N} H \mathrm{HC}$ é que cla possui três planejadores: Plancjador de Missão, Navegador c Piloto. O Planejador de Missão possui prioridade sobre os outros planejadores; 6 mais "inteligente" do que cles, e é responsável por localizar onde o robô está e aonde cle deve chegar. O Navegador possui maior prioridade do que o Piloto e recebe os dados do Planejador de Missão, ficaudo responsável por traçar a rota pcla qual o robô deve seguir para chegar ao seu objetivo. O Piloto simplesmente reccbe a rota do navegador e as ordens de açôs (tais como siga cm frente, vire à direita, etc.) que são passadlas ao Controle de Baixo Nível. O Controle de Baixo Nível 6 o "atuador" do robo. Ele recebe as informaçoes do Piloto c as decolifica de forma a fazer os motores funcionarem.

Essa quebra en três ctapas de planejamento permite que o robô realize plancjamentos mais simples sempre que possivel. Somente quando o mapa do ambiente muda é que o Planejador de Missão é executado novamente. Se isso não ocorrer, o Piloto sabe exatamente quais são as ordens que ele deve passar para o Controle de Baixo. Isso pernite que o sistena execute mais rapidancnte do que se existisse 
um inico planejador, visto que o P’iloto é nenos complexo do que o Planejador de Missão e por isso é capaz de executar as suas rotinas cm menor tempo.

\subsubsection{Excmplo de uma Arquitetura Reativa: Subsumption}

$\Lambda$ arquitetura Subsumption [130] [131] é considerada como a arquitetura reativa de maior influéneia nos pesquisadores de robótica [140]. Isso se deve principalnente a dois fatores: primeiro porque ele era totalmente contrário a tudo que cstava sendo desenvolvido na área de robótica na época do scu surgimento, e segundo por causa. do tom dogmático dos artigos que introduziram essa arquitecura. Nesses artigos, Rodney Brooks 33] pregava os seguintes dogmas da robótica:

- Comportamento complexos não são necessariamente o produto de controlcs complexos:

- A inteligência está nos olhos do observador;

- Sinplicidade é uma virtude:

- Robós deven ser baratos;

- Planejar é apenas una forma de evitar descobrir o que deve ser feito a seguir;

- Toda computação on-board é importante:

- Os sistemas devem ser feitos de forma incremental;

- Nada de representagrio.

Muito do sucesso dessa arquitetura se deve ao fato de que ela possibilitou aos robôs que eles eran capazes de andar e evilar obstáculos de forma suave, ao contrário dos robôs deliberativos da época que possuían una certa pausa decorrente do tempo gasto no planejamento antes do se mover. 
Os comportancntos, a base dos robôs reativos, são organizados em camadas na arquitetura Subsumption. As cantas mais inferiores realizan tarefas (conportamentos) vitais para o robo, tais como evitar obstáculos. As canadas mais superiores realizan tarefas mais inteligentes (complexas). Os comportamentos nats camadas supcriores podem inibir ou sobrescrever a saída de comportamentos en camadas inferiores a eles.

A linguagem utilizada para se progranlar robôs utilizando a arquitetura subsumption é uma extensão das máquinas de estado finizo (Fig. 4.3). Una característica importante da subsumption decorre desse estilo de codificas:ão: cla pode ser compilada diretanente para hardware, o que torna os robôs extremanente rápidos.

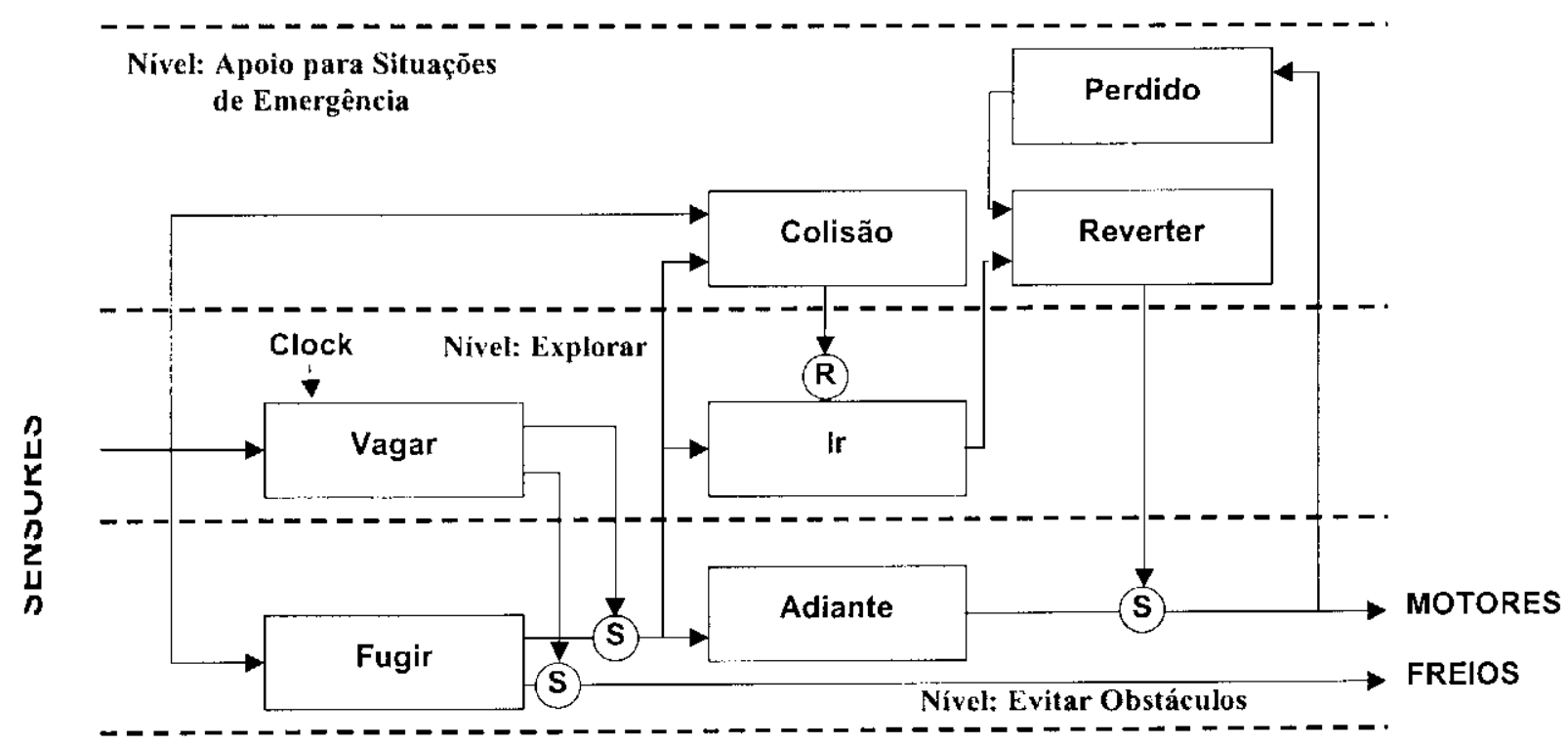

Figura 4.3: Exmmplo de Descrição dos Comportamentos de un Robô Móvel cm Subsumption 1300$]$. 


\subsubsection{Exemplo de uma Arquitetura Híbrida: Autonomous Robot Architecture}

Essa arenuitetura foi a primeira arquitetura híbricla a ser proposta. A Autonomous Robot Architecture (AuRA) [34] [35] consiste de cinco subsistemas:

1. Cartógrafo: encapsula as funçôs de rração e loitura de malpats necessário parà a nlavegação;

2. Planejador: pode ser clividido en três sub-módulos (Planejador de Missões, Navegador e Piloto), análogos aus planejadores da arquitetura NHC;

3. Sensores: responsáveis por obter e fundir os dados do ambiente e cuviá-los ao atuadores e au callógrafo:

4. Atuadores: incorporam alguns comportamentos (como evitar colisóes) e recobem o traçado a ser seguido dado pelo Piloto;

5. Controle Homeostático: é responsável por manter o equilíbrio do sistema através da modificação dos comportamentos dos atuadores.

Os subsistemas descritos podem ser classificados como fazendo parte do paradigma deliberativo on reativo. Os dois primeiros subsistemas podem são classificados como sendo deliberativos. Os dois segnintes são claranente reativos. Já o Controle Honeostático reside num local entre esses dois paradignas.

\subsection{Robôs Probabilísticos}

Robôs são inerentemente imprecisos quanto ao estado de seu ambiente. Essás intprecisöes são conseqüencias de limitações dos sensores, ruidos nos sensores e do fato de que a maioria dos ambientes sào inprevisíveis. Na hora de se oltter dados dos scusores, robôs probabilísticos [160] [157 59 , [147] [157], connputam distribuiçōes 
probabilísticas sobre o que deve estar acontecendo no seu anbiente ao invés de gerar apenas un único resultado determinístico. Desta forma, eles podem se recuperar de forma mais suave de possiveis cros, poden liclar com ambigüidades e podem integrar dados de vários sensores de forma mais consistente.

Qual é a vantaigem de se usar robôs probabilísticos? A vantagem é que um robô que carrega uma noção de suas incertezas (de sua ignorância) e age de acordo, obterá melhores resultados do que unı que não conhece suas próprias limitaçócs.

As duas principais áreas em que a computação probabilística tem sido utilizada con sucesso são: percepção e controle. A percepção de un robô sobre o scu anbiente ć conhecida como o problema mais fundamental para prover un robô móvel com capacidades autönomas. Particulamente complexo, ó o problemà da localização global no qual um robô não sabe a sua posiçāo inicial e tem que se localizar.

Sob uma ótica probabilística, o problema da localização é um problema de estimativa cle una densidade probabjlística, onde o robô procura estimar una distribuição posterior sobre o domínio de sulas possíveis localizaçós condicionadas áos dados disponíveis.

O principal objetivo da robótica é construir robôs que façan a coisa certa, ou seja, que ajajn corretamente. Como mencionado anteriomente, um robô que tem noção das suas incertezas e levam em consideração essas incertezas na hora de tomar suas decisões tenderão a tomar decisões molhores. Os dois principais conceitos envolvidos nos algoritmos probabilísticos são a regra de Bayes e a Suposição de Markov [16(0)].

\subsection{Robôs Reconfiguráveis}

Robôs reconfiguráveis são aqueles que possuem a habilidade de modificar a sua própria forma (configuração), visando melhor se adeçuar a realização de uma determinada tarefa. Os estudos nessá área têm crescido nuito nos últimos anos devido at necessidade do so criar robón móveis que possan so adaytar às dificuldades do torreno para se locomover da forma mais eficiente possível. Esse tipo de robô é par- 
ticularmente requerido para as aplicaços de reconhecimento de terreno en regioes perigosas (em guerra) e para o resgate de reféns e fericlos en locais perigosos para a entrada de seres humanos; apesar de que outras aplicaçoes tanmbćm poden aproveitar esse tipo de robó.

Geralmente, os robôs reconfiguráveis são modulares, ou seja, são compostos de múltiplos módulos que se unem de forma a permitir que o robô obtenha o seu objetivo. Esscs módulos costuman ser bastante simples e, geralnncntc, os robôs são compostos por módulos de um único tipo.

As vantagens de robôs modulares reconfiguráveis säo 110$]$ :

- Manufatura: como os nódulos que compöen esse tipo de robó são relativamente simples eles costmmam scr mais fáceis de serem fabricados do que os componentes dos robôs clássicos. Quando vários desses módulos são criakios o custo de fabricação e desenvolvinnento de robòs tianbém cam: pois esses módulos poden ser reutilizados em inúmeros robôs para as mais diferentess tarefas;

- Reparo: como o rolbó é composto de múltiplos módulosi, basta reparar (ou substituir) o módulo con problema:

- Robustez: como existe a redundáncia de módulos, muitas ve\%es a tarefa de um módulo danificado pode ser exceutada por ontro módulo. Além disso, o sistema possui uma degencração gradativa, on seja, o sistena ainda funciona bem com apenas alguns poucos módulos danificados.

Entretanto, robôs reconfiguráveis introduzen novas problenáticas:

- Deve ser determinada qual a configuração que deve estar ativa num determinaldo momento.

- Deve ser considerado o custo de roconfiguração do robò e qual o bencfício que a reconfiguração poderá trazer. 
- O objetivo do robô deve ser considerado no momento de reconfigurar o robô. Para ilustrar esse problema suponha um robó com duas configuraçoes: una para terrenos acidentados - o robô se locomove mals lentamente nessa configuração - e outra para terrenos planos - ele consegue se mover mais rapidamente. O objetivo desse robô é desativar uma bomba c ele está na configuração para terrenos plano e irá entrar mum terreno acidentado. Isso levaria a configurar o robó para o modo de terreno acidentado, porém o robô tem ponco tempo para desativar a bomba o na configuração de terreno acidentado cle não conseguirá chegar na bouba a tempo. Nesse caso o robó poderia manter a configuração mais rápida numa tentativa desesperada de chegar na junto a bomba no sen devido tempo.

- Ao planejar a melhor forma de se olster o objetivo, torna-se cssencial considerar a secuünncia de configuraçóes necessárias para seguir o plano especificado.

- Se o robó for modular é preciso prover un mecanismo de comunicação e cooperação entre os módulos e considerar qual o número de módulos necessários para se obter o objetivo.

A maioria desses problemas permanece en aberto, mas há vários projetos envolvendo muitos aspectos mencionados. A seguir serề descritos de forma breve alguns projetos na área de robôs reconfiguráveis modulares.

\subsubsection{Polypod}

O Polypod[110] [127] foi desenvolvido na Universidade de Stanford com o patrocínio da XEROX. O Polypod é un robó reconfigurável bi-modular, ou seja, ele é composto por exatamente dois tipos de módulos, os quais são descritos a seguir.

1. Módulo Segmentos : são os módulos principais do Polypod. Eles possuem todos os componentes para tornarenl-se um robô por si só, com exceção da fonte de cnergia. Ele possui um microprocessador, um motor, sensores de 
proxinicłade, torque e ângulo e também módulos de comunicação local (infravermelho) o global (serial) (likg. 4.4).

2. Módulo Nós (Fig. 4.5): Sĩo responsáveis por fornecer energia para os segmentos e por permitir que os segmentos scjann conectados de forma näo serial.

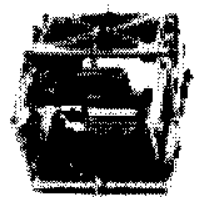

l'igura 4.4: Módulo Segmento do Polypod :127.

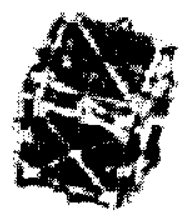

Figura 4.5: Módulo Nó do Polypod [127].

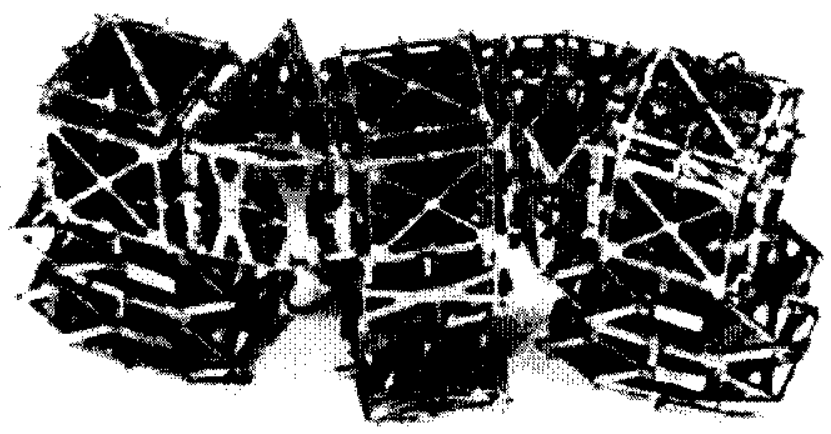

Figura 4.6: Módulos do Polypod Configurados em Forma de Lagarta [110].

Inúmeras configuraçöes foram testadas para avaliar como cada uma se comportava em cada tipo de terreno e como deveria ser o controle da reconfiguração do robô. A figura 4.6 demonstra uma configuração do Polypod. 


\subsubsection{I-Cubes}

O I-Cubes ${ }^{3}$ [118] [119] [92] são robôs reconfigurávcis modulares bi-partidos desenvolvidos na CMU. Eles são compostos por dois tipos de módulos: ligaçōes e cubos. Os módulos de ligação são os atuadores do sistema (permitern que o robó se mova, suba objetos, etc.). Os cubos são basicamente elementos de conexão para os módulos de ligação. Os cubos podem ou não conter sensores dependendo da tarefa a ser realizarda.

Os clementos de conexão são capazes de se concetar e desconectar das faces dos cubos. Portanto, eles podem realizar os seguintes movimentos (Fig. 4.7):

1. De uma face de um cubo para outra;

2. De um cubo para outro;

3. Mover um cubo.
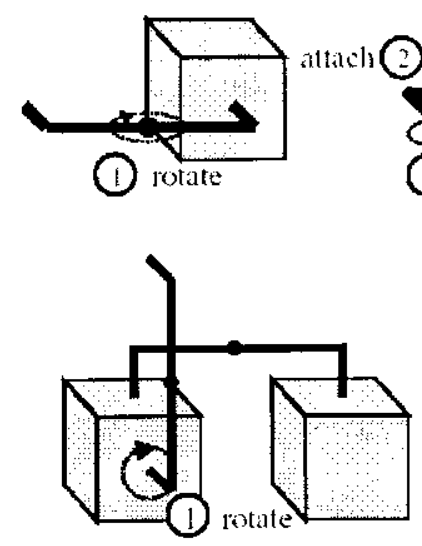

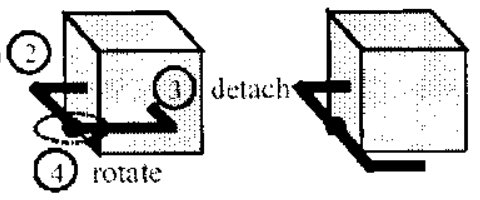

(a)

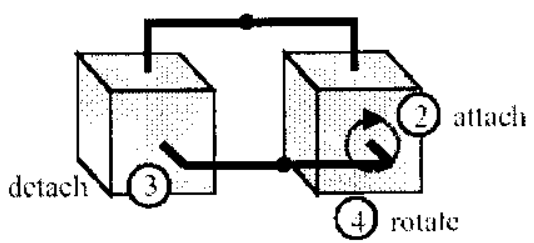

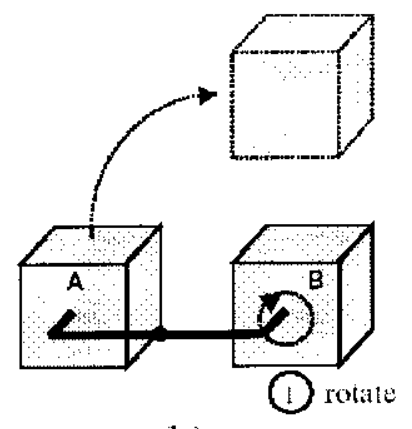

(b)

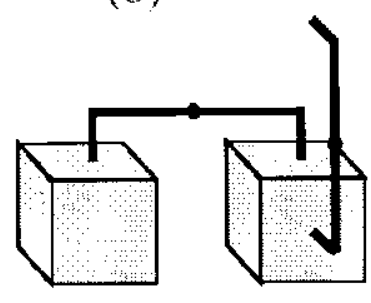

Figura 4.7: Possíveis Movimentos dos Elementos de Ligação dos I-Cubes [119].

\footnotetext{
${ }^{3} \mathrm{O}$ nome I-Cubes ven de ice cubes (cubos de gelo).
} 
Os arranjos de módulos de ligação e cubos forman un grafo onde os cubos são os nós e os elementos de ligação são as arestas. O grafo formado muda sempre que houver un movinnento de un módulo de ligaçào.

Os I-Cubes possuem as seguintes características:

- Cada módulo do robô pode ser controlado de forna independente;

- Todos os módulos de ligação e cubos são idênticos;

- Módulos podem transmitir e receber informaçón dos outros módulos com os quais eles estão conectados;

- Permite movinentação en 3 dimensôes.

Os I-Cubes são controlados através de una interface gráfica de programação e monitoramento (Fig. 4.8) ou manualmente, através de botoes existentes nos módulos.

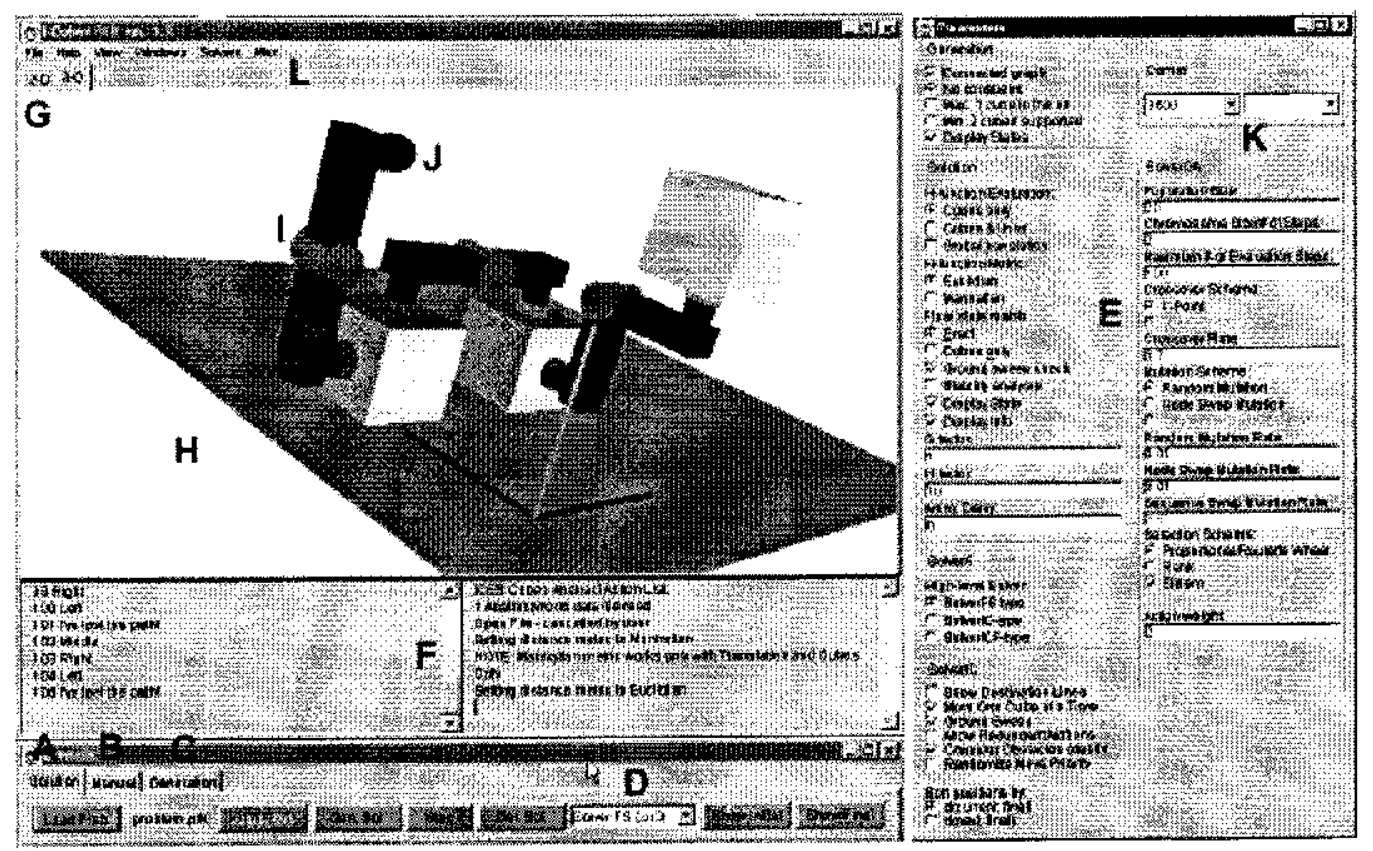

Figura 4.8: Interface Gráfica de Programação dos I-Cubes [119]. 
Os I-Cubes foran testados em várias situações; tais como escalar um objeto e levantar um robó (cubo) provido de sensor para monitorar uma região.

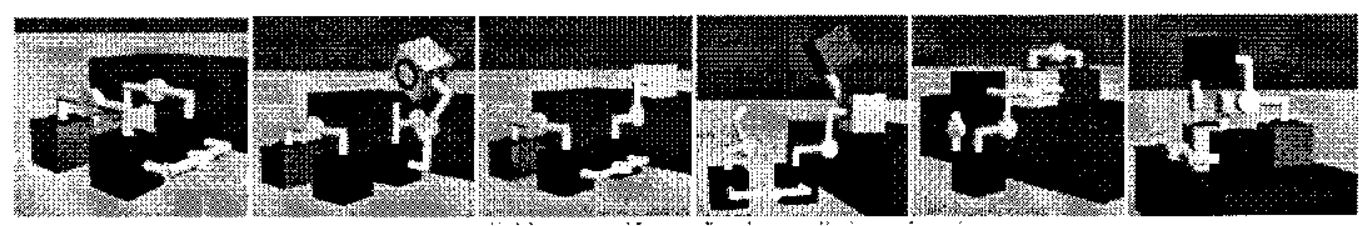

Figura 4.9: I-Cubes Escalando um Objeto [119].
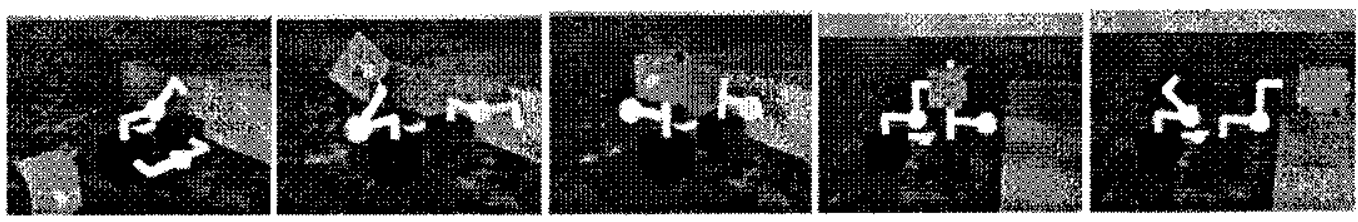

J'jgura 4.10: I-Cubes Posicionando um Cubo para Monitoramento de uma Região $[119]$.

\subsubsection{Crystalline}

Crystalline [105] [38] 106] [108] [107] [99] é um projeto de robôs reconfiguráveis uni-modulares que está sendo desenvolvido por posquisadores da Universidade de Dartmouth, Inglaterra.

A fonte de inspiração para o projeto foi o comportamento dos músculos dos seres vivos. Os músculos são capazes de se contraírem ou cxpandirem de acordo con a tarefa a ser realizada.

Bascado nisso foram criados cubos, denominados átomos, capazes de se contraírem para metade do seu tamanho e se expandirem ao seu tamanho original (Fig. 4.11). Múltiplos átomos sâo conectados através das suas faces. Cada átomo é composto de baterias, um microprocessador da Atmel, um motor para expandir/contrair o átomo, um motor de rotação para girar o átomo e dispositivos de comunicação 
(serial ou infra-vermelho) com um PC, o qual é responsável pelá progranação dos átomos.
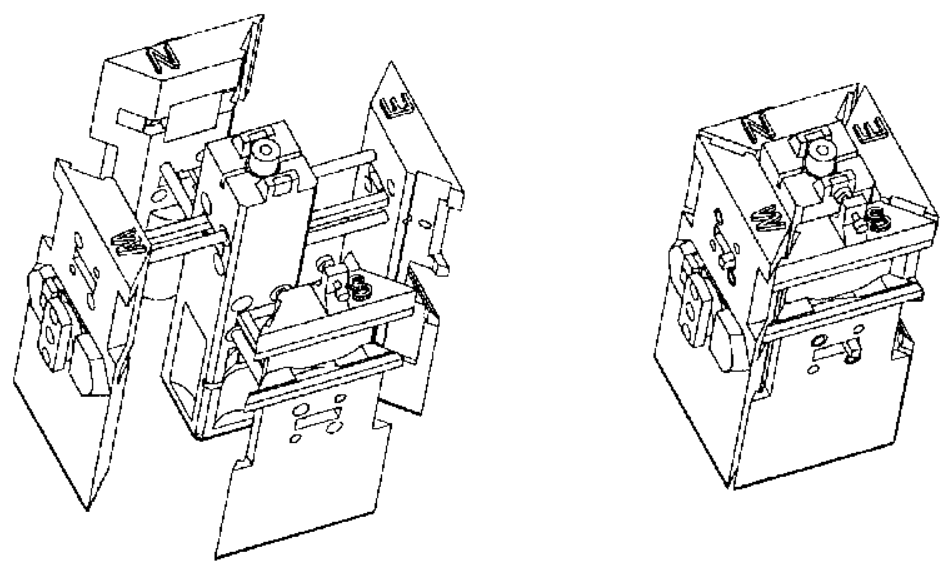

Figura 4.11: Átomo Crystalline Expandido c Contraído [107].

Os robôs Crystalline possuem quatro prinitivas (operaçòes) básicas:

1. expand(atom, dimension) - expande o átomo atom na dimensào dimension $(x, y$ oul $z)$.

2. contract(atom, dimension) - contrai o átomo atom na dimensão dimension $(x, y$ ou $z)$.

3. bond(atom, dimension) - conecta o átono aton com o vizinho na direção dimension.

4. free(atom, dimension) - libera o áromo atom do seu vizinho na dirç̧ão dimension.

Quando diversos átomos são conectados, essas cluatro propriedades permitem o movimento arbitrário de un átomo para qualquer região da estrutura formada. A figura 4.12 ilustra o movinento de dois átomos e a figura 1.13 ilustra a metamorfose de una estrutura de átomos em forma de um cachorro para a forma de um sofá. 


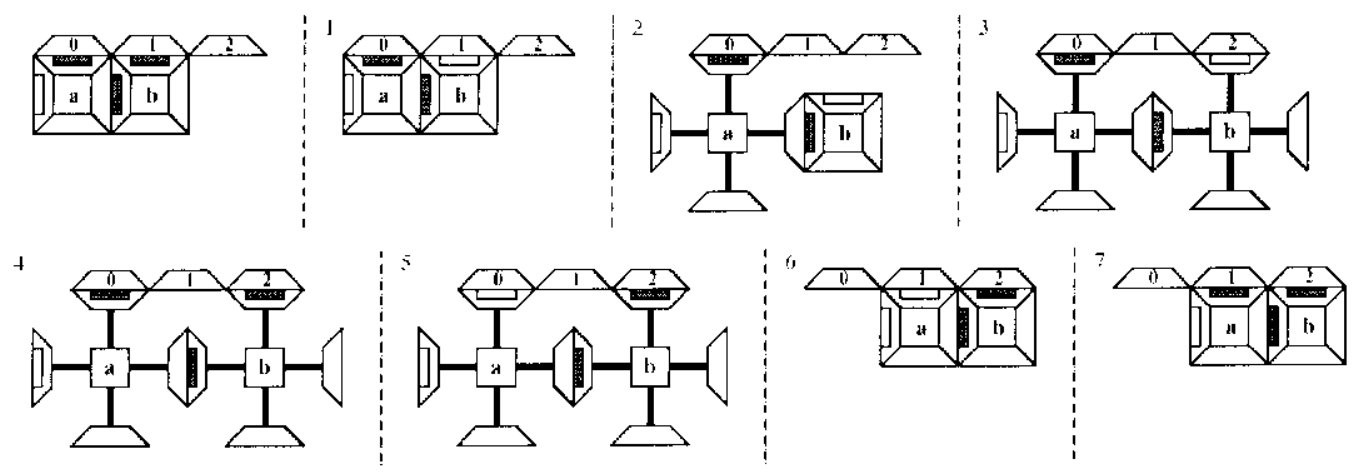

Figura 4.12: Dois Átomos se Movendo [105].
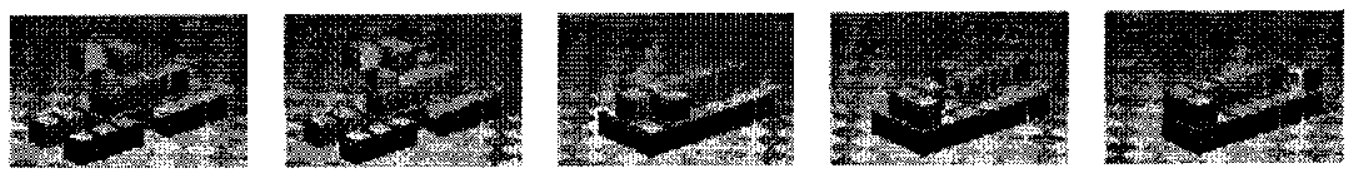

Figura 4.13: Metamorfose de um Robô Crystalline em Forma de Cachorro para a Forma de um Sofá [119].

Uma característica importante que está sendo incorporada aos robôs Crystalline é o auto-reparo. Os robôs Crystalline são capazes de identificar quando um átomo não está funcionando corretamente c clininá-lo do sistema. Outros átomos se expandem de forma a realizar a tarefa que estava sendo realizada pelo átomo defeituoso (Fig. $4.14)$.
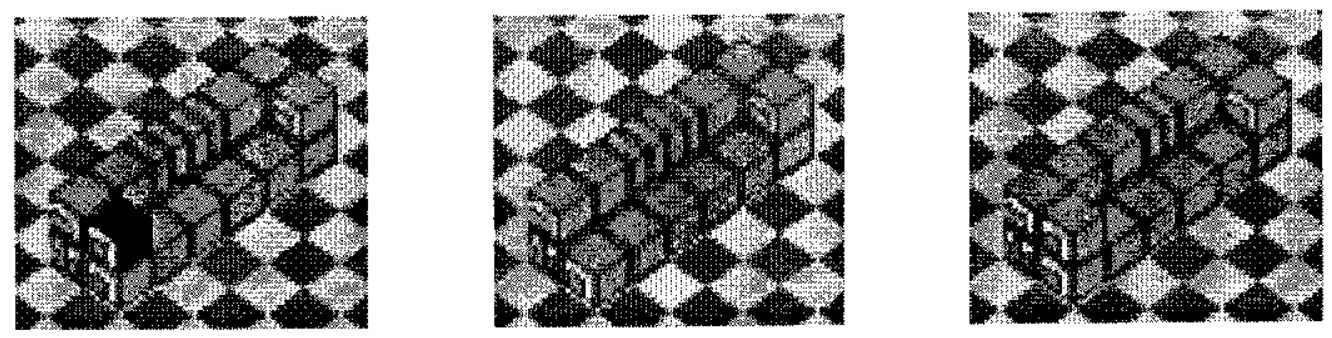

Figura 4.14: Um Átomo Defeituoso (Mais Escuro) sendo Fliminado do Sistema e Substituído por um Átomo que estava Contraído [99]. 


\subsection{Linguagens para a Programação de Robôs}

Robô são sistemas complexos e, portanto, difíceis de serem programados. Muitas linguagens foram criadas com o objetivo de tornar essa tarefa mais amena 27] [148] [120] [91] [158] [161].

As linguagens de programação de robôs podem ser divididas em duas categorias principais: linguagens visuais e linguagens textuais.

A programação en linguagens visuais é feita através do uso de descnhos, íconcs, botôes e caixas de diálogo. Esse tipo de programaģäo costuma ter uma curva do aprendizado bastante acentuada e permite que mesmo usuários leigos possam criar facilmente algumas funcionalidades. () principal problema desse tipo de linguagem é que ela não dá muito poder ao programador: nem todo tipo de funcionalidade permite uma representação gráfica. Esse tipo de programação se adequa bem ao paradigma reativo onde a maioria dos comportamontos podem ser criados através do uso de máquinas de estado finito, as quais são representação visuais. Contudo, é difícil inaginar cono um robô deliberativo ou híbrido poderia ser progranado destá forma. Além disso, na maioria das vezes, o programa executável por elas gerado poderia ser muito mais otimizado.

Já as linguagens textuais dão grande liberdade ao programador: cle pode combinar as construçôes da linguagem como ele bem entender. Geralmente, o código criado é bem mais rápido do que aquele que foi criado utilizando uma linguagem visual. Porém, o progranador tem mais traballıo para codificar a funcionalidade.

Na subseção 4.5.1 é descrita de forma bastante sucinta uma linguagem de programação visual, a SDM [120]. Como exemplo de unla linguagem de programação textual podemos citar a CES [158] [161], a qual será descrita no capítulo 5 devido a sua grande relevância para esse projeto. 


\subsubsection{Exemplo de uma Linguagem Visual de Programação de Robôs: SDM}

A Software Definition Module (SDM) [120] é uma linguagem visual criada para a construção de robôs utilizando-se a arquitecura subsumption (reativa) [130] [131]. A arquitetura subsumption é baseada em comportamentos, canadas e a inibição de comportamentos. A SDM tem uma tela para a criação de comportamentos e camadas (Fig. 4.15). Existem ícones que permitcm que um comportanento numa camada iniba o comportamento de una camada inferior (Fig. 4.16). Os sensores e atuadores podem ser adicionados como entradas ou saídas de um comportamento, arrastando-os para esse comportamento (lig. 4.17). Os comportamentos são criados através de editores de máquinas de estado (Fig. 4.18).

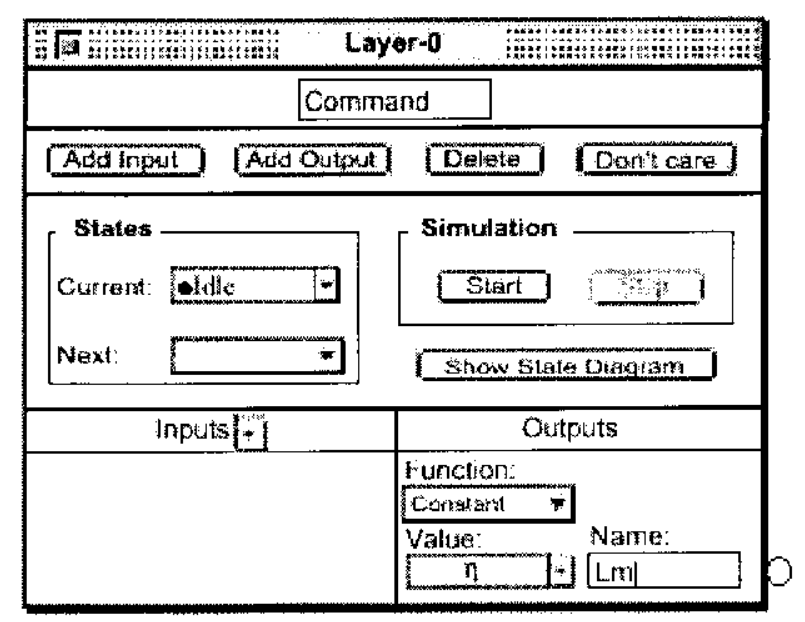

Figura 1.15: Tela de Criação de Camadas [120j.

Uma vantagem adicional dessa linguagem é que a programação e a simulação do robó podem ser fcitas num único ambiente. Isso elimina a necessidade do desenvolvedor de robôs en se familiarizar com un ambiente de progranaçäo e com um ambiente de simulação: os dois estão integrados.

Apesar de ser baseada na arquitetura subsumption essa linguagem não tira 


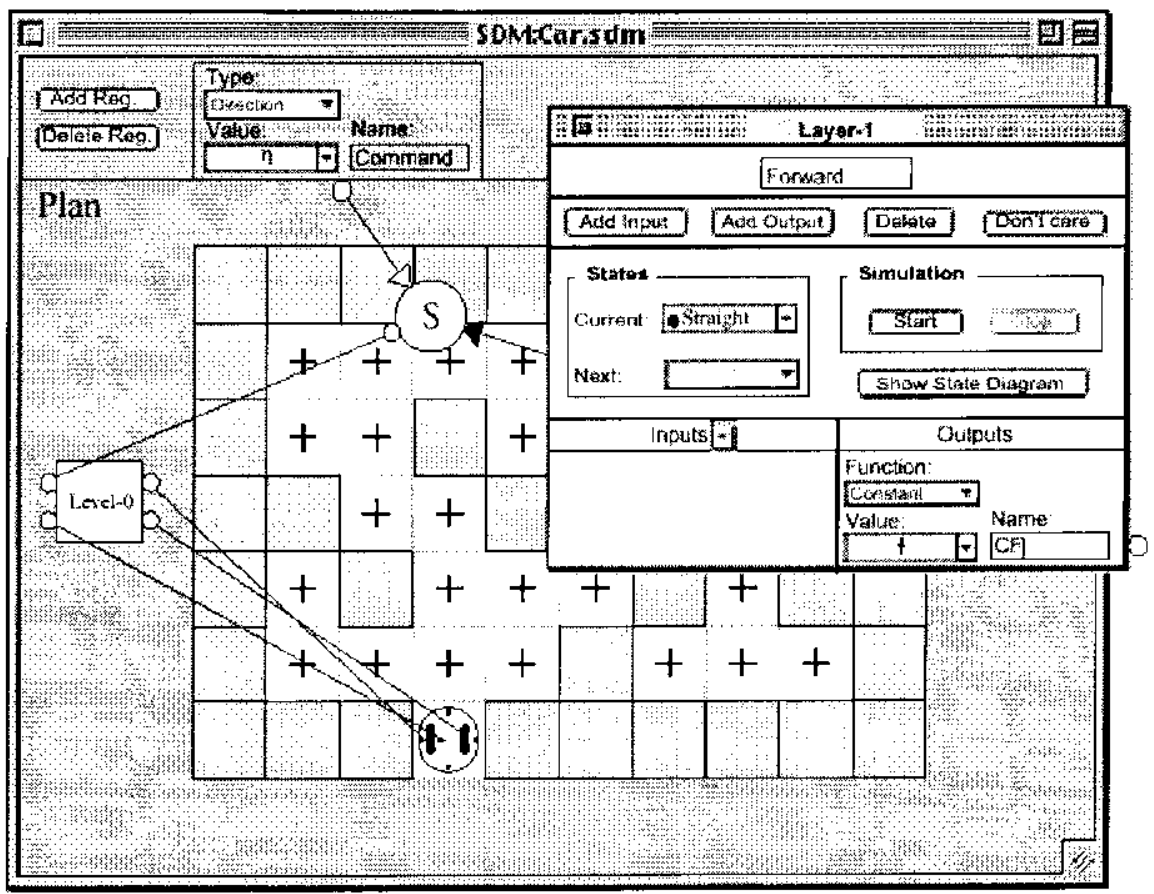

Figura 4.16: Camada 1 (Layer 1) Inibindo (S) a Camada 0 (Level 0) [120].

proveito da maior virtude da subsumption: a capacidade de gerar hardware à partir da descrição dos comportamentos presentes no robô. A SIDM gera um programa exceutável para um robô cujo hardware já está construído. Essa linguagem é nuito simples e permite que robòs reativos scjam criados facilmente. Contudo, a criação de robôs de outros paradigmas que não o reativo é simplesmente impossível nessa. linguagem.

\subsection{Alguns Problemas em Aberto na Robótica}

Os robôs que são construídos hoje cm dia säo bastante limitados se comparados aos robòs que são propostos pela fição científica (HAL de 2001: Uma Odissćia no Espaço; RD2D2 e C3PO de Gucrra nas Estrelas e mais recentemente o robô 


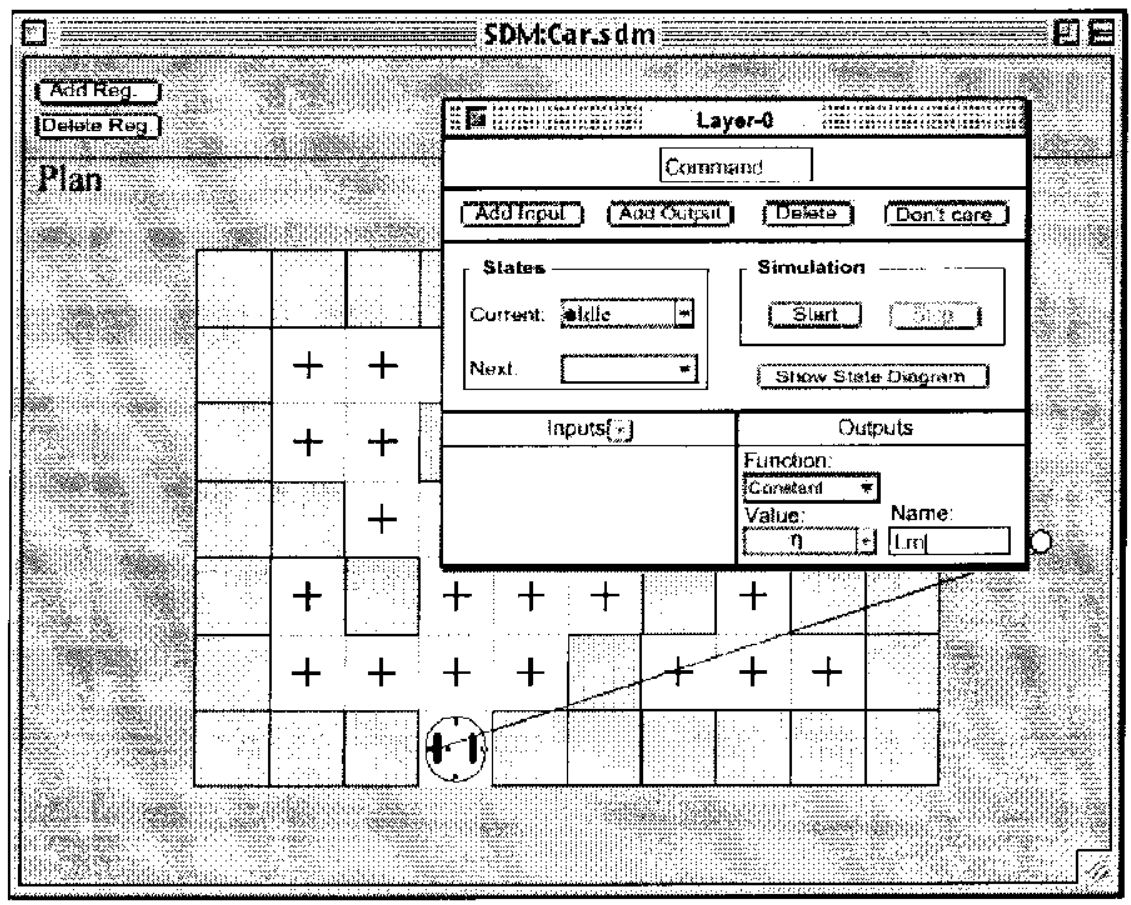

Figura 4.17: Associando a saída Lm ao Motor da Roda Esquerda do Robô [120].

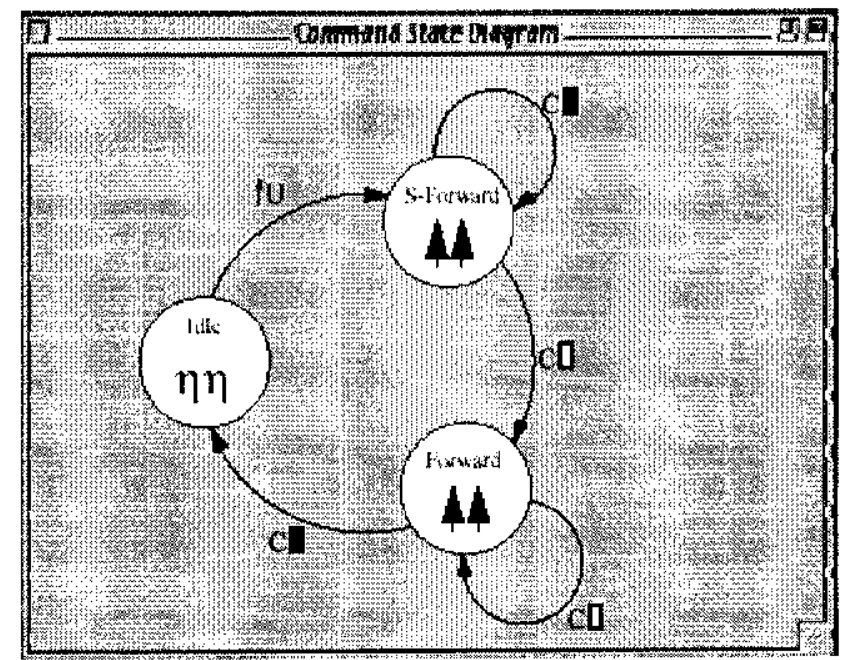

Figura 4.18: Comportamento Sendo Criado Através do Editor de Máquinas de Estado $[120]$. 
menino do filme $\mathrm{AI}^{4}$ ). Portanto, os robôs ainda têm que evoluir muito para atender as expectativas criadas em seus usuários pelos contos de ficção científica. Alguns dos problemas a serem resolvidos são [5]:

- Navegação: o máior problema em navegação é como representar os dados do ambiente. Robós reativos apresentam a seguinte resposta: simplesmente não representando os dados do ambiente. Contudo, os robôs reativos não consegnem traçar rotas ótimas entre a sua localização atual e sen destino, exatamente por não possuírem nenhum tipo de representação do ambiente. Por outro lado é absolutamente inviável representar todos os detal hes do ambientc na menória de um robô. Consequientemente surgem as questões: Qual representação utilizar? Quais as estruturas de dados necessárias? Qual o grau de detalhismo da representação? Quantos sensores são suficientes para coletar os dados necessários para a bod navegação do robô? É necessário a fusão de sensores?

- Reconhecimento: os robós deven ser capazes de reconhecer alguns padrões do ambiente, cono por exemplo, pegar un objeto, conscrtar un dispositivo on simplesmente interagir com uma pessoa. Na maioria das vezes esse problema requer algoritmos complexos e custosos do ponto de vista computacional. Fica em aberto, portanto, a criação de novos algoritmos para o reconhecimento de padrões (objetos) e a forma de representar eficientemente esses padrões.

- Aprendizado: uma característica marcante dos robôs da ficção científica é que eles são capazes de raciocinar e aprender novos conceitos. Essa capacidade é bastante limitada (quando existe) nos robôs atuais. Nesse ponto surge a pergunta: será possível criar robôs realnente inteligentes?' O que eles serão cápazes de aprender? Quais algoritmos devem ser utilizados? Os robôs poderão se voltar contra os hunanos num futuro próximo?

\footnotetext{
${ }^{4} \mathrm{O}$ qual teve urua contribuiçâo científica do Brooks: o qual não esconde de ninguém que seu maior sonho é criar um robô que aja como um ser humano
} 
- Miniaturalização: os robôs, atualmente, costumam ser nunito grandes para as tarefas que eles fazem. Por exemplo, será que um robô realmente precisá ter um metro e mejo do altura parä guiar alguns visitantes por um muscu? Surge, então, a questão de criar novos sensores, atuadores e elementos de processámento que sejam mais rápidos, consumam monos energia e sejam monorcs. A diminuiçâa no tamanho dos robôs será extremanente benéfica principalmente para as indústrias.

- Cooperação: quantos robôs são nocessários para realizar uma determinada tarefa? Se o uso de mais de un robô se fizer necessário on trouxer bencfícios para a execução de uma determinada carefa cria-se então a necessidado do cooperaçäo entre esses robôs. Mas como cles deven cooperar? Eles deven sc comunicar explicitanente ou apenas un deve monitorar (por meio de câneras, por exemplo) as atividades do outro? Se eles devern se comunicar, como eles devem se commicar? Por rádio, infravermelho, som? Um pode realizar a tarefa do outro se o outro não a estiver realizando de forma precisa ou eficiente?

São muitas questões que somente o tempo e muito csforço cm pesquisa poderão responder. 


\begin{tabular}{l|l|l|}
\cline { 2 - 2 } & Capítulo \\
\hline & 5 \\
\hline
\end{tabular}

\section{A Linguagem de Programação de} Robôs CES

A linguagem CES foi descnvolvida especialmente para a programação de robôs, cm especial a progranaçăo de robôs probabilísticos. Ela suporta o desenvolvimento de código adaptável: instruir un robó em CES alterna fases de programação convencional e de treinamento, na qual o código a melhorado atravós de exemplos (treinamento supervisionado).

Na presente data, existem basicamente duas metodologias para a programação de robôs (as quais são utilizadas de forma isoladas apesar de sercm complementares): a programação convencional e o aprendizado de máquina. A maioria dos robôs foram programados usando linguagens procedinentais ou orientadas à objetos, tais como $\mathrm{C}, \mathrm{C}++$ ou Java. Contudo; os robòs, suas tarefas e o ambiente nos quais cles interagem são extremannente complexos, o que faz com a progranação robótica 
geralmente seja muito custosa (tanto do ponto de vista financeiro quanto do tempo de desenvolvinento).

Trabalhos recentes substituíran com sucesso a programação convencional por técnicas que lhes permitiam treinar seus códigos [45] [44] [159! 165]. Mas o problema das linguagens que adotaram esse paradigma ć que clas romperam totalnente com as linguagens convencionais e existem várias tarcfas da progrannação de un robô que são muito mais facilmente descritas en linguagem convencional.

A CES tenta extrair as vantagens de ambos os lados: ela permite que o código seja creinado e ao mesmo tempo prove todos os recursos das linguagens tradicionais (no caso da linguagem C). Além dos recursos anteriormente descritos, á linguagen possui funçoes e tipos de dados especiais para lidar com computaçoes que envolvam distribuições probabilísticas. Esse recurso foi incorporado à linguagem devido ao sucesso que técnicas envolvendo tais distribuições tèm obtido na programação de robôs (cm cspecial na área de navegaçào de robôs móveis) [160].

É inportante salicntar que os resultados obtidos até o presente momento pela linguagen CES säo bastante animadores: un código de robô móvel escrito en linguagem C que possui 50000 linhas foi portado para un código CES equivalente de apenas 58, um ganho de duas ordens de magnitude[161].

\subsection{Programação Probabilística na CES}

Essa seçāo descreve os tipos de daulos probabilísticos, seus operadores e funçócs. Fisses recursos possibilitam que o progranador possa lidar de forma mais natural com as imprecisóes dos dados obtidos pelos sensores dos robôs e com as incertezas existente nos ambientes com os quais eles interagem [161][160].

\subsubsection{Tipos de Dados Probabilísticos}

A CES utiliza métodos da teoria da probabilidade para representar e processar informaçooss incertas. Tais informaçôs são representadas pelo novo tipo de dado: 
prob<type > (essa variável descreve uma distribuição estatística de dados do tipo type - onde type é um tipo de dado numérico).

Esse novo tipo de dados é utilizado para declarar variáveis que representam distribuiçoes probabilísticas sobre us valores do tipo especificado por type. Por exemplo, uma variável declarada como sendo prob $<i n t>$ especifica para cada valor inteiro $\mathrm{x}$ a probabilidade do valor daquela variável ser $\mathrm{x}(\operatorname{Pr}(X-\mathrm{x})$. De acordo com Kolmogorov, esses valores devem ser nẫo negativos c a soma desses valores não deve exceder 1. Essas propriedades são garantidas pcla linguagem.

A linguagen provè mecanismos para inicializar as variáveis probabilísticas com algumas distribuçós contínuas pré-definidas (aquelas que possuem maior relevància dentro do contexto da programação robótica) ou para distribuiçóes discretas.

\subsubsection{Operadores Aritméticos}

Aritmética com tipos de dados probabilísticos é análoga a aritmética convencional em $\mathrm{C} / \mathrm{C}++$. Por exemplo, vamos assumir que $\mathrm{x}, \mathrm{y}$ e z sào três variáveis probabilísticas do tipo Probint ${ }^{1}$ e que $\mathrm{x}$ e y possuem a seguinte distribuição:

$$
\begin{aligned}
\operatorname{Pr}(x)= & 0.5 \text { se } x \quad 0 \\
& 0.5 \text { se } x \cdots 3 \\
& 0 \text { caso contrário } \\
\operatorname{Pr}(y)= & 0.1 \text { se } 0<=y<10 \\
& 0 \text { caso contrário }
\end{aligned}
$$

Então a expressão $z=x+y$ gera a seguinte distribuição:

\footnotetext{
${ }^{1}$ tipo probabilistico no donnínio dos inteiros, analogamente existen tipos probabilísticos para a domínio dos reais e de outros tipos muméricos
} 


$$
\begin{aligned}
\operatorname{Pr}(z)= & 0.05 \text { se } 0<=z<3 \\
& 0.1 \text { se } 3<-z<10 \\
& 0.05 \text { se } 10<=z<13 \\
& 0 \text { caso contrário }
\end{aligned}
$$

A operação descrica acima assume a independência entre os operandos do lado direito da atribuição. Mais especificamente. cla assume a independência estocástica entre $\mathrm{x}$ e $\mathrm{y}$.

\subsubsection{Conversão de Tipos}

Para tornar mais simples a progranaçio utilizando tipos probabilísticos e tipos numéricos convencionais, a CES provê mecanismos para a conversão de tipos. Vejamos como funciona a conversão entre tipos probabilísticos e convencionais ${ }^{2}$ :

a expresisão

$$
y=(\text { probfloat }) x
$$

faz com que y represcnte a seguinte distribuição:

$$
\begin{aligned}
\operatorname{Pr}(y)= & 1 \text { se } y=x \\
& 0 \text { se } y !=x
\end{aligned}
$$

È a expressāo:

$$
x=(\text { float }) y
$$

fack com que $\mathrm{x}$ recelba a média da distribuição y.

\footnotetext{
${ }^{2}$ o mecanismo utilizado anui 6 o casting
} 


\subsection{Principais Funções}

As duas principais funçoes probabilísticas da CLS são o truncamento e a inversão. () truncamento elimina todas as probabilidades que são menores que o parâmetro passado vezes a maior probabilidade existente dentro da distribuição e nomaliza a distribuição (faz com que a soma dos valores dos dados da distribuição antes e depois do truncamento se mantenha constante). O valor passado como parâmetro deve estar contido no intervalo 0,1$]$. Essa função é particularmente útil para eliminar situaçóes que são extremamente improváveis mas que podem ocorrer (ou seja, situaçôes cuja probabilidade de ocorrencía é muito baixa). Já a função de inversão é a função matemática de inversão clássica. O) seja, se $\operatorname{Pr}(X=x)-y$ a inversa de $\mathrm{X}$ é $\operatorname{Pr}(Y=y)=x$.

\subsection{O Comando probloop}

O conlando probloop foi criado na lingnagem CES para permitir que o programador lide con dados probabilísticos como se fossem valores tradicionais. Isso é especialmente útil quando estamos lidando com dados que são dependentes (os operadores da linguagem assumem independència entre os dados).

A sintaxe do comando probloop é a seguinte:

probloop(var-list-in; var-list-out) progran-code

onde var-list-in e var-list-out são listas de variáveis probabilísticas separadas por vírgulas e progran-code é çualquer código em linguagem CES.

\subsection{Aprendizado de Máquina na Linguagem CES}

Progranar en CES ó uma tarefa gue intercala desenvolvinento de código convencional e fases de aprendizado. Ao progranar um robó en CES o progranador pode definir un nível básico do funcionalidades (cm linguagem convencional) e doixar 
mecanismos que dependem de aprendizado (como, por excmplo, una rede neural) para serem treinados mais tarde. É inportante salientar que esses elementos de aprendizado podem ser treinados (ou re-treinados) durante qualquer instante da fase de programação e que não é necessário treiná-los todos ao mesmo tempo.

Com isso, conseguimos definir muito mais facilmente como esses elementos que cnvolvem aprendizado interagem com os elementos de programação convencional. Além disso, toda a lógica do robò que independe dessa fase de aprendizado pode ser programada e validada antes, durante ou depois que os elementos que envolvem aprendizado tenhan sido treinados (dando una maior flexibilidado ao programador).

A maneira pela qual definimos esses clementos trcináveis no código é declarando funçōes de aprendizado (como, por exemplo, uma rede neural). $\Lambda$ sintaxe é a. seguinte:

fa<tipo-entradas,tipo-saídas> (tipo-função, parâmetros) nome-da-função:

onde nome-da-função é o nome que o usuário quiser dar para aquela função de aprendizagem espccífica: tipo-função pode ser uma rede neural, una regressão linear, entre outros; os parámetros são dependentes da funçâo escolhida e o tipo-entradass c tipo-saídas definem o tipo das entradas e saídas respectivanente.

Para se treinar una função evocamos o método train dessa função: nome-dafunção train(). Durante essa fase é utilizado o método de gradicnt descent para atualizar os parânetros da rede (no caso de uma rede neural, por exemplo, os parâmetros são scus pesos e suas bias).

E para utilizarmos essa função depois de treinada usamos a função eval: nonedá-funçào.cval().

Uma das funçoes de aprendizado mais utilizadas da CES é aquela que cria redes neurais multi camadas (MLP) [161]. Devido a esse fato, as primeiras unidades funcionais reconfiguráveis que serão criadas para o ARCHITECT-R 51] [4] [52] são as que implementam esse tipo de redes, as quais são descritas no próximo capítulo. 


\section{Descrição e Especificação do Sistema} ARCHITECT-R

O ARCHITECT-R [51; [4] 52] é uma proposta de um sistema de computação reconfigurável aplicado à robótica que atua no descnvolvimento de pesquisas nas áreas do compiladores e arquitetura de computadores reconfiguráveis, visando à cxploração máxima do paralelismo cncontrado nas mais diversas aplicaçós dessa área.

Para isso seräio utilizadas técnicas modernas de otimização de compiladores [151] [42 [122] :128], exploração de paralelismo em nível de instruçòes (ITP) [8] [134] e computação reconfigurável [71] [60] [139].

O ARCHITECT-R é um projeto bastante ousado e incorpora conhecimentos de áreas bastante distintas. Portanto, ó imprescindível para a sua implementaçäo que ele seja mnito bom especificado e particionado de forma a permitir que o seu descnvolvinento seja modular e incremental. Para que isso aconteça é necessário 
que as funcionalidades dos diferentes módulos do projeto sejam descritas de forma clara, servindo como base para a especificação e futura implementação do sistema.

Nas seçôes seguintes serano descritos os módulos do ARCHIT'LCI'-R e a linguagem UML, a qual foi utilizada para a sua especificacáo.

\subsection{O Compilador do ARCHITECT-R}

O compilador do sistema ARCHITECT-R extrairá o máximo de paralelismo possível das aplicaçoes, ntilizando-se técnicus de otinnizaçào de código bascadas em ILP e trabalhando em conjunto com o LEGUS System (Seção 6.1).

Una decisão fundanental na construção de um compilador [42] ć a escolla da linguagem a partir da qual cle gcrará o código fonte. Tendo-se em mente que o sistema ARCHITECT-R possui um domínio bastante específico (robótica), optonse por se utilizar uma linguagem específica para esse domínio: a CES.

Outro fator relevante dentro do contexto do compilador é al utilização de técnicas de ILP. A opção pelo uso dessas técnicas ó baseada no fato de que, geralmente, os programks para controle, navegação e demais funcionalidades de un robô podem sofrer grandes ganhos em termos de desempenho com a utilização do paralelismo en nível de instruçäo sem terem que sofrer modificaçóes notórias ao programador; ou seja, o programador continua desenvolvendo o seu código da mesma forma, porén o resultado linal será mais eficiente.

Dada a notória complexidade en se escrever um compilador otimizante, esse projeto não criará um novo compilador: será escolhido um compilador para servir de base de descnvolvinento e lhe serâo acrescentadas as funcionalidades restantes que o ARCHITECT-R necessite. Dada a importância do compilador para o sucesso do ARCHITECT-R, optou-se por comentar, mais detalhadamente, assuntos relacionados ao mesmo num capítulo à parte (Capítulo 7). 


\subsection{Hardware do Sistema ARCHITECT-R}

Una parte do hardware do sistema ARCHITECT-R será gerado usindo as ferramentas do sistema Excalibur [13] da Altera. $\Lambda$ ferramenta Excalibur da Altera ó uma solução que provê tanto a capacidade de conliguração dos dispositivos lógicos programáveis (PLDs) quanto o desempenho e facilidade de uso dos processadores embutidos[12]. A linha Excalibur da. Altera oferece cores ${ }^{1}$ de processadores RISC otimizados especialmente para lógica programável. Possuindo tanto soft cores como hard cores, esta linha é capaz de atender aos recuisitos do fle-xibilidade e desempenho que as aplicaçós de robótica necessitam.

Uma outra parte do hardware do sistema ARCHITECT-R será composta por blocos arquiteturais especiais (redes neurais, algoritmos genéticos, support vector machines, entre outros). Esses blocos arquiteturais serão criados usando a linguagem de descriçäo de hardware VHDL [76] [162] e/ou Verilog [43] [89], dando uma. maior flexibilidarle para a ntilização dos mesmos. Essces blocos serão incorporados ao hardware criado pelo Excalibur na forma de Unidades Funcionais Reconfiguráveis (RPUs).

Dessa forma, Lemos una arquitetura de hardware bastante flexível para atender todos os requisitos dos sistenas de robótica. A criação do hardware do ARCHITECTR., mais especificamente a criação de RPUs, será mais detalhada no capítulo 8.

\subsection{LEGUS System}

O LFGLS System (Fig. 6.1) [4. é formado por uma base de conhecimento, uma biblioteca de blocos arquiteturais especificados cm VHDL e/ou Verilog e um agente inteligente que é responsável pela síntese final da arquitetura do sistema.

A idéia do LEGUS System é a mesma do jogo LEGOC, onde a criança monta

\footnotetext{
'Cores são códigos sintetizáveis (ou pré-sintetizados), seralnente paranotrizáveis, que implementam algum tipo de lardware (nesse caso particular, un procesiatior).
} 


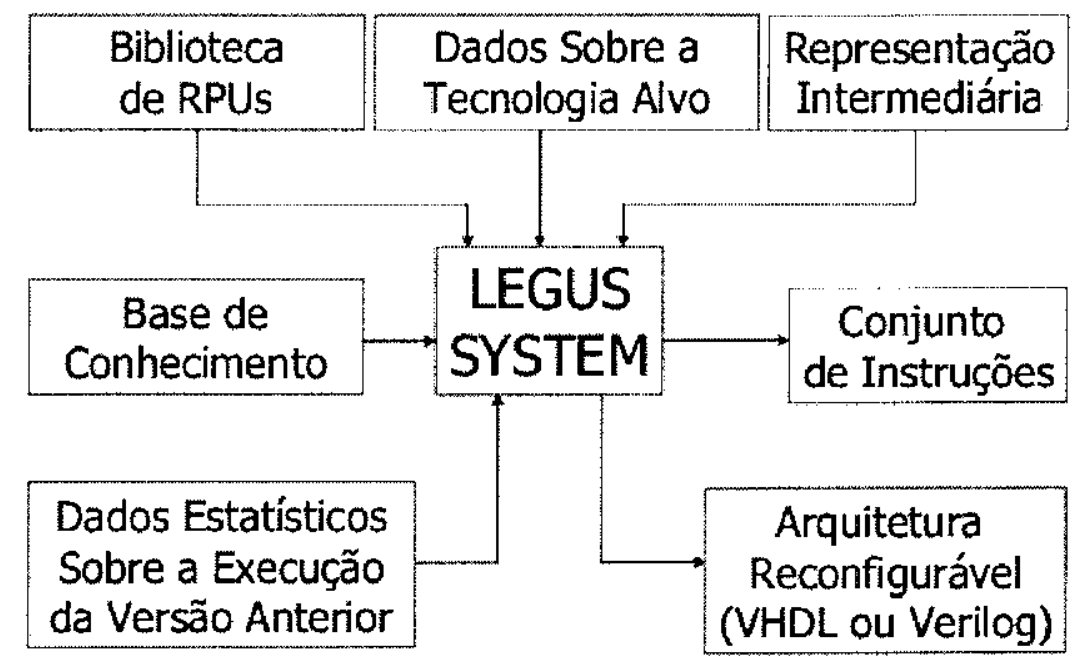

Figura 6.1: Diagrama de Blocos do LEGUS System.

uma determinada estrutura escolhendo os blocos mais adequados para aquela tarefa. No LEGUS System, o agente inteligente innita a criança, agrupando os blocos arquiteturais que serāo combinados en várias unidades funcionais e interligados com os bancos de registradores, de forma a gerar a arquitetura mais otimizada para a aplicação específica. O resultado final é um processador. Este tipo de processador é conhecido por ASIP (Application Specific Processor).

A base de conhecimento será composta pelas especificaçôes dos vários blocos que podem ser usados pelo compilador para compor a arquitetura e seus atributos. Alguns dos atributos serão:

- Número de I.ABs (arrays de blocos lógicos) ocupados pelo circuito;

- Número de IOBs (blocos de cntrada e saída) necessários para o circuito;

- Profundidarle do pipeline do circuito;

- Clock máximo do circuito;

- Númcro e tipo de registradores necessários para o circuito; 
CAPÍTULO 6. DESCRIÇÃO E ESPECIFICAÇÃO DO SISTEMA ARCHITECT-R78

- Número e tipo das Unidades Funcionais que compõem o circuito.

A biblioteca do blocos arquiteturais possui a codificação em linguagem de descrição de hardware (HDL) dos componentes que podem ser usados na criação das RPCs.

O Legus System irá operar de acordo conn o algoritmo a seguir:

1. Determinar quais unidades funcionajs reconfiguráveis podem melhorar o desempenho do sistema;

2. Determinar o impacto de cada RPU escolhida no desempenho do sistema;

3. Inserir as RPUs que forem possíveis, inscrindo primeiro aquelas que possmem um maior impacto no desenupenho do sistema;

4. Modificar o código fonte de forma a acomodar essas novas RPUs;

5. Resolver as inconsistências geradas;

6. Permitir que o ARCHITECT-R gere e simule o sistema proposto;

7. Retornar ao primeiro passo e usa os clados da simulação para corrigir possíveis erros e melhorar o desempenho;

8. Encerrar o ciclo quando não for mais possível otimizar o sistenla ou não conseguir resolver as inconsistências.

Como pode ser observado na Figura 6.2, o Legus System é a parte fundanental do ARCHITECT-R.

\subsection{Sistema Operacional do ARCHITECT-R}

Um sistena operacional para un sistema de computação reconfigurável diverge de um sistema operacional couvencional em vários aspectos: 
- Deve ser capaz de identificar quais as unidades funcionais (reconfigurávcis o convencionais) estäo disponíveis a cada instante;

- Deve ser capaz de realizar a comunicação entre essas unidades funcionais;

- Deve prover mecanismos de suporte para cache de configuraçôes;

- Deve prover mecanismos para o gerenciamento dos recursos do sistema, os quais podem ser reconfiguráveis ou não;

- É responsável por efetuar a reconfiguração em tempo de execução do sistema;

- Devo se adequar às necessidades imediatas do sistema, as quais são dinâmicas.

Esssas novas caracteristicas tornam a construçào deste sistema operacional uma tarefa árdua e bastante complexa. Para aliviar um pouco essa complexidade, o sistema operacional do ARCHITECT-R será alesenvolvido à partir do eCos :72] [64] [73]. Una característica importante do eCos é que ele é parametrizável; ou seja, pode ser configurado de forma a melhor se adequar ao sistema como um todo. Deste modo, ele estará totalmente portado para o ASIP gerado pelo ARCHITECT'R.

\subsection{Simulador do ARCHITECT-R}

O simulador do ARCHITECI-R tem por objetivo permitir a validação do sistcma gerado e testar a sua eficiência. Para isso, o simulador deverá prover as seguintes funcionalidades:

- Coletar dados estatísticos sobre a utilização de cada uma das instruçóes do sistella;

- Coletar dados estatísticos sobre a frequència de execução de cada trecho do progranı:

- Coletar dados estatísticos sobre a uiilização das Unidados Funcionais Reconfiguráveis; 
- Coletar dados sobre a execução predicativa e especulativa de instruções;

- Coletar dados sobre o número de reconfigurações que foram realizadas durante a exccução do sistema;

- Determinar o tempo mínino e máximo entre a reconfiguração do sistema para uma determinada configuração;

- Determinar quais são as configuraçõos que estão presentes na cache de configuração;

- Deteminar o número de caches misses da cache de configuraçõs;

- Determinar o númoro de vezes que cada conliguração foi carregada;

- Demonstrar quais seriann os resultados do sistema se ele realnente estivesse sendo executadio.

Muitas das funcionalidades do simulador do ARCHITECT-R estão presentes no simulador do sistema ' I'RIMARAN [40', 141]. Dessa forma, pretende-se modificar o simulador do TRIMARAN de forma a se adequar ao projeto ARCHITECT-R.

\subsection{Diagrama de Blocos do Sistema ARCHITECT-R}

A Figura 6.2 apresenta o diagrama de blocos do sistema ARCIIITFCT-R. Pode-se notar que os elementos principais do ARCHITECT-R são: o front-end compiler ${ }^{2}$, o back-end compiler ${ }^{3}$ c o LEGUS System. Também foi introduzido no sistema um

\footnotetext{
${ }^{2}$ É a parte do compilador que realiza málise léxica, sintática e semântica. Além disso taunbém é responsável pela geração de código intermediário e polat realizaçăo de otimizaços independentos de máciquina.

${ }^{3}$ F́; a parte do compilador que realiza as ol imizaçócs dependentes de máquina e a geraçäo de cócligo executível.
} 


\section{CAPÍTULO 6. DHSCRIÇÄO E ESPECIFICAÇÃO DO SISTEMA ARCHTECT-R81}

processador de I/O para o tratamento separado das instruções de entrada e sáda de una determinada aplicação. Este processador se comunicará com o hardware reconfigurável de modo a realizar as operações de carga de dados e a retirarla dos resultados do processamento.

O hardware reconfigurável será inicialnente inulenentado com a família de FPGAs APEX [12] [17; [18]. Para o desenvolvimento da aplicação nas FPGAs APEX será utilizado o sistema Excalibur da Altera. 'Tanto o hardware reconfigurável como o dispositivo de I/O serão controlados pelo kernel do sistema operacional, o qual será encarregado, inclusive, da reconfiguração dinánnica da FPGA.

O fato do ARCHITECT-R estar usando a tecnologia de computação reconfigurável, permitirá a construção dle arquiteturas que serão reconfiguradas cm tempo de exccuçăo (sem que o hardware seja desligado), dando às mesinas a possibilidade de trabalhar com diversos tipos de hardware numa mesma implementação. Isto viabilizará a obtenção de um sistema mais flexível e de mais fácil adaptação a diferentes ambientes, voltado principalmente a aplicaçòes de robótica em ambientes extremamente dinâmicos.

\subsection{Especificação do ARCHITECT-R: UML}

A UML (sigla em inglès para Linguagen de Modelamento Unificada) [87] [32] é conjunto de técnicas de descriçăo, a maioria gráficas, para a especificaçäo e documentaçâo de sistemas orientados a objetos. Ela foi proposta por Grady Booch, Ivar Jacolsson e James Rumbaugh como uma notação padrâo para análise e desenvolvimento de sistemas. A UML incorpora técnicas derivaldas de outros métodos de sucesso que foram criados pelos mesmo autores. Na verdade a U.ML surgiu como una forma de unificar (é dosse fato que deriva o termo "unificada"no nome do método) os métodos desses aulores. Contudo tanbén foram incorporados outros princípios que não faziam parte de nenhum dos métodos originais.

Una das principais vantagens desse método é fato de que ele permite tanto 


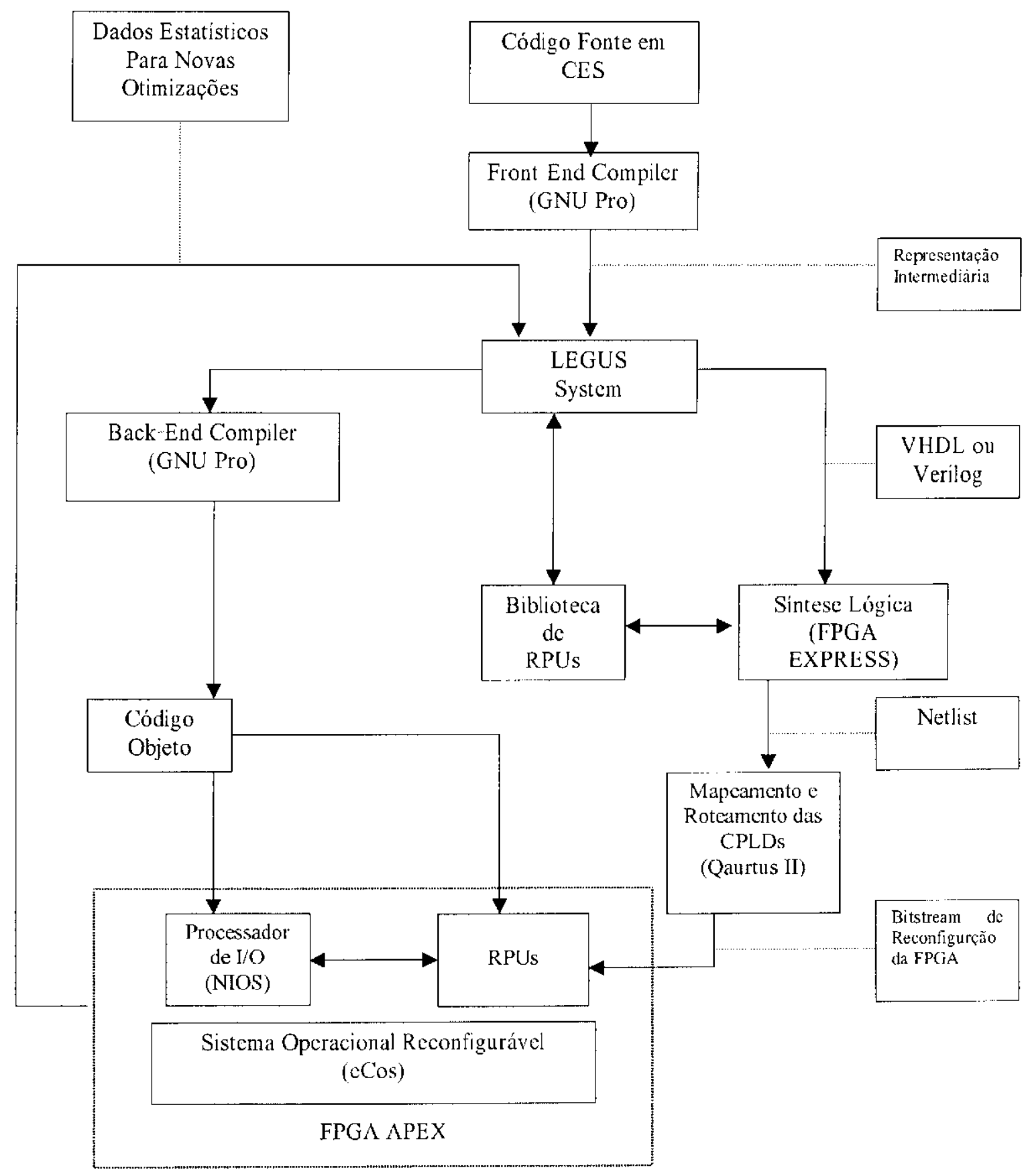

Figura 6.2: Diagrama de Blocos do Projeto ARCHITFCT-R. 


\section{CAPÍTULO O. DESCRIÇÃO E ESPECIFICAÇÃO DO SISTEMA ARCHITECT-R83}

descrever una ampla ganna de sistemas (sistemas de software ou hardware, sistemas complexos on simples e assim por diante). Além disso, ela provê técnicas para a descrição de vários aspectos do sistema sendo modelado.

\subsubsection{Principais Técnicas}

As principais técnicas utilizadas na U.MT, são:

- Diagramas de Estruturas Estáticas: modela, basicamente, os dados do um sistema orientado a objetos. Contén, também, informações sobre a funcionalidade dos dados. Essa classe de diagramas pode ser dividida em dois tipos: Diagrama de Classes e Diagrama de Objetos. Os diagramas de Classes mostram as classes associadas com o sistema, seus atributos, operações, relacionamentos e dependèncias. Diagramas de Classes constituem a pedra fundamental da descrição de um sistema orientado a objetos. Diagramas de Objetos demonstram as várias instâncias que podem aparecer em tempo de execução;

- Diagrama de Casos de Uso: modela as interações cntre os usuários e o sistema num nível de abstraçâo bastante elevado. Serve como estrutura para descriçoes mais concretas da funcionalidade do sistema;

- Diagramas de Seqüencia: demonstra a commicação entre os usuários e os oljetos do sistcma. Possui construçôes para a criação e remoção de objetos, ben cono para distinção entre connunicaçooes síncronels e assinncronas;

- Diagramas de Colaboração: Constitui un caso especial de diagranas de oljetos onde o modelo é extendido para conter informaçoes sobre o fiuxo de mensagens entre os objetos e sobre a criação e remoção de objetos. Como é facilnnente perceptível pelo leitor, os diagramas de colaboração e de seqüencia possucm basicannente a mesma finalidade (modelan o mesmo tipo do informação), a principal diferença entre cles é que os diagramas de colaboração 
se concentram nos relacionamentos entre os objetos enquanto que os diagramas de seqüencia focam o aspecto temporal da ordem dos eventos;

- Diagramas de Atividades: São um tipo especial de diagramas de transição de estados usados especificamente para controlar os estados;

- Diagramas de Componentes: Demonstra a estrutura dos componentes nos quais o sistema está particionado;

- Diagrama de Distribuiçāo: Enquanto todos os demais diagramas utilizados pelo UML se preocupam en modelar o sistema de forma abstrata, esse diagrama se preocupa com a parte concreta do sistema (sua implementaçäo). Essses diagramas modclam os códigos execuláveis e os recursos compntacionais que serào empregados na. implementação do sistcma.

\subsubsection{Ferramentas para Especificação}

\section{Poseidon UML}

O Poseidon UMI da Gentleware ó uma ferramenta para especificação de sistemas orientados a objetos en UML. Ela é derivada do ArgoUML o qual é una ferramenta de especificação UML criada pclo meio científico. O Poseidon UML é semelhante a vários outros sistemas para modelagem de software, contudo possui algumas características que o tornam peculiar:

- Implementa totalmente o padrão UMIL além de ontros correlacionados;

- Foi totalmente desenvolvida cm linguagem Java, o que a toma independente de plataforma;

- É um produto de código aberto, o que permite que a ferramenta esteja sempre sendo croluída:

- Por ser derivada de uma ferranenta clesenvolvida pelo meio científico, cla ainda possui uma versão gratuita para usuários não-comerciais. 
CAPÍTULO 6. DESCRICAOO ETESPECHFICACZÃO DO SISTEMA ARCHITECT-R85

Esse último fator constitui o principal atrativo dessa ferramenta que apesar de implementar cotalmente o padrão UML ainda é um pouco pobre em recursos de documentação textual da especificaçào.

\section{Rational Rose}

O Rational Rose é a ferramenta de especificação UML mais amplamente utilizada pelas grandes incorporaçöes e provavelmente a mais cvoluída também.

Ela implenent a totalmente a linguagem CML e ainda a extende em alguns aspectos. Algumas das características que a distingue das ferramentas similares são:

- Geração de esqueletos de código à partir da especificaçāo. Aceita as linguagens $\mathrm{C}++$ e Java;

- Geração de página web con toda documentação gráfica e textual da especificação;

- Geração de especificação à partir do código-fonte cm C++ ou Java (on seja, engenlaria reversa):

- Extensão da linguagen UML para permitir un molhor modelanento dos dados.

O Rational Rose é em inúmeros aspectos superior ao Poseidon LML em termos de recursos, contudo o scu custo também é bem mais elevado.

\subsubsection{Escolha da Ferramenta para a Especificação do ARCHITECT-R}

A escolha da ferramenta de especificação e docunentação de CML levou en consideração fatores tecnológicos e financeiros. Do ponto de vista tecnológico, sem a Inenor dúvida a melhor escolha recairia sobre o Rational Rose, contudo o seu alto custo absorveria boa parte dos recursos bastante escassos que estão desprendidos na construção desse sistema. Haveria a possibilidade da docunentação ser feitá ná versảo de avaliaçào do Rational Rose, a qual é gratuita. Contudo essa versão só pode 


\section{CAPÍTULO 6. DESCRIÇĂO E ESPECIFICAÇĂO DO SISTEMA ARCIITECT-R86}

ser utilizada por trinta dias, fato que inviabilizaria futuras modificaçôs/atualizaçoes da descrição sem que a mesma tivesse que ser portada desse documento para una ferramenta de especificacão.

Feitas essas consideracoocs optou-se pela utilização do Poseidon UML, o qual é inteiramente gratuito e pode ser rodando tanto em plataforma Unix/Linux quanto em plataforma. Windows, o que pode vir a ser de grande valia em ctapas futuras do projeto, cuando pretende-se migrá-lo para o ambiente Linux.

Apesar de possuir menos recursos tecnológicos, a ferramenta Poseidon UML não ofereceu em instante nenhum restrições para o projeto da especificaçào do sistema ARCHITECT-R, a qual se encontra no endereço: http://www.icme.sc.usp.br/ler/ architect.zargo.

Optou-se por colocar a especificação na intenct de forma que todas as pessoas cuvolvidas com o projeto tenham acesso a cla. Para manter um certo controle sobre essa documentação apenas uma pessoa ć capáz de modificar a versão que cstá no site (no presente nomento, al pessoa responsável é o autor desse documento). Outras pessoas podem modificar a documentação, mas devem enviar a sua versão nodificanda para a pessoa responsável pela docuncutação para que a mesma venha a avaliá-la e decidir se é prudente ou nào submetce-la como documentação mais recente do sistema. 


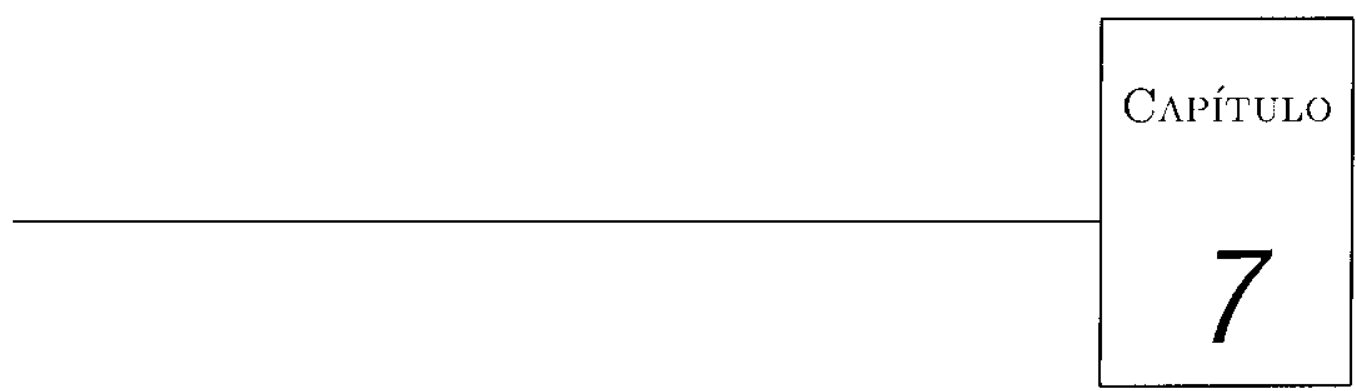

\section{Compilador do ARCHITECT-R}

O compilador do ARCHITHCT-R é uma das partes fundamentais do sistema. Por isso, todas as decisôcs a ele rclacionadas devem ser tomadas com extremo cuidado, visto que podem ter influências diretas cm todo o sistema.

Dessa forma, foram estudados alguns compiladores que apresentavam potencial para servir como base para o desenvolvinento do compilador do ARCHITECT-R.

Entre eles, destacaran-se o GNU P'ro, o SUIF'2 e o Elcor cutre os compiladores para arquiteturas "convencionais"e o Xenya/Galadriel (front-end e back-end compiler, respectivannente) dentre os compiladores para arquiteturas reconfiguráveis. Esses são descritos mais detalhadamente nas seções a seguir. 


\subsection{GNU Pro}

O GNU Pro [66 [124] [67] é um compilador de código aberto que serve como referéncia para implementação de compiladores para a linguagen C. Ele já foi portado para inúmeras arquiteturas (Pentium, Power PC, Athlon XP, PA-RISC, entre várias outras) e vários sistemas operacionais (Linux, HP UX, AIX, Windows, entre outros). Ele é composto por compiladores para diversas linguagens (entre elas JAVA, $\mathrm{C} / \mathrm{C}++$, Fortran, Pascal e Cobol), por un depurador: un link-editor e um montador.

É un compilador bastante robusto e relativamente fácil de ser portado (principalmente, devido a imensa quantidade de informação sobre o assunto na internet).

Possui praticamente todas as técnicas clássicas de otimização de código (todas aquelas citadas no livro do Aho [42], o qual pode ser considerado a bíblia da árca). O seu problema para uso no ARCHITECT-R se encontra no fato de que ele foi criado tendo em mente arquiteturas super-escalares, enquanto que o ARCHITECT$R$ pretende explorar arquiteturas no estilo LPIC [142]. Isso pode fazer com que uma parte das otimizaçoes tenham que ser refeitas e várias outras otimizaçóes tenham que ser incluídas para que o compilador possa lidar com esse tipo de arquitetura.

Outro problenna que pode ser encontrado é o fato de que portar o código do GNU Pro para uma nova arquitetura exige a mmodificação/criação de inúmeras linhas de código. É difícil prever o grau de complexiclade que isso pode vir a trazer para a. ferramenta, visto que é obrigaçào do LEGUS System fornecer/criar um compilador otimizante para a arquitetura por ele criada. Fato que é agravado pelo fato de que o compilador näo foi criado para a arquitetura alvo do ARCHITECT-R.

Un fator que é extremamente favorável ao uso do GNU Pro é o fato dele já ter sido portado para trabalhar com a ferramenta Excalibur [13] [14], a qual será utilizada pcla ferramenta cono plataforma de desenvolvimento de hardware, na verdade cle é parte dessa ferramenta. Contudo a arquitetura dos processadores utilizados no Excalibur é adequada ao GNU Pro (ou seja, escalar ou super-escalar, 
dependendo da versão: NIOS on ARM, respectivanuente).

\section{$7.2 \quad$ SUIF2}

O SUIF2 68] [101] [95] [164] [163] pode ser encarado mais como um ambiente para desenvolvimento de compiladores do que como um compilador propriamente dito. Isso possui a vantagem de torná-lo mais fácil de portar do que o GNU Pro, por exemplo.

Ele foi desenvolvido na Universidade de Stanford para estudo da criação de técnicas de otimização de compiladores. F́ uma das referências mais fortes no meio acadêmico dentro da área de compiladores, vindo a fazer parte do projeto para desenvolvimento de compiladores do governo americano.

Sua principal virtude é a farta documentação sobre a sua utilização para criar inúneras técnicas de otimização. Contudo não existe nenhum compilador comercial que utilize o SUIF2 como base e seja do conhecincnto do autor.

Un fator que deve ser mais estudado no SUTF2 é a sua capacidade de se adequar à arquitcturas EPIC reconfiguráveis. Esse fator é determinante para avaliar a possibilidade de seu uso como compilador base para o ARCHITECT-R.

\subsection{Elcor}

O Elcor [154] [128; já foi projetado para lidar com arquiteturas FPIC, VLIW e supcr-cscalares, o que é uma vantagem significativa para o seu possível uso como compilador base do ARCHITECI'-R.

O Elcor possui uma linguagem intermediária bastante propícia para a exploração de paralelismo em nível de instrução e paralelização de loops (os quais são fundamentais para o sucesso do compilador do ARCIITECT-R).

Outra vantagem bastante significativa que cle é paranetrizável. Isso significa quo: (sse recebe a descrição de mua arquitctura (em linguagem mdes [155) e já é 
capaz de gerar código para essa arquitetura, o que simplificaria em muito o projeto não só do compilador, mas tanbém do LEGLS System.

Somado a tudo isso está o fato do Elcor fazer parte do Trimaran. O Trimaran [144] é un ambiente para desenvolvinento de compiladores e arquiteturas que foi criado pela HP e disponibilizado para uso pelo meio acadênico. Ele possui, além do Elcor; ferramentas para descrever uma nova arquitetura e para simular e avaliar o descmpenho do sistema sendo criado. O avaliador de desempenho seria particularmente útil por fornecer bastante medidas sobre o desempenho da arquitetura em tempo de execução, as qualis podcriam ser utilizadas para re-alinentar o LEGUS System e permitir o refinamento da arquitetura atual para mana arquitetura mais adequada para a aplicação sendo utilizada.

Outra ferramenta interessante do Trimaran é um visualizador dos grafos utilizados pelo compilador, o que permite que o projetista do compilador possa acompanhar visualnente os resultados que estào sendo gerados pelas otimizaçóes do seu compilador e torna mais fácil a melhoria (ou deteç̧ão de erros) nessas otimizaçoes.

Outro fator que pesa favoravelnente ao Elcor é o suporte técnico da HP, o qual ten sido fornecido para todo o sistena Trimaran.

\subsection{Nenya/Galadriel}

O Nenya/Galadricl 121] [39' [122] säo, respectivamente, o fronl-end e o back-end compiler para arquiteturas reconfiguráveis desenvolvida a tese de doutoramento de João Manod de Paiva Cardoso [121].

Esses compiladores reconlıce bytecodes (representação intermediária utilizada pela linguagem .Java) e cria uma arquitctura reconfigurável própria para a execução dos mesmos.

Fxistem alguns compiladores para arquiteturas reconfiguráveis, algms dos quais foram citados no capítulo 2 , dessa dissertação. A escollha desses compiladores reconfiguráveis en particular ocorren devido ao grau de solisticaçâo dos mesmos: cle pos- 
suom inúmeras tćcnicas de otimização relevantes para arquiteturas reconfiguráveis. Alguns exemplos são:

- Análise de Tamanho de Variáveis Escalares: analisa qual o tamanho mínimo que una variável precisa ter para armazenar corretannente o resultado a cla atribuído. Essa otimização tem impacto direto na área ocupada do chip reconfigurável e no tempo de execução do trecho de programa que envolve essa variável. Especial atenção é dada as variáveis as quais são atribuídos valores durante iterações de um loop. Variáveis que fazem parte de vetores são desconsideradas devido a complexidade de sua implementação;

- Eliminação de Algumas Operações Envolvendo Constantes: em liardware, algumas operaçöes podem ser simplesmente inplementadas como conexões de fios, ou seja, praticamente nào ocupan hardware (sào praticamente elininadas). O exemplo mais clássico do uso desse tipo de otimização é a multiplicação ou divisão de unu número que é potência de 2;

- Substituiçāo de Multiplicaçōes e Divisōes por Somas e Subtrações: a multiplicação e a divisão são operações classicamente difíceis de serem innplementadas em liardware. Essa otimização permitc que quando o segundo operando é um valor constante, essas operações possas ser substituídas por somas e subtrações con ganlıos tanto em termos de área quanto em termos de tempo de execuçào da operaçào ${ }^{1}$

- Criação e Gerenciamento de Configurações de IIardware: essa é, talvez, a tarefa majs complexa de um compilador para arquiteturas reconfiguráveis. Durantc essa otimizaça o compilador deve gerar hardware específico para atender algumas instrugões, particionar esse hardware em diferentes configurações de hardware, escalonar as instruçoes especiais a serem executadas e selecionara qual configuração deve estar ativa a cada instante da execução da aplicação.

\footnotetext{
${ }^{1}$ Apesar que o uso de Aritmética Distribuida poderia, en alguns casos, obter resultados melhores):
} 
A inclusão dessas otimizaçoes no compilador do ARCHITECT-R são necessárias e deverão ser feitas independentes do compilador base escollido.

\subsection{Considerações Finais}

A escolha do compilador base para o ARCHITECT-R é uma das tarefas mais importantes para o desenvolvimento desse sistena. Uma escolha errada prejudica o projeto como um todo.

Dentro dos aspectos inportantes para o projeto, o Ellcor leva uma considerável vantagem sobre os seus concorrentes. Essa vantagem se deve principalmente a dois fatos: ele é parametrizável e ele está integrado ao 'Trimaran. Então, a principio, esse deverá ser o compilador base para o ARCHI'TEC'T'R.

Apesar de possuir inúmeras qualidades, o Elcor não é perfeito e deve ser melhor adequado para as necessidades do sistema. Nesse sentido, a principal tarefa a ser realizada nesse compilador será a inclusão de otinnizaçós para que o compilador possa lidar com arquiteturas reconfiguráveis. Una das primeiras tarcfas dentro desse escopo, scrá portar as otimizaçós do Nenya/Galadriel para o Elcor. Essal tarefa, por si só, já bastante complexa e deverá tomar um tempo considerável dos projetos futuros do sistema. Mas o desenvolvedor do compilador não deverá ser saatisfazer en apenas portar essas otimizações: ele deverá melhorá-las e acrescentar novas otinizaçôes, algumas das quais citadas na tese de doutoranento do João [121].

Espera-se que o compilador do ARCHI'T'ECT-R possa ainda criar novas otimizaçö́s para arquiteturas reconfiguráveis e EPIC, colaborando para o estiado da arte nessas áreas. 


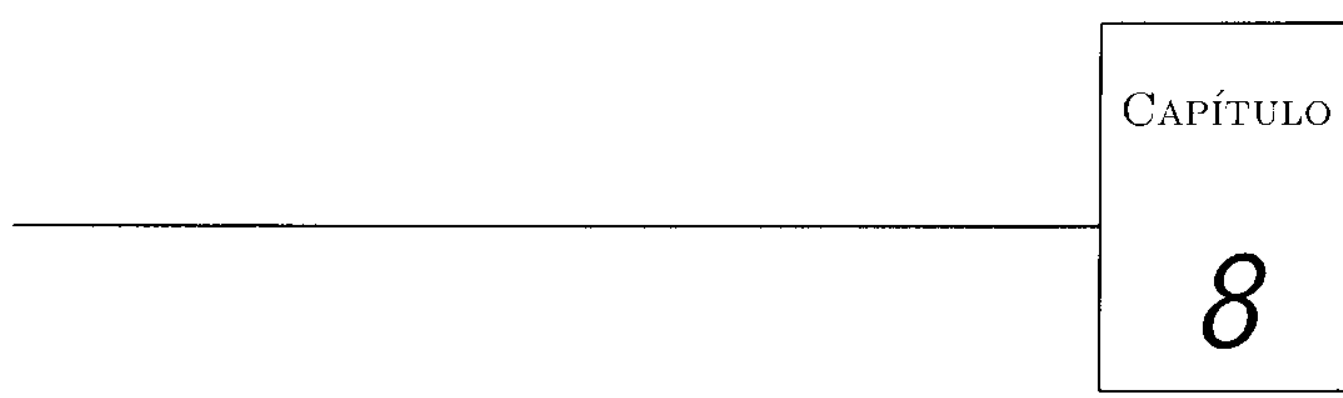

\section{Construindo RPUs para o} ARCHITECT-R

Como já foi citado anteriormente, as RPLs são parte integrante e possuem grande relevancia dentro do projeto $A R C H I T E C T-R$. Levando-se en consideraçào esse fato, e também o fato de que os códigos escritos cm linguagem CES utilizan freqüentemente redes do tipo MLP' [161] 158], fica claro que a inplementação dessas redes en hardware pode aumentar significativanente o desempenho das aplicarcóos escritas en CES. Assim sendo, a implementação de $u$ m gerador do RPUs para redes neurais será a primeira implementação de um gerador de hardware reconfigurável a ser desenvolvida para o ARCIITECT-R.

Nas seçōes seguintes seräo descritas as redes neurais MLP, as ferrannentas de hardware utilizadas o as implementaçôes propostas. 


\subsection{Redes Neurais Multi-Camadas}

As Redes Neurais Artificiais são uma forma de computaçào inspirada no cérebro humano. Elas não possuem regras ou algoritmos e constituem uma alternativa a computaçāo convencional [150].

As redes neurais são compostas por unidades de processannento simples (neurônios - Fig. 8.1) que calculann determinadas funçôes matemáticas (funções de transferência - Fig. 8.2). Essas unidades estão normalmente organizadas en camadas e interligadas por un grande número de conexões. Fim grande parte dos modclos de redles neurais, essas conexócs estäo associadas a pesos, os quais armazenam o conhecimento armazenado pela rede. Para obter o seu conhecimento, uma rede neural deve ser treinada.

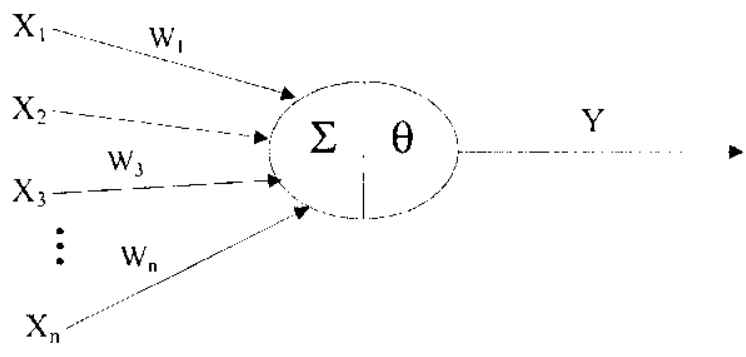

Figura 8.1: Descrição de mm Neurônio Computacional [150].

$\Lambda$ s recles neurais MLP (sigla em inglês redes nulticamadas) possuem una camadà de entrada, una camada de saida e uma ou mais camadas incernediárias (Fig. 8.3).

Fsse tipo de rede possui duas fases: forward (para fronte, ou seja, os sinais são propagados das camadas de níveis mais baixos para as camadas de níveis mais altos) c backward (para trás, ou seja, os sinais são propagados das camadas de níveis mais altos para as camadas de níveis mais baixos). A fase forward corresponde a execução propriamente dica, já a lase backward corresponde ao aprendizado da rede. 

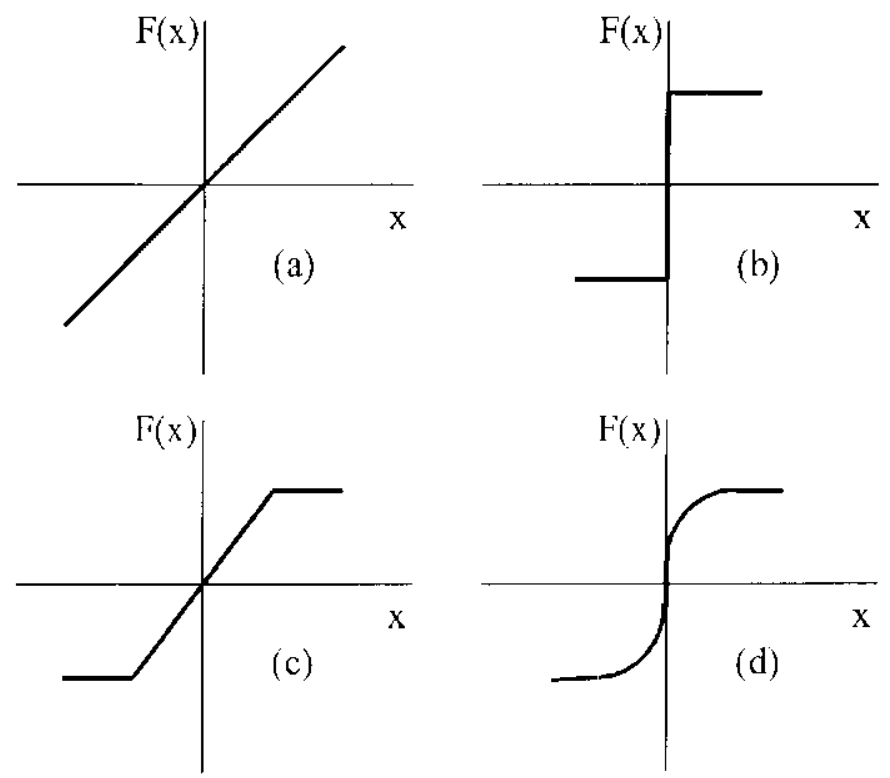

F'igura 8.2: Possíveis Funçōes de Ativação de un Neurônio 150].

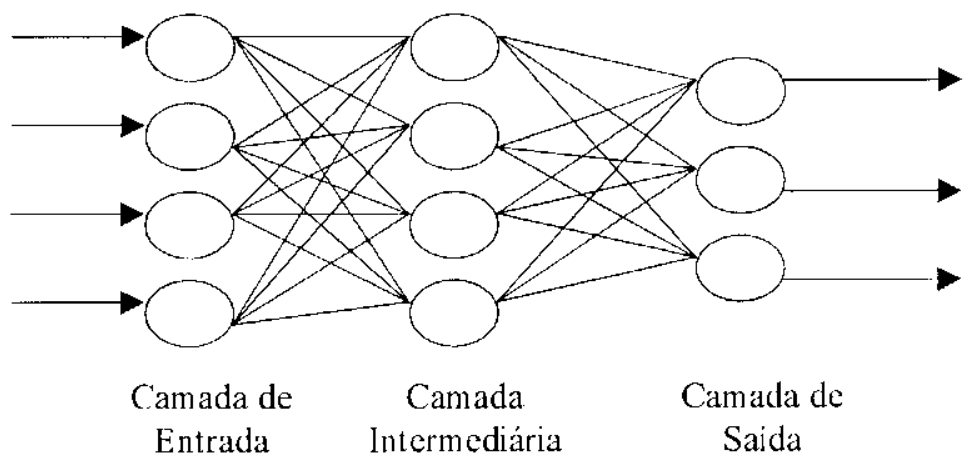

Figura 8.3: Lma Rede Neural MLP com una Camada Intemediária.

$\Lambda$ equação que detcrmina a saída de um deteminado neurônio da rede na fase forward é:

$y_{j}=f\left(\sum_{i=0}^{m} w_{j i} * x_{i}\right)$

onde:

$y_{j}$ corresponde a saída do neurônio j;

$f(x)$ corresponde a funçäo de ativaçào do neurônio;

$w_{j i}$ é o peso associado a entrada i no neurônio j; 
$x_{i}$ é a entrada i.

As redes MLP utilizan aprendizado supervisionado; on seja, a rede recebe um conjunto de entradas e as saídas desejadas para elas, a rede calcula a suas saídas: compara com as saídas desejadas e atualiza os pesos (conlecimento) de forma a diminuir o erro entre as saídas geradas e as saídas desejadas.

O algoritmo niais conlecido para treinamento destas redes é o algoritmo de backpropagation [88]. Através desse algoritmo pode-se estimar o valor do erro nas camadas intemediárias da rede neural c, conseqüentennente, ajustar os pesos dos neurônios. Os ajustes são realizados utilizando-se o método dos gradientes segundo a equação 8.1 .

$$
\begin{aligned}
& \Delta W_{i j}=\eta \cdot \delta_{j} \cdot o_{i} \\
& \delta_{j}=f_{j}^{\prime}\left(\text { net } t_{j}\right)\left(t_{j}-o_{j}\right) \text { para a camada de saida } \\
& \delta_{j}=f_{j}^{\prime}\left(\text { net }_{j}\right) \Sigma_{k} \delta_{k} w_{j k} \quad \text { para as camadas intermediarias }
\end{aligned}
$$

onde:

$\eta$ ć o fator de aprendizado;

$\delta_{j}$ diferença cntre a saída da rede c o valor desejado na unidade $\mathrm{j}$;

$t_{j}$ valor desejarlo na unidade $j$;

$o_{i}$ saída da unidade precedente i;

$i$ índice do predecessor da unidade j atual com peso de $w_{i j}$ i para j;

jíndice da unidade atolal;

$k$ índice do predecessor da unidade j atual com peso $w_{j k}$ de j para k;

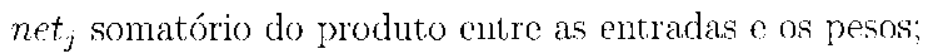

$f_{j}^{\prime}$ derivada da função de ativação.

As funções de ativaçào mais comumente utilizadas sào a sigmoidal logística $\left(1 / 1+e^{-\left(n u t_{j}(t)-\Theta_{j}\right)}\right)$ e tangente liperbólica $\left(\tanh \left(n \ell_{j}(t)+\Theta_{j}\right)\right)$. O que gera a necessidade de se lidar con essas funçōes cm hardware (quer scja pela implementargáo direta dessás funçoes quer seja através de funçōes que aproximam as mesinas). 


\subsection{Redes Neurais MLP em Hardware}

As redes neurais MLP possuem uma estrutura bastante homogenea o que facilita o desenvolvimento de hardware, cu especial hardware reconfigurável. Por isso, existem várias implementalçôes de redes neurais en hardware reconfigurável [103] [53] [104] [102: [62] [37] 69] [93]. Contudo, algumas consideraçōes devem ser fcitas:

- O aprendizado da rede deve ser feita no hardware (on-line) ou fora dele (offline)?

- A representação nunérica dos dados deve ser de ponto-fixo ou de ponto flutuante?

- Quantos bits são necessários para representar os dados de entrada pesos c sáclas da rede?

- A funçâo de transferència deve ser implenentada no hardware dedicado ou num processador de propósito geral?

- Se a função de transfercincia for inplementada no hardware, qual deve ser o método de calculá-la (tabcla, aproximação polinomial, CORDIC ou híbrida)?

- Quais funções de transferência estarão disponíveis?

- Quáis algoritmos de aprendizado poderão ser utilizados?

- Cono será a implementação da arquitctura da rede neural (arrays sistólicos, vetorial ou outras)?

O problema ó que para a maioria desses problemas as respostas dependem da aplicação que está sendo desenvolvida, e deste modo, ou o usuário tem cue criar um novo hardware customizado para aquela aplicagano específica ou ele utiliza um "hardware de propósito geral". A vantagen de se utilizar um hardware totahnente customizado é que o desempenho tenderá a ser melhor, contudo o custo de implementação desse hardware será altíssimo. Por outro lado, o uso de hardware mais geral denigre o desempenho do sistena ao custo de ma maior flexibilidade. O ideal 
seria a criação de un hardwaxe totalmente customizado sem que o usuário precisasse projetá-lo. É exatamente nesse ponto que se encaixam os geradores de hardware, os quais permitem alto grau de customizaçãa do hardware a um baixo custo de implementação.

Um dos objetivos desse projeto ć a criação de um (protótipo de) gerador de hardware reconfigurável para redes nemrais MLP. Contudo, antes de tratarmos da implementação en hardware utilizada nesse trabalho, faz-se necessária uma revisão das redes neurais MLP implementadas em hardware, destacando-se suas vantagens e desvantagens de forma cue a nossa inplementaçäo possa ser melhor avaliada.

Visando uma melhor caracterizaçăo dos hardwares, os mesmos foram divididos em hardwares comerciais o hardwares cientílicos.

\subsubsection{Hardwares Comerciais}

\section{Accurate Automation's Neural Network Processor (NNP)}

O NNP '41] utiliza arquitetura de múltiplos chips com características MIMD, o que possibilita a execução en múltiplos chips sem degradação de desempenho. Cada chip possui um processador de 16 bits com capacidade de armazenamento do valor dos pesos no próprio chip. Cada chip pode conter até 8,192 neurônios e a velocidade de processamento é do 140 MCPS (Milhões de Concxões por Segundo). O processador possui um conjunto de instruçöes com apenas 9 instruçòes (contudo as instruções são bastante complexas, tais como o cálculo da função de ativaçio de una redo neural). O númcro máximo de processadores que podem ser utilizados num único sistemá 10, o que corresponde a una taxa máxima de 1,4 GCPS (Bilhões de Conexões por Segundo). A comunicação entre processadores é fcita através de um barramento proprietário. Unna das vantagens desse hardware é que ele pussui um conjunto de ferramentas especiais pari o desenvolvinento do software. O preço estimado de carla chip é de $\mathrm{LS} \$ 4.000,00)$

É importante ressaltar que o NNP foi utilizado no projeto Lotlyte, o qual visava 
a criaçâo de aetonaves com à capacidades de direção autónomá (Figr. 8.4).

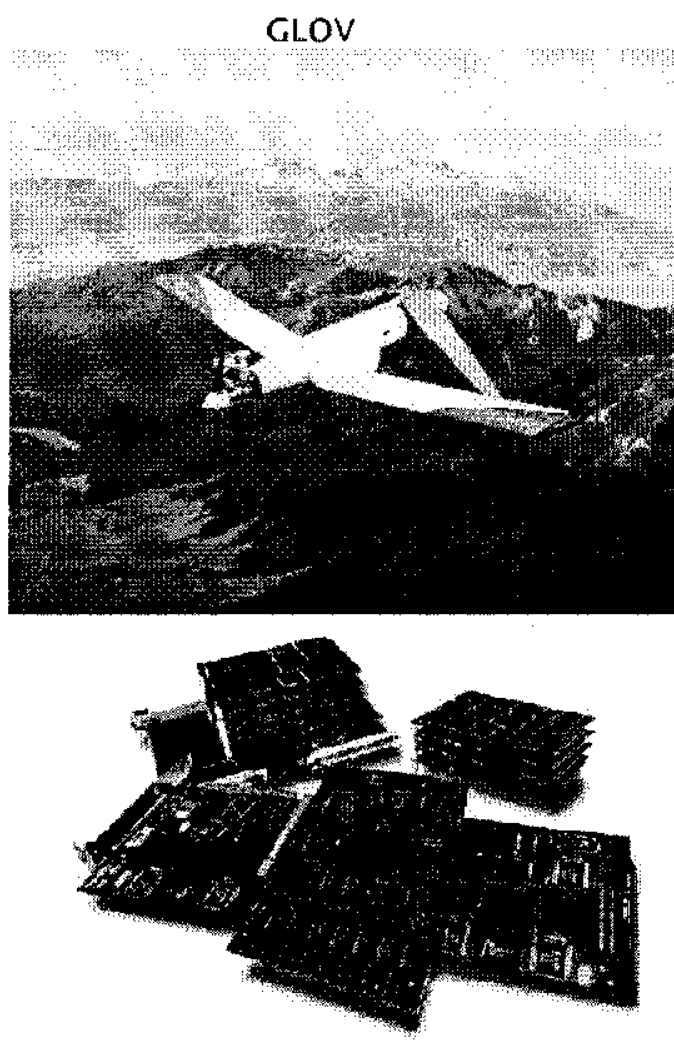

Neural Network Processor
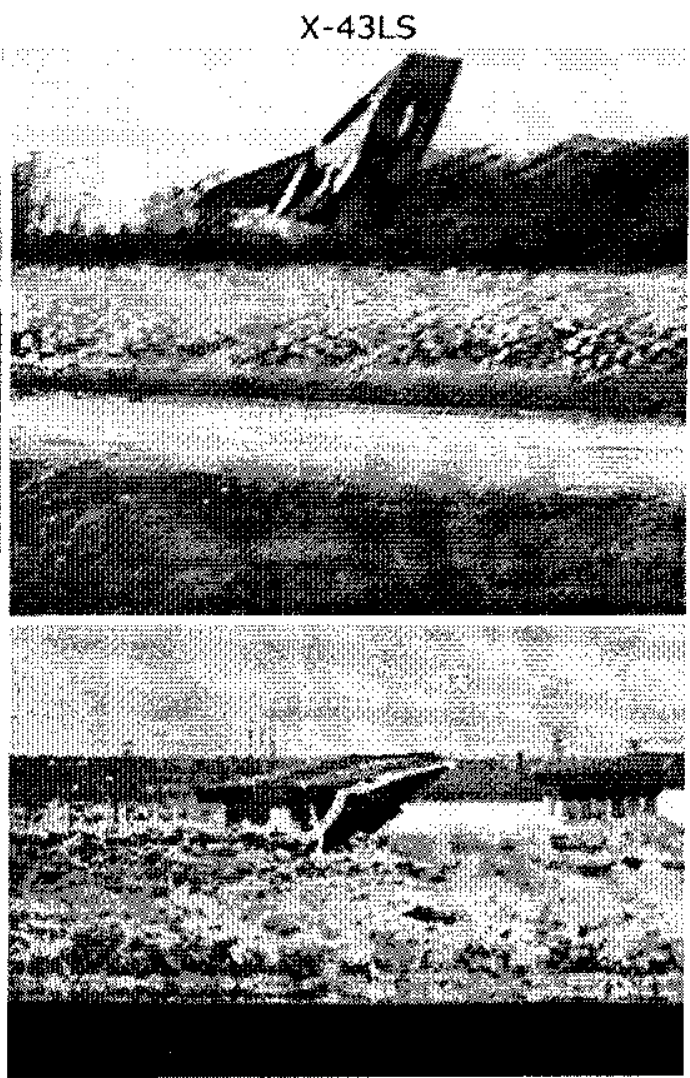

LOFLYTE

Figura 8.4: Aviōos Utilizando o NNP (Acima e Abaixo à. Direita) e Placa com Chips NNP (Abaixo à Esquerda) [41].

\section{Adaptive Solutions CNAPS}

O CNAPS [70] é um sistema completo de desenvolvimnento de redes neurais baseado no chip CNAPS-1064 Digital Parallel Processor, o qual possui 64 sub-processadores trabalhando em modo SIMD. Cada sub-processador possui $4 \mathrm{k}$ bytes de memória local e uma unidade de aritmética de ponto fixo para dados de 1,8 ou 16 bits. Desse modo, cada sub-processador pode emular um ou mais neurônios e vários desses chips podem ser utilizados em paralelo. O conjunto de ferramentas para o CNPAS 
inclui un compilador para a linguagem C (CNAP-C), uma biblioteca de funções comumente utilizadas (Quicklib) e algumas redes pré-compiladas (BuildNet). O desempenho máxinno obtido foi 10,24 billıões de instruçôes de M $\Lambda \mathrm{C}$ (nultiplicą e acumula) por segundo utilizando-se 128 processadores (é importante salientar que essá medida não corresponde ao MCPS, visto que essá segunda medida tambén leva cm consideração a função de ativação da rede).

\subsubsection{Hardwares Científicos}

\section{Neural Chip SAND/1}

O SAND/1 (Figura 8.5) [50] possui uma arquitetura bascada en arrays sistólicos, tendo sido desenvolvido visando a utilizando de mais do um chip no processamento de una rede neural (ou seja, ele é fortemente expansível). Cada processador SAND/1 possui quatro elementos de processamento sendo que cada um deles possui um multiplicador e dois somadores em pipeline para a avaliação da somatória do produto das entradas pelos pesos $\left(\sum x_{i} * w_{k} i\right)$. Como dito anterionmente, o processador funciona como um array sistólico e dessa forma a entrada e passada para o primeiro elemento de processamento o qual, após os cálculos, passa esse valor para o próximo elemento de processamento c assim succssivamente. Esse fato alivia o uso de clementos de roteamento para a distribuição das cntradas. Os valores dos pesos dos neurônios são armazenados en memórias extemas. O cálculo da função de ativação também é feita fora do processador e geralnente faz uso de unia tahela implementada como ROM. O desempentho do processador é de 200 milhões de MACs por segundo.

\section{RRAN: Run-time Reconfiguration Artificial Neural Network}

O RRAN [93] [94](Fig. 8.6) divide os cálculos necessário para à execução e treinamento de uma rede neural nulti-camadas en três etapas:

1. Estágio de Propagação para Frente (Fig. 8.7) : possui seis unidades de MACs para o cálculo da somatória do produto dos valores de entrada pelos 


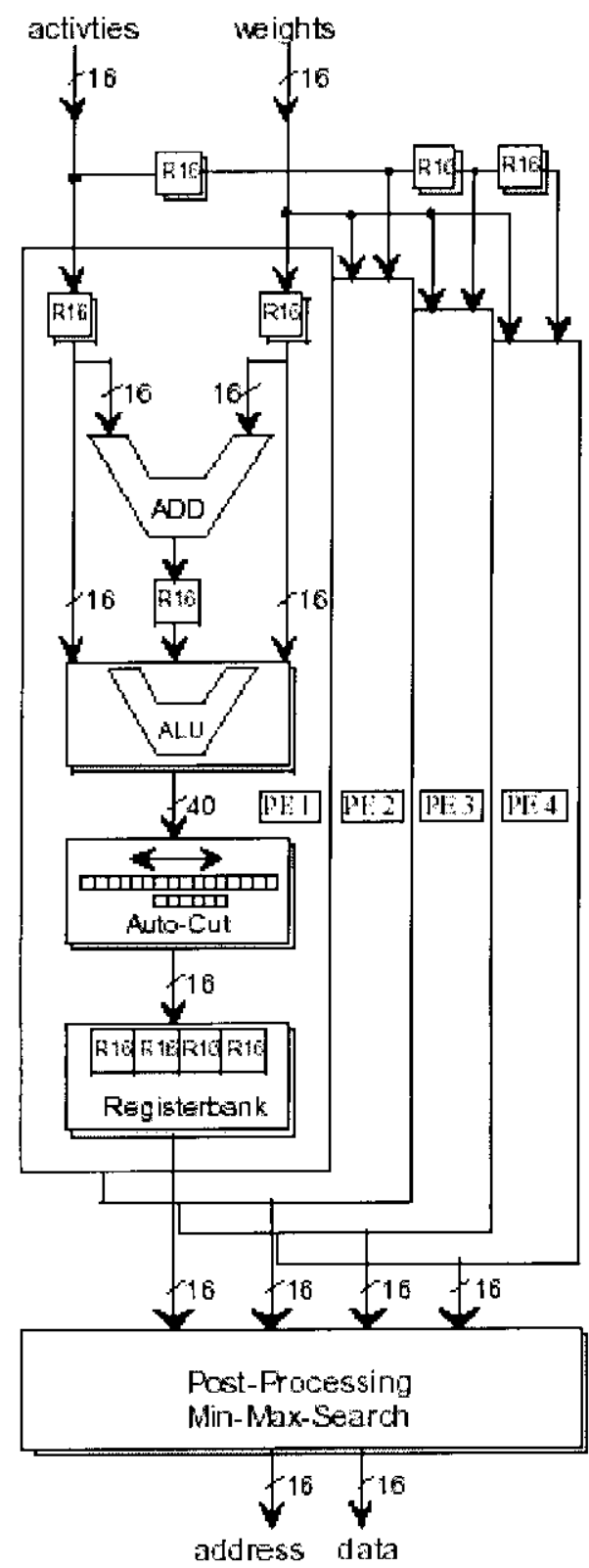

Figura 8.5: Arquitetura do Sand/1 [50]. 


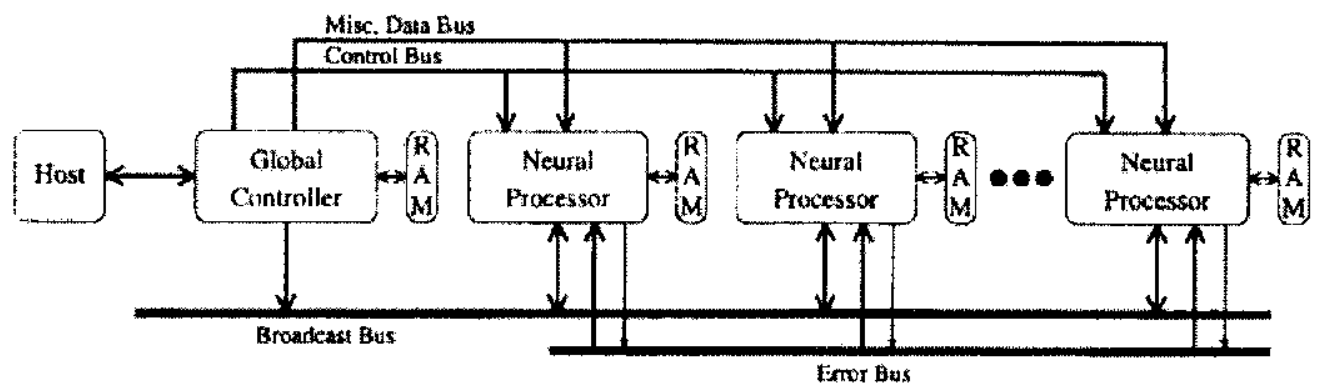

Figura 8.6: Arquitetura do RRAN [93:

pesos e uma tabela implementada como ROM que implementa a fumção de ativaçà̃o, também calcula o erro na camada de saída;

2. Estágio de Propagação para Trás (Fig. 8.8): possui seis unidades de MACs para o cálculo da somatória do produto dos pesos pelos $\delta s$, uma tabela implementada como ROM para fornecer o valor da derivada da função de ativação e um multiplicador para o cálculo do produto dessa derivada pela somatória anteriormente citada;

3. Estágio de Atualização dos Pesos (Fig. 8.9): possui doze multiplicadores para o cálculo dos valores de atualização dos pesos da rede e somador/subtrador para atualizar csses valores. 


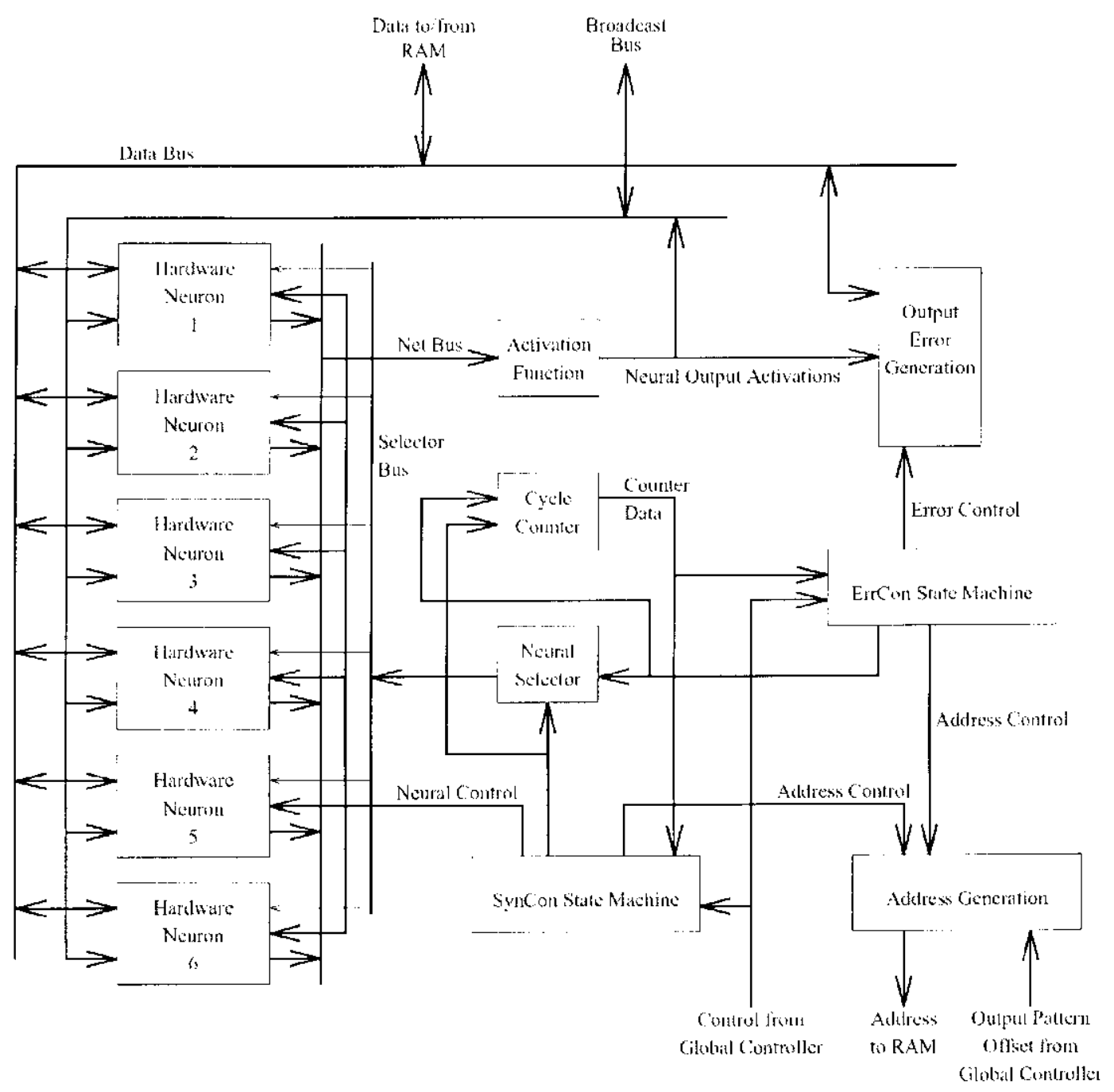

Figura 8.7: Diagrama de Blocos do Hardware de Propagação para Frente [94]. 


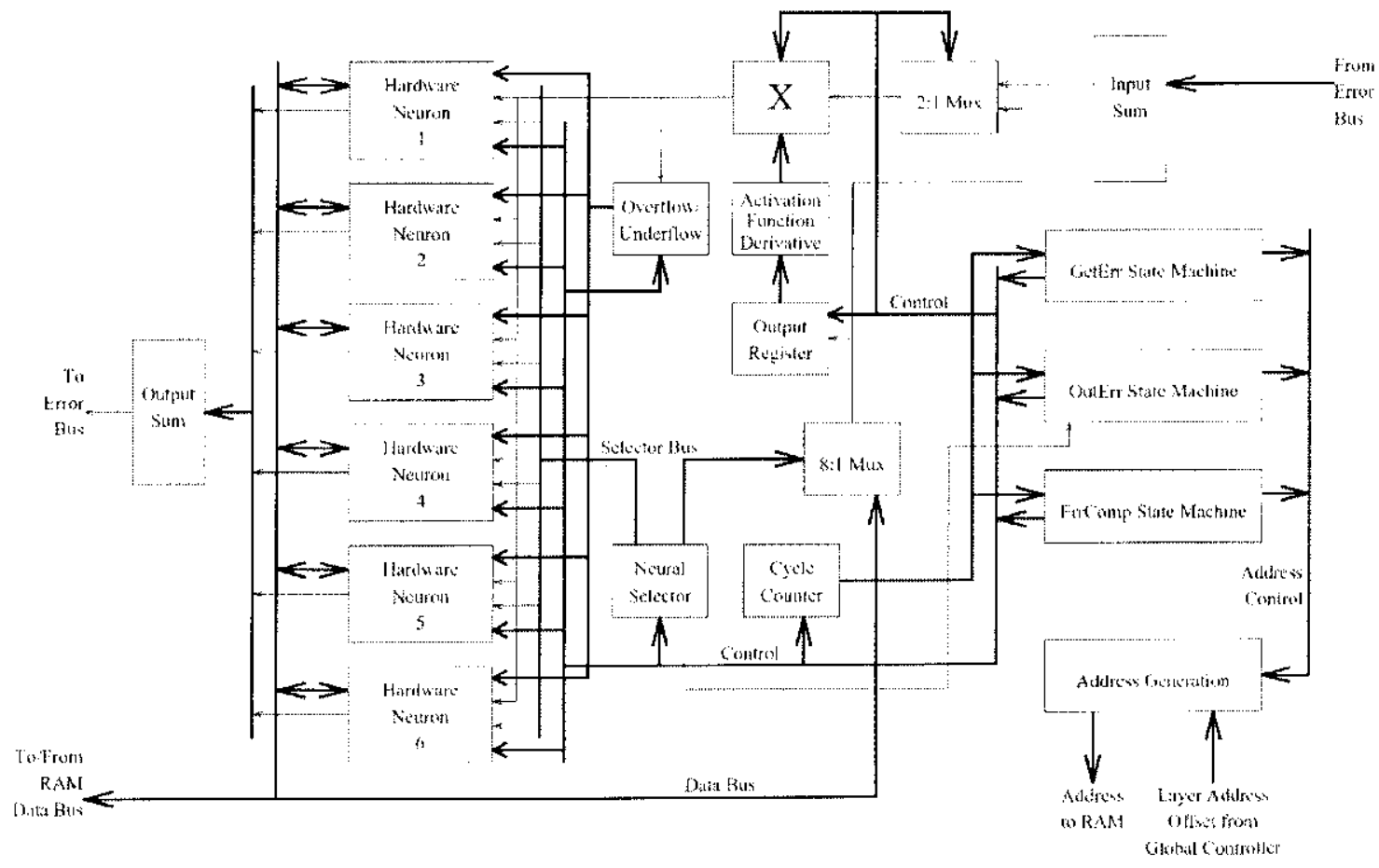

Figura 8.8: Diagrama de Blocos do Hardware de Propangaça para 'l'ás [94]. 


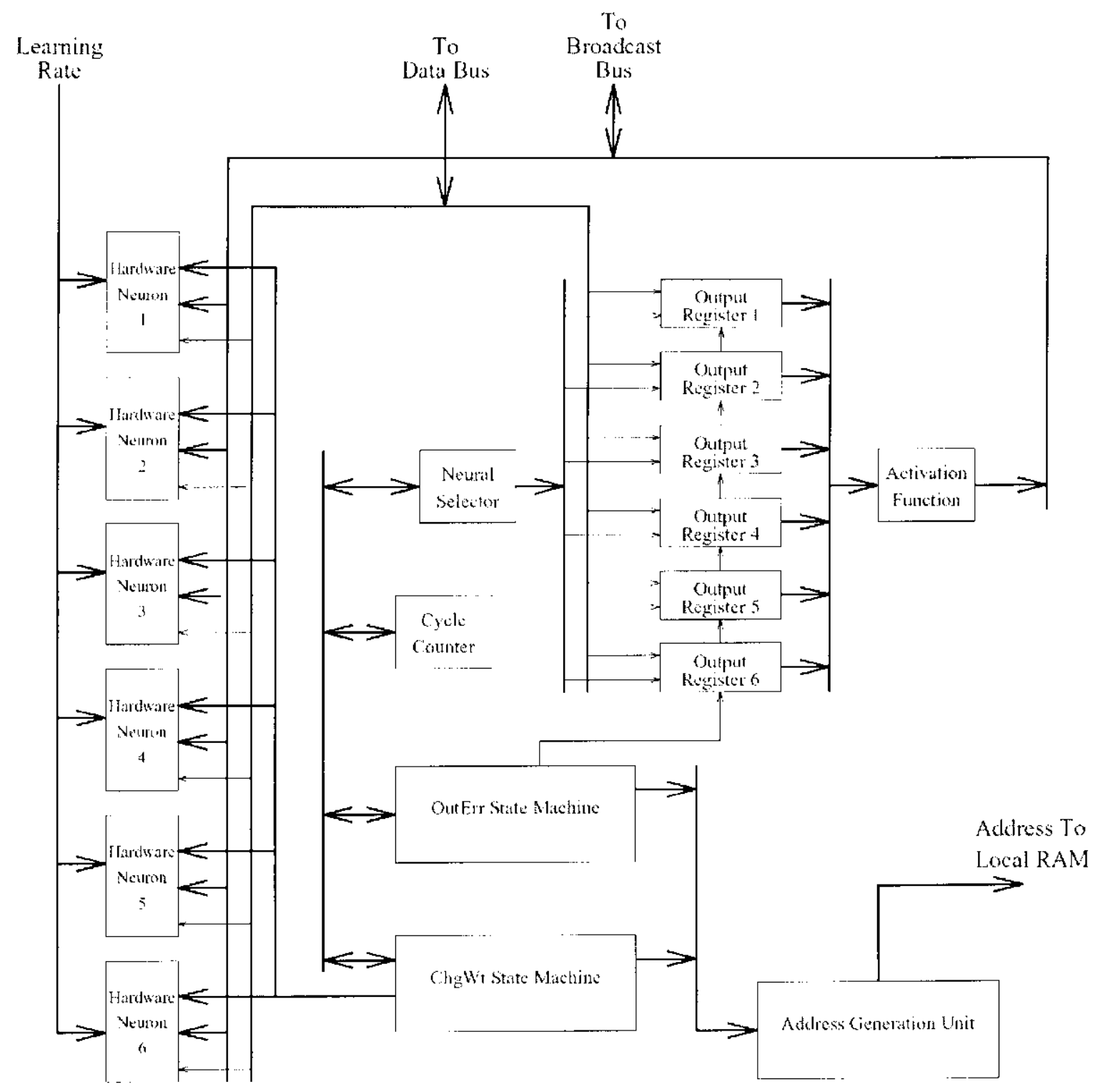

Figura 8.9: Diagrama de Blocos do Hardware de Atualização dos Pesos [94]. 
Essa separaçäo em etapas foi feita para aproveitar a propriedade de reconliguração dos circuitos FPGA XC3090 onde csse hardware foi implementado. Dessa forma, cada etapa corresponde a mua configuração do circuito; sendo, portanto, necessária uma reconfiguração após a execuçấo do cada etapa.

Essa implementação foi importante pois demonstrou que o uso de reconfiguração de circnitos poderia trazer benefícios em termos de descmpenho do sistema, o qual correspondia a aproximadamente 2 XCPS em 60 FPGAs XC3090.

Por economia de hardware, todas as funçöes form implementadas de forma serial, ou seja, bit a bit.

É importante, ainda, salientar (jıe essa inplementação permite o treinamento da rede no próprio hardware fo que é raro de se acontecer devido aos custos dessa implementação).

\subsection{Dispositivos Lógico Programáveis e Ferramen- tas de Desenvolvimento de Hardware Utilizadas}

O hardware e as ferramentas de desenvolvimento envolvidas tèn vital importància para a qualidade do hardware gerado e devem ser levadas em consideraçăo na criação de geradores de RPUs. Os dispositivos lógico programáveis e as ferramentás utilizadas são descritos nass subseções a seguir.

\subsubsection{Famílias APEX e APEX II de Dispositivos Lógico Programáveis}

As famílias APEX c APEX II [17] [18` [19], as FPGAs (Field Programmable Gate Array) mais avançadas da Altera, foram descnvolvidas tendo-se em mente que o uso fut uro dos dispositivos lógicos programáveis serão os chamados SOPCs (System on a Progranable Chip). SOPCs são sistemas que integram toda a funcionalidade necessária (processadores, periféricos, momória, entre outras coisas) num único chip. 
Para atingir esse objetivo, os dispositivos APEX possuem grande capacidade e diversidacle de elementos lógicos internos e uma velocidade bastante elevada con dispositivos externos (via de regra, apenas dispositivos de entrada e sáda para a interface com o usuário). A fannília APEX e APFX $I I$ implemetam a arquitetura MultiCore $^{T M}$, a qual incorpora look-up tables (LUTs), tcrmos-produto e memória embutida (Fig. 8.10). As LUTs são utilizadas para implementar funçôes que necessitam de registradores: os termos-produto são utilizados para implementar lógica combinacional intensiva; e a memória embutida é utilizada para criar RAMs, ROMs, FI$\mathrm{FO}$ s, CAMs, entre outras estruturas de memória. Os ternos-produto e as memórias sāo implementadas pelos ESBs (Embedded System Blocks). A arquitetura MultiCore é dividida en múltiplos clementos denominados estruturas MegaLAB ${ }^{T M}$. Cada estrutura MegaLab contém um grupo do Logic Array Blocks (LABs - arranjo de blocos lógicos $)^{1}$, um FSB e uma interconexão que mapeia os sinais na estrutura. (Fig. 8.11). Cada LAB é composto por 10 elementos lógicos (LEs) (Fig. 8.12). Os LEs, por sua vez, forman a estrutura lógica mais básica da arquitetura MultiCore. Cada LE é composto de una LUT de quatro entradas, un registrador c lógica para propagação de cadeia de carry-bits (usada para funções aritmóticas e propagação em cascata (usada em funções com uma grande quantidade de entradas - fan-in.

Os elementos lógicos podem operar em três modos [19]:

1. Normal: usarto na maioria da funçóes lógicass, om especial aquelas que possuem muitas entradas;

2. Aritmético: usado para implementar funções aritnéticas, em especial somadores, subtratores, acumuladores e comparadores;

3. Contador: utilizada na criação de contadores (síncronos). Possui a limitação de que se um LE de una LAB opera nesse modo, nenhum LE' desse mesmo LAB pode operar no modo aritmético.

Cada macrocélula da APEX permite que dois termos-produto sejan calcula-

\footnotetext{
${ }^{1}$ No caso dia AP'BX El'20K200E, esse grupo é formade por $16 \mathrm{LABs}$.
} 


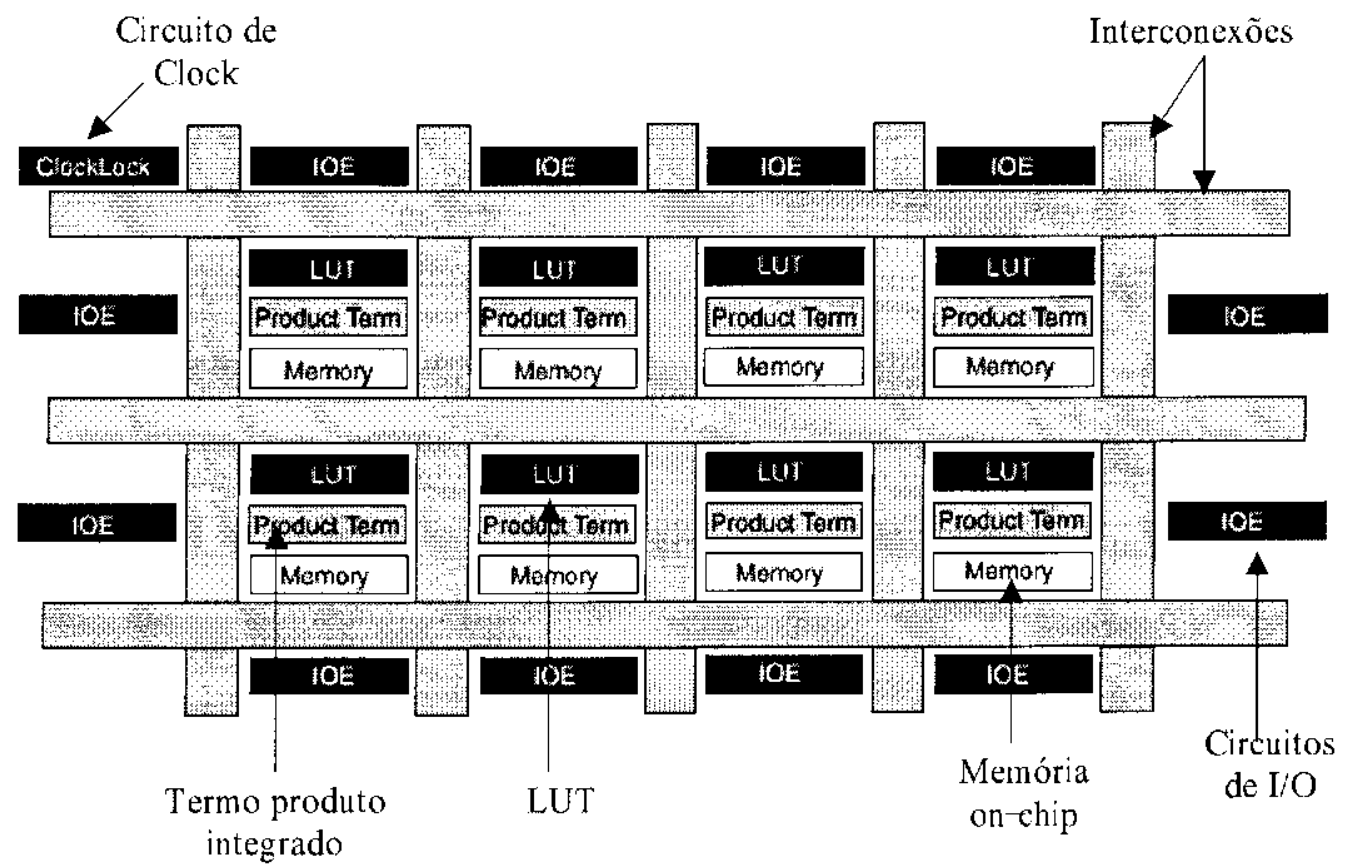

Figura 8.10: Arquitetura MultiCore ${ }^{T M}[19]$.

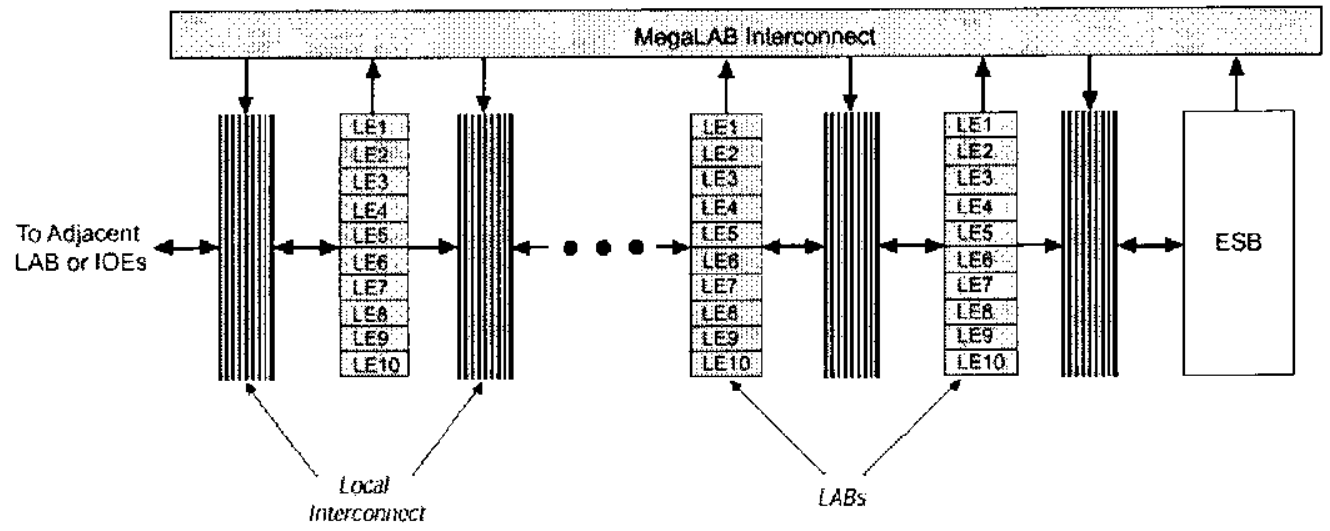

Figura 8.11: Estrutura MegaLab [19]. 


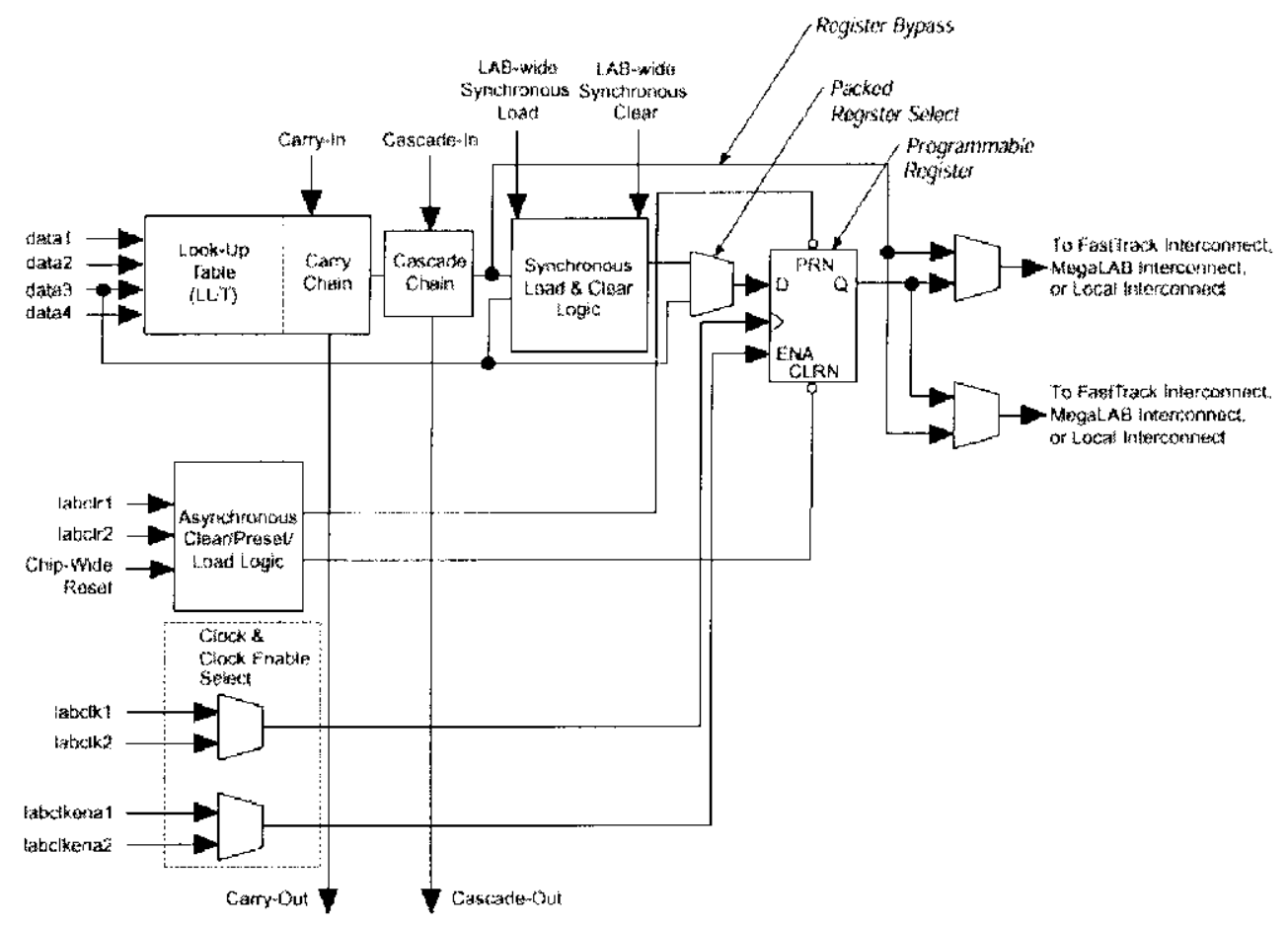

Figura 8.12: Estrutura de um Elemento Lógico (LE) [19]. 
dos. Estes temos-produto podem servir de cntrada para a porta OR ou XOR da macrocélula, ou pode servir para expandir a lógica de outras macrocélulas.

O último tipo de estrutura utilizada pela família APEX são os Embedded System Blocks (ESBs), os quais implementam dispositivos de memória interna dos chips. Os ESI3s podem ser configurados para funcionar como RAM, ROM, FIFO on CAM.

\subsubsection{Família Stratix de Dispositivos Lógico Programáveis}

A família Stratix [24] [25] corresponde ao estado da arte em termos de dispositivos lógico programáveis da Altera, una das principais fabricantes de PLDs do mercado mundial.

Os elementos lógicos e esquemas de conexónes entre os recursos do chip de uma Stratix sào idènticos aos das Apexll. O que toma a Stratix mais evoluída é a inchlısão de blocos especiais para DSP e blocos especiais para memórias TriMax c a maior capacidade dos scus dispositivos.

Blocos de DSP são elementos especiais de hardware que foram introduzidos de forma a acelerar aplicaçoes IJSP. lais aplicaçös, comumente, necessitam muito de multiplicaços; o que, como dito anteriomentc, năo é muito eficiente de ser implenentado em FPGA. Para suprir essa falha deficiencia, a Altera introduziu esses blocos DSP. Eles sño implementados usando tenologia ASIC de última geração.

Existem diversos blocos DSP cm cada FPGA Stratix. Cada bloco possui três modos de operação (visando as mais diferentes aplicações DSP): multiplica, multiplica e soma (ou subtrai) e multiplica c acumula (Fig. 8.13). Cada um desses trés modos pode utilizar operandos de très diferentes tamanhos: 9, 18 e 36 bits.

A outra modificação feita foi a inchusão de memórias en tres diferentes tamanhos: $32 \times 18,128 \times 16$ e $4000 \times 144$ bits. A inclusão dessas nenórias no chip também foi motivada pelas aplicacooes DSP, as yuais necessitan de muitos dados locais, os quais (agora) podem ser armazcnados facilmente no próprio PLD. 


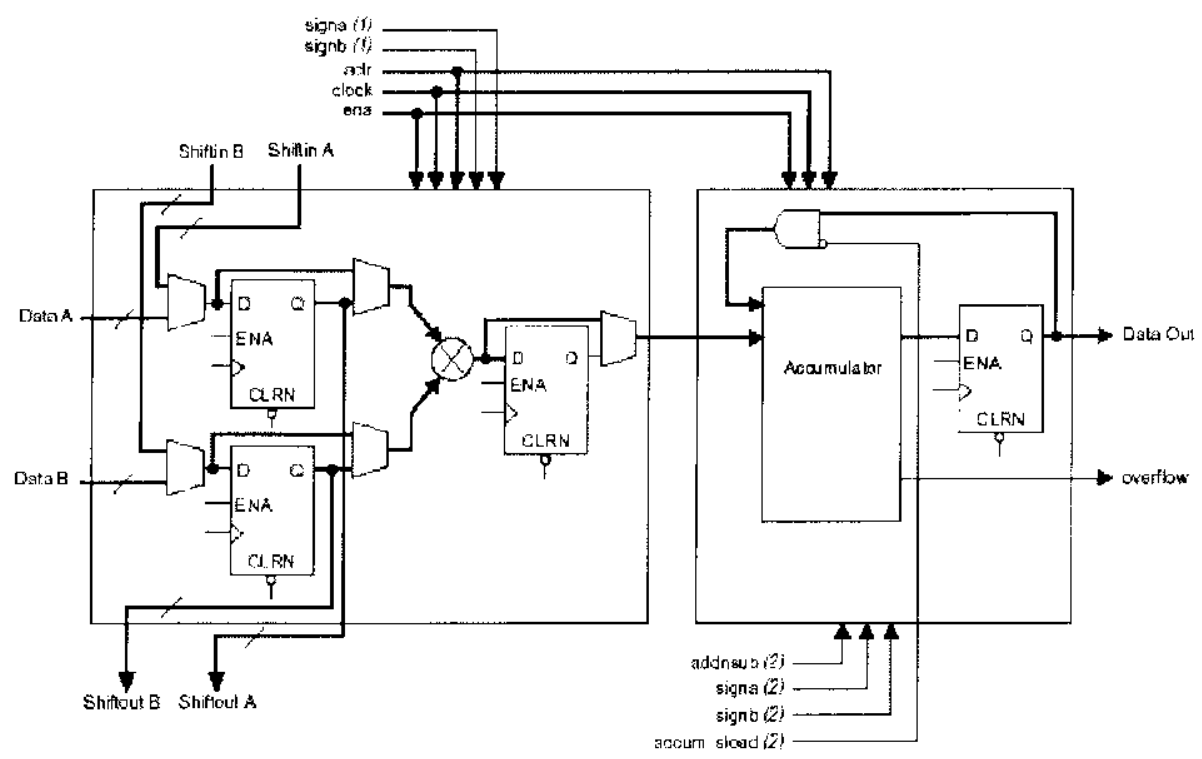

Figura 8.13: Bloco DSP da Stratix no Modo Multiplica e Acumula [2:3].

\subsubsection{Excalibur}

O Excalibur [13] [14] é un kit de descnvolvimento de hardware e software para ¿lispositivos lógico programáveis (PLD). O kit possui:

- Core de um processador RISC configurável (NIOS);

- Compilador GNU Pro;

- Software de desenvolvinento de hardware para PLDs Quartus II;

- Placa de desenvolvimento conn una APEX FI'20K200E, dois barramentos PCI, uma interface serial, 1Mbyte de memória flash, 256 Kbytes de memória SR $\wedge$ M, entre outros periféricos [20] (Fig. 8.14).

\section{Soft Core NIOS}

O processador embutido NIOSC) (Fig. 8.15) ć um soft-core que pode ser agregado pelo usuário em seus projetos. 


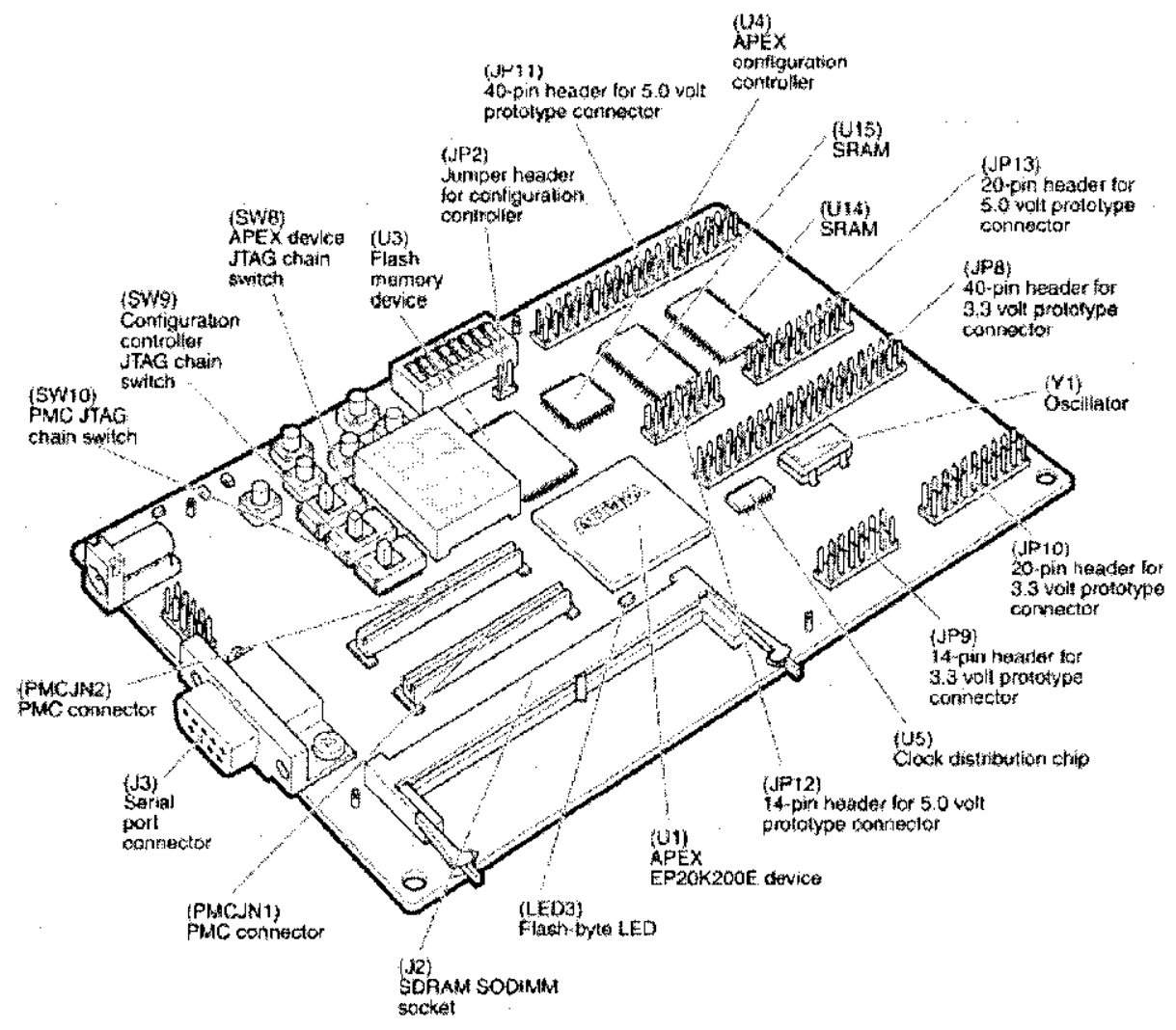

Figura 8.11: Placa de Desenvolvimento do Kit Excalibur con Processador Nios [20].

Inicialmente, destinado para a família de dispositivos APEX da Altera, este processador ocupa apenas $12 \%$ da área de un dispositivo de 200 mil portas lógicas (EP20K200E). A família APEX já possui dispositivos con até 4 milhôes de portas lógicas (APEXII EP2A90), significando que há una grande quantidade de recursos disponíveis para o restante do sistema. Vários periféricos já estão disponíveis e en desenvolvinento para o NIOS, como timers [22], contadores, receptores e transmissores assíncronos universais (UARTs) [15], dispositjvos de entrada c saída paralela (PIOs) [21], controladores de disco c controladores SIJRAM.

As possibilidades para o processador embutido NIOS são amplas. Por excmplo, sistemas DSPs (Digital Signal Processors) podem ser desenvolviclos com a adição de ítens como filtros FIR (Finite Impulse Response), osciladores e transformada de 


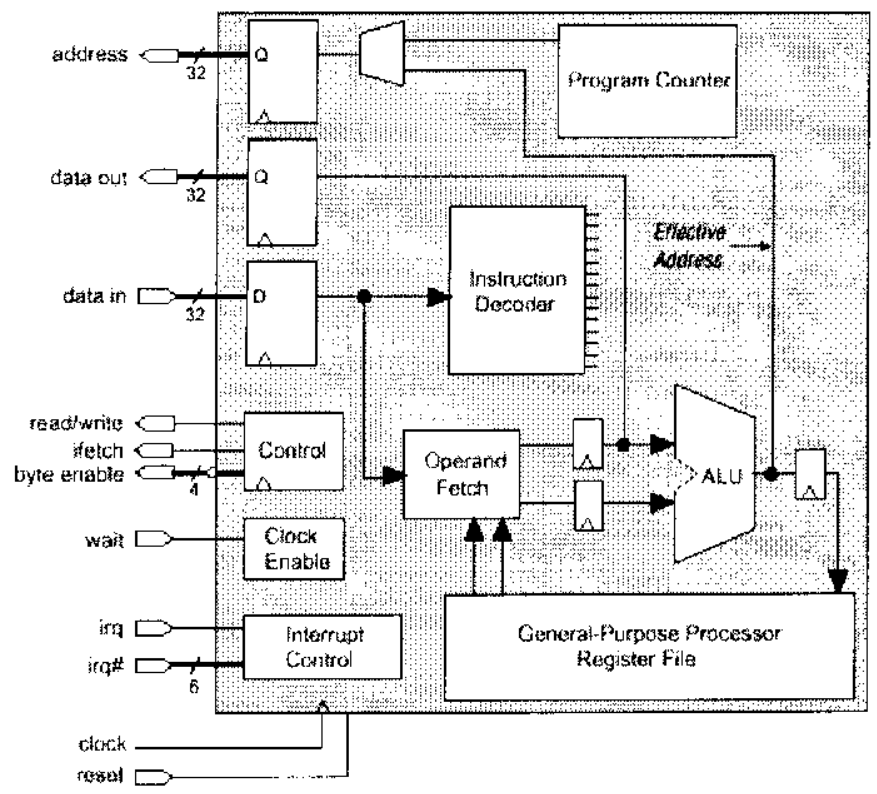

Figura 8.15: Diagrama de Blocos do Processador Nios [16].

Fourier (FFT). A eficiência de uso do dispositivo possibilita também que múltiplass instâncias do processador possam ser usadas para aplicações de alto desempenho que requeiram implementações com múltiplos processadores, como mostra a Figura 8.16 .

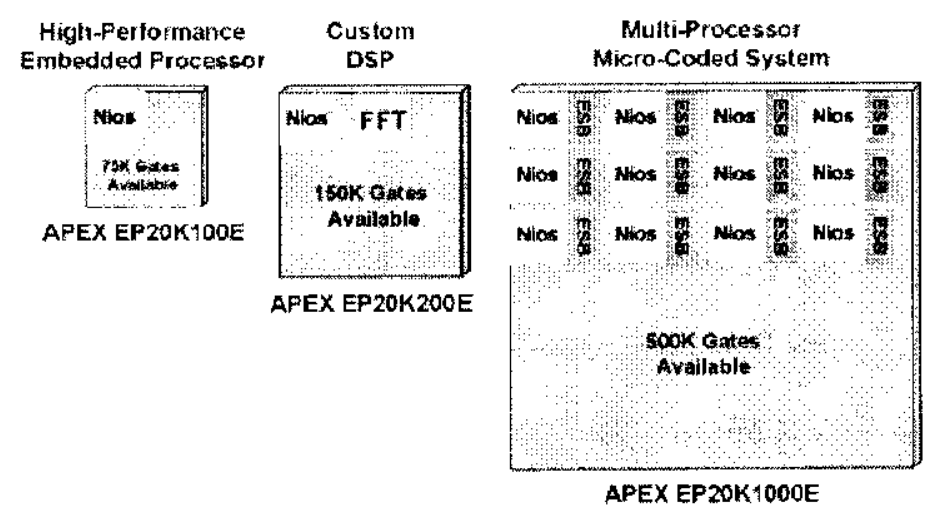

Figura 8.16: Flexibilidade e Escalabilidade dos Processadores Embutidos NIOS [16].

Por ser paranctrizável, o processador NIOS permitirá que o LEGUS System 
possa fazer o balanço entre o custo e o desempenhı dos processadores a serem utilizados. Apesar da possibilidade de configuraçăo dos processadores NIOS, o coujunto de instruçoes permanece sempre o mesmo.

\subsubsection{Simulador de Linguagens de Descrição de Hardware ModelSim}

O ModelSin [112] [113; [111] ó o simulador de linguagens de descrição de hardware mais popular do mundo. Ele possuí inúmeros recursos que são indispensávcis para ıma boa depuração de um hardware scudo desenvolvido, particularmente ele ć bastante propício para o uso de testbenches ${ }^{2}$. Essa ferramenta torna a depuração do un hardware bastante semelhante a depuraçào de software, simplificando o traballıo do projetista de hardware.

A principal virtude do ModelSim é poder diagnosticar de mancira mais precisa qual o crro que está acontecendo no seu hardwarc (caso algum esteja acontecondo) e demonstrar de mancira mais clara do que os simuladores de sinais de onda, comumente utilizados para depuração de hardware, o que realmente está acontecendo no hardware sendo depurado.

Outra vantagem importante do simulaclor que ele tende a diminuir o tempo de projeto do hardware. Isso ocorre devido a maior facilidade de se compreender e encontrar os erros que podem ocorrer no hardware.

É importante salientar que todos os circuitos de hardware gerados nesse trabalho foram validados utilizando-se o ModelSim. Sem essa ferramenta o trabalho de validação dos circuitos reconfiguráveis teria sido, com certeza, muito mais árduo.

\footnotetext{
${ }^{2}$ Conjunto de testes especial para testar a funcionalidade do lardware
} 


\subsection{Implementação do Gerador de Redes Neurais Multi-Camadas}

Nessa implementação de un gerador de Redes Neurais MLP' será considerada apenas a fase forward das redes, futuras implementaçôes desse gerador podem vir a acrescentar a fase de aprendizado on liardware dias mesmats.

A principais funções envolvidas na fase forward são: multiplicação, adição (mais especificamente acumulação) e avaliação da função de ativação. Portanto, a prinıcira tarcfa para a criação de una rede neural eficiente é exatamente a criação de módulos que implementem en hardware essas funçôes de unna maneira eficiente.

\subsubsection{Tratamentos para a Multiplicação}

A unultiplicaçäo talvez seja a função mais crítica para a a criaçăo de un laardware para redes neurais. Isso se deve não somente a complexidade da função em si, mas também ao número clcvado de vezes que essa funçào ten que ser excutada para se obter o resultarlo da rede.

Devido a esse fato, o liardware que implementa a multiplicação deve ser o mais rápido possível para não comprometer o camiuho crítico do circuito. Para isso, existem duas altcmativas: a criaçào de multiplicadores combinacionais extremamente rápidos (e, portanto, ocupando nunita área) on o uso de pipeline no multiplicador (ao custo cle $u n$ certo acréscimo na área do circuito, nas con uma redução considerável na latència do circuito).

A Tabela 8.1 apresenta os dados de área e latência de diversos tannanhos de multiplicadores nas FPGAs das famílias Apex e Stratix da Altera. Pode ser observado que tanto a área quanto a latència dos miltiplicadores da Apex crescem quase que linearmente com o número de bits. Já os multiplicadores da Stratix possuem um comportamento mais interessante: a utilização e latència do circuito só cresce a cada 9 bits. Contudo o núnero de DSPs existentes om cadia Stratix pode ser bastante 
linitado. Esses dados são extremamente relevantes para a criação do circuito da. rede neural, visto que (na maioria dos casos) a latência desse circuito determina a latencia do pipeline do circuito da rede neural.

Tabela 8.1: Dados sobre Multiplicadores nas Fannílias Apex e Stratix da Altera

\begin{tabular}{|c|c|c|c|}
\hline Família & Número de Bits & Área & Latência \\
\hline Apex & 8 & 103 LEs & $22.5 n \mathrm{~ns}$ \\
\hline & 9 & $142 \mathrm{LEs}$ & $26.1 \mathrm{~ns}$ \\
\hline & 10 & $162 \mathrm{LEs}$ & $30.1 \mathrm{~ns}$ \\
\hline & 12 & $228 \mathrm{LEs}$ & $33.6 \mathrm{~ns}$ \\
\hline & 14 & $285 \mathrm{LESs}$ & $34.8 \mathrm{~ns}$ \\
\hline & 16 & 373 LEs & $36.5 \mathrm{~ns}$ \\
\hline & 18 & $444 \mathrm{LEs}$ & $42.1 \mathrm{~ns}$ \\
\hline Stratix & 8 & 1 DSP & $4.1 \mathrm{~ns}$ \\
\hline & 9 & 1 DSP & $4.1 \mathrm{~ns}$ \\
\hline & 10 & 2 DSPs & $4.9 \mathrm{~ns}$ \\
\hline & 14 & 2 DSPs & $4.9 \mathrm{~ns}$ \\
\hline & 16 & 2 DSPs & $4.9 \mathrm{~ns}$ \\
\hline & 18 & 2 DSPs & $4.9 \mathrm{~ns}$ \\
\hline
\end{tabular}

Outra possibilidade é a utilização de aritmética logarítmica, onde a multiplicação ć reduzida a uma soma. O problema dessa abordagem é que o número tem que ser convertido para a representação logarítmica c de volta para a representação binária de ponto fixo, o que exige uma aproximação da funçào logarítmica e exponencial. Para facilitar o cálculo do logaritmo, o valor de entrada da função logarítnica é multiplicado por $2^{16}$ (considerando entradas de 16 bits, para ontros valores de entrada essa constante deve ser adaptada), eliminando a parte fracionária do valor de entracla. Usando essa aproxinnação, a multiplicação fica reduzida a seguinte equação:

$$
x * y=\operatorname{Exp}_{2}\left(\log _{2}\left(x * 2^{16}\right)+\log _{2}\left(y * 2^{16}\right)\right) / 2^{2 \times 16}
$$

Como os circuitos que implementam as funções logarítmica e exponencial serão 
utilizados apenas para a multiplicação, tanto a multiplicaa̧ãa por $2^{16}$ quanto a divisâo por $2^{2 * 16}$ säo incorporados nos seus respectivos circuitos. A Figura 8.17 mostred a implementação do circuito da função logarítmica e a Figura 8.18 denonstra a implementação do circuito da função exponencial.

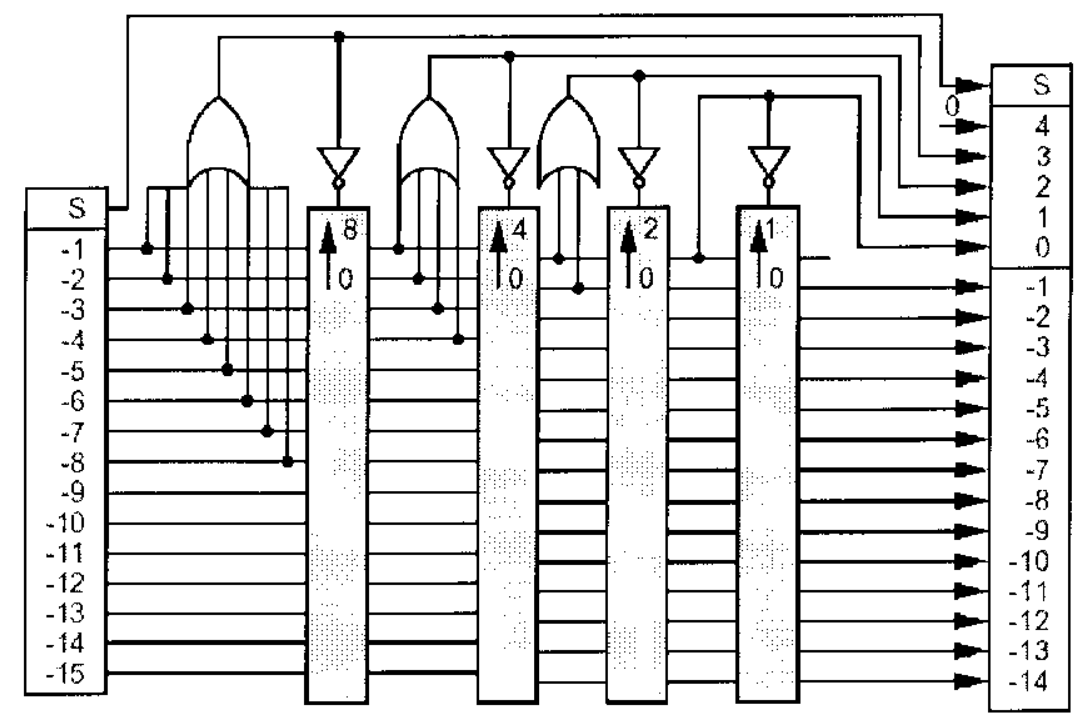

Figura 8.17: Diagrama de Blocos do Circuito que Calcula o Logaritmo de um Númoro Multiplicado por $2^{16}[109]$.

A Tabelas 8.2 mostma a latência e a árca dos circuitos que implementan a multiplicação utilizando aritmética logarítmica. O erro máximo desses blocos é de $8.6 * 10^{-2}$

Considerando os dados apresentados fica evidente que 10 caso de uso de FPGAs da família Apex o uso de aritmética logarítnica é bastante vantajoso. Já no caso da família Stratix o uso ou não de aritnética logarítnica depende da rede sendo implementada e do circuito que está scndo utilizado, on seja, só utilizanos aritmética logarítmica em una Stratix quando o número de multiplicadores presentes for muito menor do que o número de neurônios presentes na rede. 


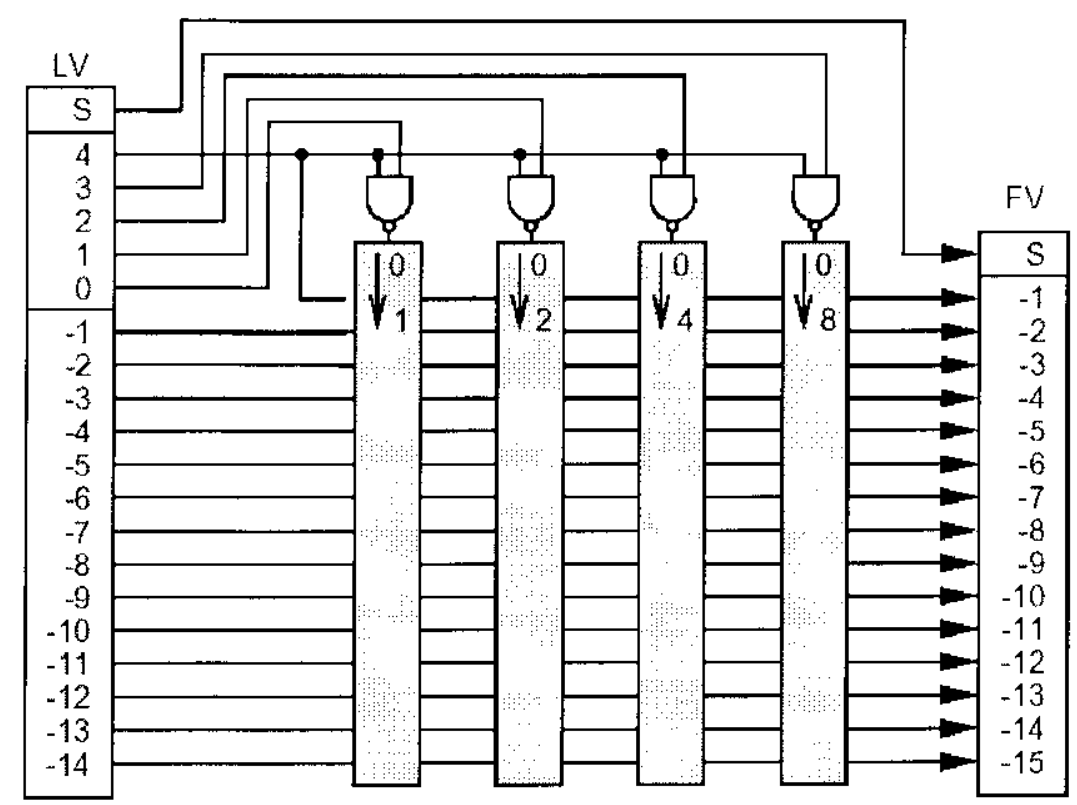

Figura 8.18: Diagrama de Blocos do Circuito que Calcula a Exponencial de Número Dividido por $2^{2 * 16}[109]$.

Tabela 8.2: Dados sobre Implennentação do Multiplicador em Aritmética Logarítmica nas Famílias Apex e Stratix da Altera

\begin{tabular}{|c|c|c|c|}
\hline Família & Circuito & Área & Latência \\
\hline Apex & Somador & $20 \mathrm{LEs}$ & $17.91 \mathrm{~s}$ \\
\hline & Log & $18 \mathrm{LEs}$ & $14.1 \mathrm{~ns}$ \\
\hline & Exp & $17 \mathrm{LEs}$ & $13.9 \mathrm{~ns}$ \\
\hline Stratix & Somador & $20 \mathrm{LEs}$ & $10.8 \mathrm{~ns}$ \\
\hline & Log & $18 \mathrm{LEs}$ & $9.8 \mathrm{~ns}$ \\
\hline & Exp & $17 \mathrm{LEs}$ & $12.8 \mathrm{~ns}$ \\
\hline
\end{tabular}




\subsubsection{Tratamentos para a Acumulação}

A acumulação pode ser tratada basicamente de duas maneiras: uso de um somador completo ou uso de um somador do tipo carry-save durante as etapas de acumulaçāo com uso de um somador completo no final para somar os valores da soma com os valores de carry.

A primeira abordagem apresenta como vantagemo uso de menos recursos (área) de hardware ao custo de uma maior latència do circuito sendo gerado. Já a segunda abordagem pode reduzir a latência do circuito ao custo de um pequeno ácréscimo na área do mesmo.

Outro fator que interfere tanto na latência quanto na área ocupada pelo circuito ć o tipo de somador completo: carry-propagate adder, conditional-sum adder; carry look-ahead adder, Ling adder, entre outros. Cada um desses somadores possui um compromisso diferente entre área ocupada e latència, sendo que cada un deles é ótimo com relaçăo a algum aspecto.

A Tabela 8.3 demonstra a árca e a latência gasta na implementação de acumuladores de diversos tamanhos. No caso da família Apex, o acumulador implementa $1 u n$ somador do tipo carry-propagate que utiliza parte especial dos clementos lógicos dessa família. Já na família Stratix, o somador implementado é un carry-select que tamubén utiliza parte especial dos elementos lógicos (só que essa parte só existe nos elementos lógicos da família Stratix). O uso de acumuladores do tipo carry-save não foi considerado nessas duas famílias, visto que esse tipo de somador ocuparia mais área e teria quase a mesma latência que os somadores considerados. O uso de carry look-ahead adder também näo foi considerado pois a latência dos acumuladores considerados é compatível con a latência dos demais blocos e a área ocupada seria maior.

A escolha da abordagem a ser utilizada depende da latenncia dos demais blocos sendo utilizados, do tamanho dos dados de entrada do acumulador e do PLI) sendo utilizado. 
Tabela 8.3: Dados sobre Acumuladores nas Famílias Apex e Stratix da Altera

\begin{tabular}{|c|c|c|c|}
\hline Fannília & Número de Bits & Área & Latência \\
\hline Apex & 8 & $18 \mathrm{LLSs}$ & $4 n \mathrm{~s}$ \\
\hline & 9 & $20 \mathrm{LEs}$ & $4.3 \mathrm{~ns}$ \\
\hline & 10 & $22 \mathrm{LEs}$ & $4.8 \mathrm{~ns}$ \\
\hline & 14 & $30 \mathrm{LLs}$ & $5.3 \mathrm{~ns}$ \\
\hline & 16 & $34 \mathrm{LEs}$ & $5.5 \mathrm{~ns}$ \\
\hline & 18 & $36 \mathrm{LEs}$ & $5.7 \mathrm{~ns}$ \\
\hline Stratix & 8 & $8 \mathrm{LEs}$ & $3.3 \mathrm{~ns}$ \\
\hline & 9 & $9 \mathrm{LEs}$ & $3.3 \mathrm{~ns}$ \\
\hline & 10 & $10 \mathrm{LFs}$ & $3.31 \mathrm{~s}$ \\
\hline & 14 & $14 \mathrm{LEs}$ & $3.3 \mathrm{~ns}$ \\
\hline & 16 & $16 \mathrm{LEs}$ & $3.3 \mathrm{~ns}$ \\
\hline & 18 & $18 \mathrm{LEs}$ & $3.3 \mathrm{~ns}$ \\
\hline & 60 & $62 \mathrm{LEs}$ & $5.8 \mathrm{~ns}$ \\
\hline
\end{tabular}




\subsubsection{Tratamentos para a Função de Ativação}

Existem basicamente quatro lipos de implementaķão de funções [74; [28]:

- Cordic-like ${ }^{3}$ : implementa a aproximação da função apenas utilizando operações de soma e shift. Costuma ser extremamente rápida, mas apenas algumas funçōes podem ser aproximadas usando esse método;

- Polinomial: utiliza aproximações polinomiais da função. É o método mais comumente utilizado en implementatções em software:

- Tabela: aproxima o valor da função por valores pré-tabelados;

- Híbrido: utiliza um misto do método por tabelas e polinomial.

Nesse estudo foram considerados um método Cordic-like e dois métodos híloridos. Eles foram escolhidos por serem os mais propícios para as funçôes de ativação utilizadas om redes nourais VLP.

O primeiro método considerado foi un Cordic-like bascado naquele publicado em [109]. O método ali descrito é para aproximar a função sigmoidal logística esculonada para o intervalo [-1,1]. Nessa dissertação o métoklo foi adaptado para aproximar as furçoòcs $1 /\left(1+e^{x}\right)$ e $\left(1-e^{x}\right) /\left(1+e^{-x}\right)$.

As Figuras 8.19 e 8.20 demonstram as implementações do hardware para a primeira função e a segunda função, respectivamentc. A Tabela 8.4 apresenta os resultados obtidos. Como pode ser observado, a média do erro é 0 , o que já era esperado devido a simetria tanto dos métodos de aproximação quanto das funçós sendo aproximadas. Outros dados relevantes são o erro méclio absoluto que fica na casa dos $10^{3}$ e o crro máximo absoluto o qual fica na casa dos $10^{-2}$, o que ć equivalente a outras aproximações encontradas na literatura sobre redes neurais [65]. Dessa forma, o método proposto pode ser empregado $\mathrm{cm}$ implementações em hardware reconfigurável para redes neurais MLI' sem maiores restrições.

\footnotetext{
${ }^{3}$ Também conhecida por método shifl-add.
} 


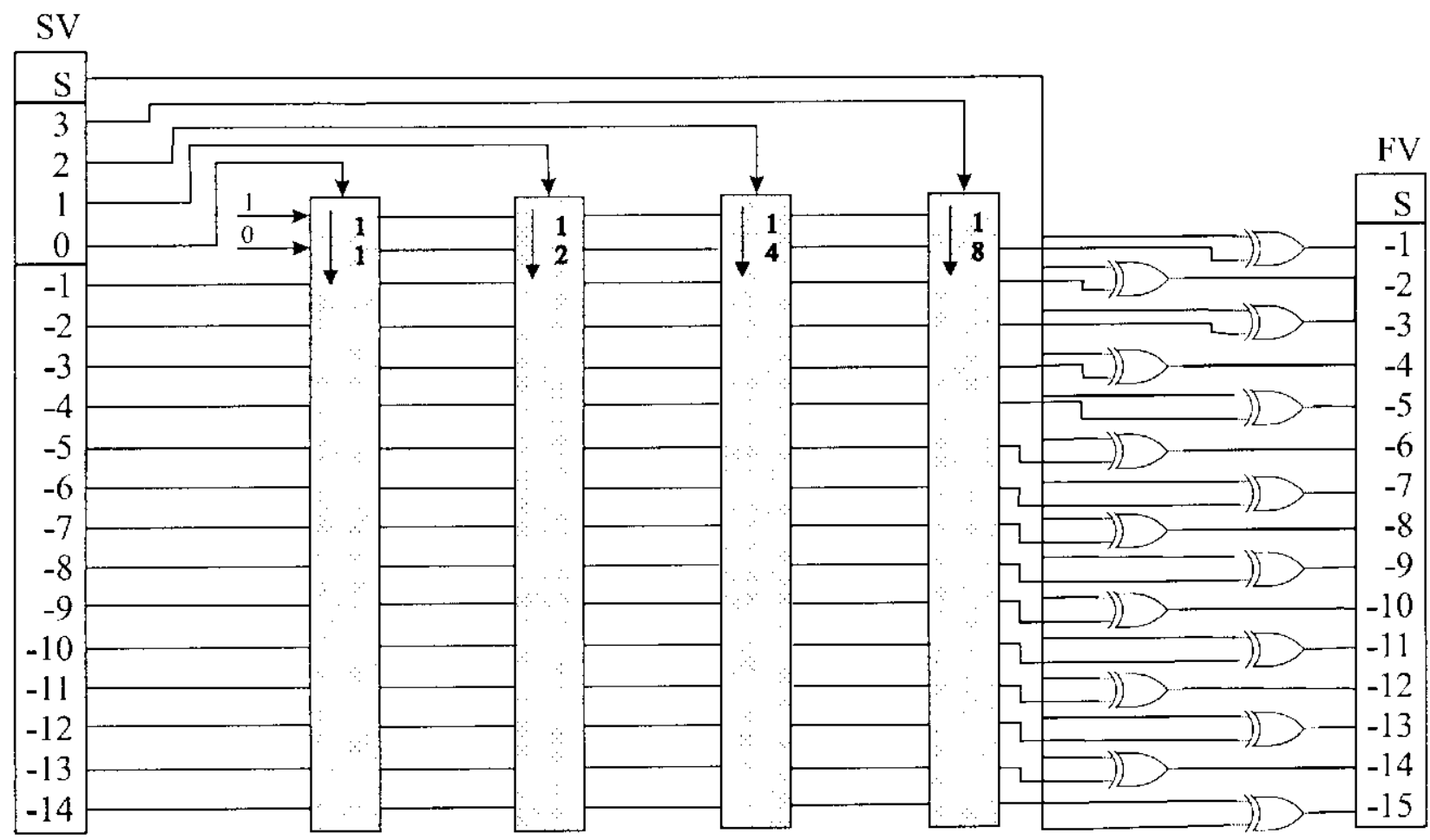

ligura 8.19: Diagrama de Blocos do Cirenito que Calcula a Aproximação da Função $1 /\left(1+e^{-x}\right)$. 


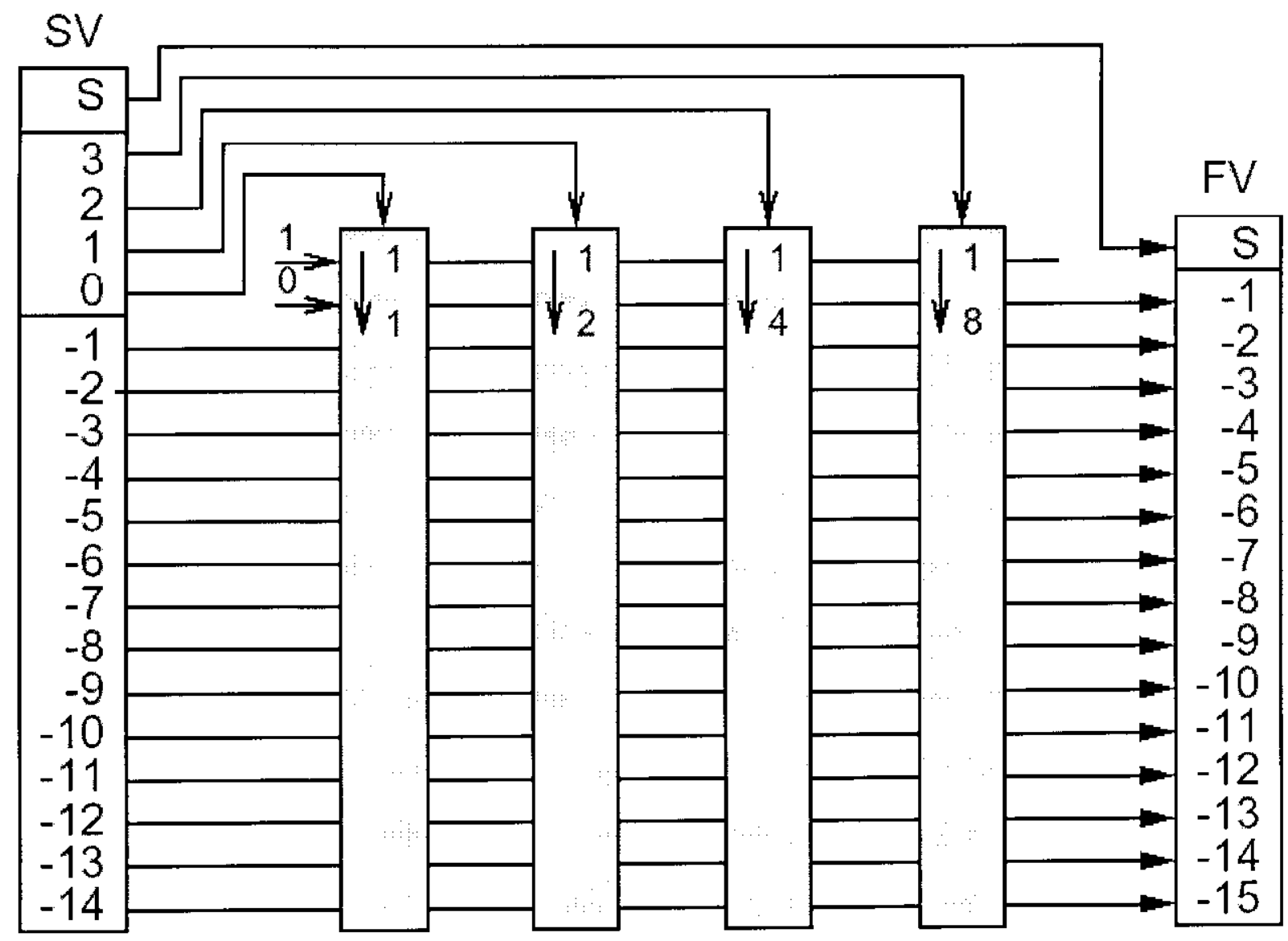

Figura 8.20: Diagrama de Blocos do Circuito que Calcula a Aproximação da Função $\left(1-e^{x}\right) /\left(1+e^{-x}\right)$. 
Tabela 8.4: Análise das Aproxinnações Cordic-like para as Funçôes de Ativação.

\begin{tabular}{|c|c|c|c|}
\hline Função & $\begin{array}{c}\text { Erro Absoluto } \\
\text { Máximo }\end{array}$ & $\begin{array}{c}\text { Média do Erro } \\
\text { Absoluto }\end{array}$ & $\begin{array}{c}\text { Média } \\
\text { do Erro }\end{array}$ \\
\hline $1 /\left(1+e^{-x}\right)$ & $1.9 * 10^{-2}$ & $4.5 * 10^{-3}$ & 0 \\
\hline$\left(1-e^{-x}\right) /\left(1+e^{x}\right)$ & $3.8 * 10^{-2}$ & $9.1 * 10^{-3}$ & 0 \\
\hline
\end{tabular}

O circuito que implementa a aproximação da função $1 /\left(1+e^{-x}\right)$ ocupa 15 LEs nunna Apex e 15 LEs numa Stratix, enquanto o circuito que implenenta a aproximação da função $\left(1-e^{-x}\right) /\left(1+e^{-x}\right)$ ocupa 17 LẺs na $\Lambda \mathrm{p}$ (x e 17 LEs na Stratix. O primeiro circuito apresenta latência de 14 ns numa Apex e 10.4 ns muma Stratix, já o segundo possui latência de 11 ns e 10.2 ns numa Apex o numa Stratix, respectivamente.

O segundo método implementado é um método híbrido, proposto em [65: File, mescla o uso de duas tabelas com uma aproximação linear. A aproximação linear consiclerada é $\mathrm{F}(\mathrm{x})=\mathrm{A}+\mathrm{Cx}$. Assim sendo, cada aproxinnação exige uma multiplicação e una soma, o que torna a implementação muito custosa para una Apex, sendo apenas considerada em IPGAs da família Stratix.

As tabelab implementadas servem cada uma para armazenar una das variáveis da aproximação para cada intervalo de aproximação. Foram considerados 8 intervalos iguais entre -4 e 4 . Portanto o tamanho de cada tabela é igual ao número de bits necessário pard armazenar as variáveis multiplicado por 8 intervalos. Considerando 11 bits de precisão para cada una das variáveis temos que cada tabela armazena 8 * 14 bits = 112 bits. Assinn sendo, ambas as tabela caben num único bloco M512 cle uma Stratix.

Os valores das variáveis A e C säo cncontrados através do uso do método dos mínimos quadrados, o que se reduz as equaçōes:

$$
\begin{aligned}
& X=\sum_{i=0}^{N-1} x_{i} \\
& X^{2}=\sum_{i=0}^{N-1} x_{i}^{2} \\
& Y^{*}=\sum_{i=0}^{N-1} F^{\prime}\left(x_{i}\right)
\end{aligned}
$$




$$
\begin{aligned}
& X Y^{\prime}=\sum_{i=0}^{N-1} x_{i} * F^{\prime}\left(x_{i}\right) \\
& C:(X * Y-X Y) /\left(X^{-} * X-X^{2}\right) \\
& A=Y-C * X
\end{aligned}
$$

onde $\mathrm{N}$ ó o número de dados amostrados em cada intervalo.

O método foi utilizado para aproximar as funções $1 /\left(1+e^{x}\right),\left(1-e^{-x}\right) /\left(1+e^{-x}\right)$ $e\left(e^{x}-e^{-x}\right) /\left(e^{x}+e^{-x}\right)$, as quais säo comumente utilizadas em redes neurais MLP.

A Tabela 8.5 apresenta os resultados obtidos. O erro absoluto náximo e a média dos erros absolutos obtidos são ligeiramente superiores ao método anterior. Contudo, o erro médio obtido é diferente de zero, apesar de ser pequeno.

Tabela 8.5: Análise das Aproximaçoes Híbridas com Multiplicadores para as l’unçōes de Ativação.

\begin{tabular}{|c|c|c|c|}
\hline Função & $\begin{array}{c}\text { Erro Absoluto } \\
\text { Máximo }\end{array}$ & $\begin{array}{c}\text { Média do Erro } \\
\text { Absoluto }\end{array}$ & $\begin{array}{c}\text { Média } \\
\text { do Erro }\end{array}$ \\
\hline $1 /\left(1+e^{x}\right)$ & $7.8 * 10^{-3}$ & $1.9 * 10^{-3}$ & $-1,1 * 10^{-5}$ \\
\hline$\left(1-e^{-x}\right) /\left(1+e^{-x}\right)$ & $1.6 * 10^{-2}$ & $3.8 * 10^{-3}$ & $-1,8 * 10^{-5}$ \\
\hline$\left(e^{x}-e^{-x}\right) /\left(e^{x}+e^{-x}\right)$ & $5.8 * 10^{-2}$ & $9.5 * 10^{-3}$ & $-2.3 * 10^{-5}$ \\
\hline
\end{tabular}

O circuito que implementa essa áproxinação possui três etapas de pipeline ${ }^{4}$ com latềncia igual a aproximadannente 5 ns (tempo aproxinnado da mutiplicação, a qual é a função mais lenta do circuito implementado). Ocupando 1 bloco de DSP, 1 bloco de memória M512, 65 elennentos lógicos (para o somador e os registradores).

O método anterior é supcrior ao primeiro método eln termos de precisäo mas consone maior área do PLD. Isso se deve principalmente ao multiplicador necessário para a implementação. Pensando nissso, foi proposta una nova implementação que restringe o valor de C a poténcias do 2 (ou seja, shifts) [65].

\footnotetext{
${ }^{4}$ Primeira etapa: lô o valor de $\mathrm{C}$ da tabela. Segunda etapa: lê o valor de $\mathrm{A}$ da tabela e calcula $\mathrm{C}^{*} \mathrm{x}$. Terceira ctapa efetua a soma $\mathrm{A}+\left(\mathrm{C}^{*} \mathrm{x}\right)$.
} 
$\mathrm{Na}$ aproximação utilizadas no método anterior, se o valor de $\mathrm{C}$ for fixo podemos facilmente calcular o valor de A através da equação $\mathrm{A}=\mathrm{Y}-\mathrm{C}^{*} \mathrm{X}$. Dessá formá, implementamos um procedimento que faz uma busca exaustiva nos possíveis valores de $\mathrm{C}$ comç̧ando $\mathrm{cm} \pm 1$ até $\perp 2^{-2 t}$. O valor de C para o qual o erro médio obtido é mínimo no intervalo sendo considerado é utilizado para calcular o valor de A e assim temos una aproximáção lincar das funçõos de ativação sem a necessidade de multiplicação. Os valores de A podem ser armazenados numa tabela idêntica a utilizada no método anterior. Já para os valores de C que variam de 0 até $上 2^{-13}$, são necessários apenas $16 \times 5$ bits $=80$ bits para a tabela que o armazena. Isso ocorre porque não armazenamos diretamente o valor de C, mas sim o seu sinal e o exponte ao qual devemos elevar o 2 (ou seja, o valor dos slifts a esquerda que devem ser realizados).

O hardware necessário é um barrel-shifter, um somador, as tabelas e os registradores para armazenar os resultados cntre as ctapas do pipcline, o que resulta em 138 LÉs utilizados e uma latência de 18.5 ns numa Apex e 126 Lt's o 12.5 ns iuma Stratix.

Como pode ser observado na Tabela 8.6, os crros do terceiro método são um pouco superiores ao segundo método e inferiores a primeiro método (exceção feita a função, para a qual o tercciro método não é aconselhável).

Tabela 8.6: Análise das Aproximações Híbridas sen Multiplicadores para as Funções de Ativação (8 Intervalos).

\begin{tabular}{|c|c|c|c|}
\hline Funçāo & $\begin{array}{c}\text { Erro Absoluto } \\
\text { Máximo }\end{array}$ & $\begin{array}{c}\text { Média do Erro } \\
\text { Absoluto }\end{array}$ & $\begin{array}{c}\text { Média } \\
\text { do Erro }\end{array}$ \\
\hline $1 /\left(1+e^{x}\right)$ & $2 * 10^{2}$ & $3.7 * 10^{-3}$ & $-1,1 * 10^{-5}$ \\
\hline$\left(1-e^{-x}\right) /\left(1+e^{-x}\right)$ & $4.0 * 10^{-2}$ & $7.4 * 10^{3}$ & $-1,8 * 10^{-5}$ \\
\hline$\left(e^{x}-e^{-x}\right) /\left(e^{x}+e^{-x}\right)$ & $1.7 * 10^{-1}$ & $1.9 * 10^{-2}$ & $-2.2 * 10^{5}$ \\
\hline
\end{tabular}

Como os resultados obtidos pelo terceiro método não furam satisfatórios a princípio, decidiu-se dobrar o número de intervalos, o que culninou numa melhora significativa 
dos resultados obtidos, como pode ser observado na Tabela 8.7 .

Tabela 8.7: Análise das Aproximações Híbridas sem Multiplicadores para as Funções de Ativaçāo (16 Intervalos).

\begin{tabular}{|c|c|c|c|}
\hline Função & $\begin{array}{c}\text { Erro Absoluto } \\
\text { Máxinuo }\end{array}$ & $\begin{array}{c}\text { Média do Erro } \\
\text { Absoluto }\end{array}$ & $\begin{array}{c}\text { Média } \\
\text { do Erro }\end{array}$ \\
\hline $1 /\left(1+e^{-x}\right)$ & $1.4 * 10^{-2}$ & $2.1 * 10^{-3}$ & $1,7 * 10^{-6}$ \\
\hline$\left(1-e^{-x}\right) /\left(1+e^{-x}\right)$ & $2.8 * 10^{-2}$ & $4.2 * 10^{-3}$ & $-1,4 * 10^{-5}$ \\
\hline$\left(e^{x}-e^{-x}\right) /\left(e^{x}+e^{-x}\right)$ & $1 * 10^{-2}$ & $4.1 * 10^{-3}$ & $-2.3 * 10^{-5}$ \\
\hline
\end{tabular}

O primeiro método deve ser o escolhido no cáso de FPGAs da família Apex, visto que é o método mais vantajoso tanto do ponto de vista de área quanto do ponto de vista de latencia para essa fanília en particular. Nessa família de FPGAs o segundo método jamais deve ser escolhido (devido a imensa área ocupada e a enorme latência do circuito gerado). Já o terceiro método, para essa família de FPGAs, deve ser escolhido sempre que se neccssite de uma precisão melhor que aqucla obtida com o primeiro método.

No casso de se estar projetando a aplicação com FPGAs da família Stratix as opcöes são nais complexas. Deve-se dar preferência para o prineiro método sempre que a área for un problema crítico para a implementação. Já se o problema for tempo, o segundo método é mais apropriado visto que cle possui latência correspondente a metade da latência dos demais métodos para essa família de FPGAs. O terceiro método ć um compromisso entre precisão e área c deve ser utilizado em monentos que o segundo método não puder ser utilizado e se desejar uma precisão maior do que aquela obticla com o primeiro método.

É importante salientar, ainda, que o segundo e o terceiro método possum o potencial para aproxinar praticancnte qualquer função e o seu uso deverá ser fortemente considerado na construção de ontros geradores de RPL's para o ARCHITECTIr (atualmente, está sendo estudado o uso desses métodos na implementação da funçào de aptidão de algoritmus genéticos). 


\subsubsection{Implementação do Hardware da Fase Forward da Rede}

A unidade básica de implementação de uma rede neural em hardware pode ser considerada como sendo um neurơnio. $\Lambda$ estrutura básica de umn neurônio em hardware 6 apresentada na Figura 8.21. Como pode ser observado pela figura, os tratamentos para os diversos blocos discutidos anterionnente formann a base para a implementação de um neurônio.

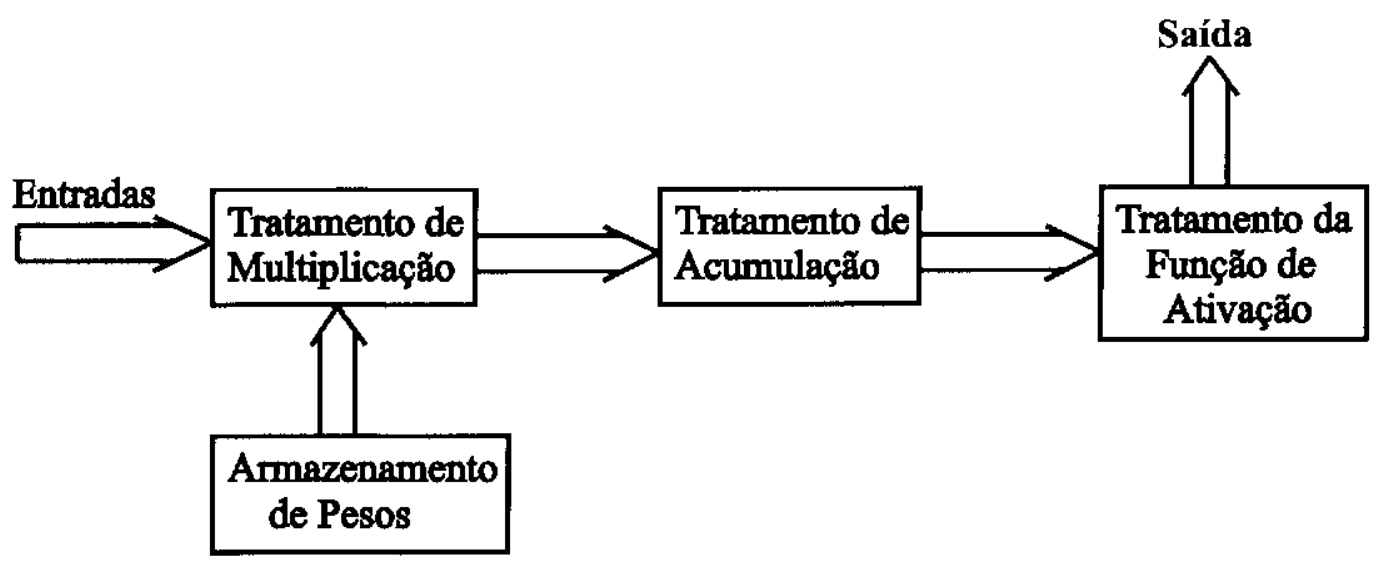

Figura 8.21: Diagrama de Blocos de um Ncurônio cm Hardware.

So considerarmos 2 possíveis forma de implementação para a multiplicaçäo (5) se considerarmos todas as formas de implementação de uma nultiplicação em uma Stratix), 2 possíveis forma de implementaşão da acumulação (a acumulação pode ser implementada no próprio DSP que inplementa a multiplicação numa Stratix), 3 possíveis funçôes de ativação e 3 formas de se implementar a funçào de ativação temos que são propostos 12 diferentes nenronios nesse trabalho.

Essa quantidade é rolativamente grande para ser tratada por um projetista humano. Daí a necessidade de se construir una ferramenta que automatize o processo de criação do hardware da rede neural à partir de sua especificação.

Porém, antes de tratarmos do software responsável pela geração da rede, ainda temos alguns assuntos pendentes: o armazcnamento dos pesos da rede e a distribuição dos dados de entrada para os neuronios, os quais são tratados a seguir. 


\section{Armazenamento dos Pesos}

É aconselhável que os pesos scjam armazenados, sempre que possível, na própria PLD. Isso se deve ao fato de que o armazenamento extemo desse pesos ou afetariam demais o desempenho do sistema ou ocupariam muitos recursos de entrada e saida do PLD, os quais costumam ser bastante restritos.

Caso o PLD não possua memória interna suficiente para o armazenamento de todos os pesos ao mesmo tempo, sugere-se o particionamento temporal dos mesmos, de forma a ter o menor impacto possível no descmpenho do hardware.

A ŕnica ressalva que se faz ao uso de armazenamento interno dos pesos é no caso de implementaçöes seqüenciais, onde o armazenamento interno dos pesos não auxilia no desempcnho do sistemá (na verdade pode até denegrí-lo).

\section{Distribuição dos Dados de Entrada}

No caso de implementaçós seqüenciais, nāo temos nenhumna opção, visto que os dados de entrada vão dircto para o único neurônio implenentado. Já no caso de redes com múltiplos neurônios temos basicamente duas opçôes:

- Distribuição dos dados de entrada para toda os neurônios da rede alo mesmo tempo: essa opção só deve ser considerada no caso de poucos neurônios; caso contrário pode consumir recursos importante do PLD com o roteamento das entradas, o que não é interessante. Não implica em ganho de desempenho caso o circuito nào possua una forma de salvar os resultados de vários (não necessariamente todos) os neurónios an mesmo tempo;

- Estilo systolic array: os dados são passados para o primciro neurônio que após utilizá-los passa para o segundo neurônio o assimu por diante. Economiza recursos de roteamento mas gasta recursos com a criação de uma cadeia de shift. É particularmente vantajosa no caso das FPGAs Stratix onde o uso desse recurso näo incorre en gasto algum, visto que o mesmo já está cmbutido nos blocos DSP, os quais são utilizados para à multiplicaçäo. 


\subsubsection{Considerações Finais}

O software que cria as redes neurais à partir da descrição das mesma ainda não cucontra-se finalizado. Alguns testes empíricos ainda se fazem necessários de forma a obter uma equação razoável para quando cada una das técnicas descritas anteriormente deve ser utilizada de forma a obter un circuito (quasi-) ótinno. A princípio pode-se fazer a simplificação de que FPGAs dà fámílià $A$ pex devern utilizar multiplicação em aritmética logarítmica, o acumulador normal e o método Cordic-like para aproximação da função. () que é una boa aproximação para FPGAs dessa fanília. O caso complica-se quando é tratada a fanília de FPGAs Stratix, a qual foi lançada apenas recentemente (final de junho) e a maioria das informações ainda não cstão devidamente documentadas. Nesse caso recomenda-se o uso dos multiplicadores convencionais (preferencialmente de 9 bits) e do segundo método de aproxinação de função quando o quesito tempo for fundamental. Já quando o quesito área for fundanental rocomenda-se o uso do primeiro método de aproximação.

Contudo essas considerações dizen respeito apenas a forma do cada neurônio. Outra informação é o número de neurônios que serão implementados em hardware (nem sempre o máximo possivel é a mclhor implcmentação). Recomenda-se equacionar o múmero de neurônios en cada canada c implementar um númoro de neurônios onde o desperdício de recursos näo seja muito grande (a não na última cannada, a qual costuna ter um número ben menor do neurónios do que as demais camadas.

A forma como os dados devem ser distribuídos também é importante. Nas Apex recomenda-se distribuir os dados para todos os neurônios para redes pequenas e utilizar arrays sistólicos para redes grandes. Já no caso das Stratix, reconenda-se, sempre, utilizar arrays sistólicos.

Outro fator relevante que ainda não foi comentado é cono integrar a rede neural ao processador NIOS. Existem basicanente duas formas: como uma instrução do processador ou como um periférico. A primeira reduz a latência do circuito en- 
quanto a segunda da maior liberdade para o descnvolvedor. Até o presente momento entende-se que para a implementação de hardware específico para cada rede neural é mais vanta joso a implementação conno una instrução do processador e para o uso compartilhado do hardware (ou seja, mais de mun rede mapeada no mesno conjunto (subconjunto) de neurônios) é mais interessante a implenentaşão como periférico.

O software está sendo desenvolvido atualmente em linguagem JAVA, mas estudase a mudança para a linguagem $\mathrm{C}++$, de forma a se compatibilizar com os demais geradores de RPCS sendo criados para o ARCHITECT-R.

Alén disso, estuda-se a possibilidade de utilizar como descriçäo de uma rede neural (além da linguagem CES) os arquivos de descrição de redes neurais do formato SNNS [55], de modo a facilitar a migraçâo de aplicaçôes em software para hardware.

Pretende-se também, num futuro breve, implementar-se a fase de treinamento das redes neurais em hardware. Idéias iniciais já estão scndo testadas, mas necessitam de muito trabalho de refinamento ainda. 


\section{Trabalhos Futuros e Conclusão}

\subsection{Trabalhos Futuros}

Como dito anteriomente, o ARCHITECT-R ć um projeto bastante grande e arrojado. Nessa dissertação foram apenas pincelados alguns aspectos da ferramenta, restando uma enomidade de trabalhos futuros a serem realizados, alguns dos quais são levemente comentados nas subseçòs seguintes.

\subsubsection{Geradores de RPUs}

A base para a construcăo de lardware são os geradores de unidades funcionais reconfiguráveis. Tais são geradores constituen a única forma de acesso a construção de hardware de todo o sistema. Assim scndo, cles são considerados de vital importância para o bom funcionamento do sistema.

$\Lambda$ qualidade do hardware gerado para uma aplicaçâo utilizando o ARCHITEC'l'- 
Ré diretamente proporcional a qualidade dos geradores de RPUs utilizados/criados. E, portanto, serâno necessários bons projetistas de hardware e software para desenvolvê-los.

Outro fato que deve ser ressaltado, é que muitos dos componentes criados para um gerador de RPUs pode ser reaproveitado em outros geradores de RPUS (tais como somadores, aproxinadores de funçôes, multiplicadores, divisores de frequência, entre vários outros). Para que essá reutilização possia ser bem feita, é necessária a adoção de un padrão de desenvolvimento desses circuitos. É do entender do autor dessa dissertação que o padrão com maior potencial para beneficiar o sistema como um todo é o SRS [114] [116] [117] [115;. Lsse padrão é adotado para a construção de circuitos integrados en vários centros de desenvolvinento da Motorola espalhados por todo o mundo e tem possibilitado o re-uso de inúneros dos componentes criados.

Outro fator a ser considerado é quais são os próximos geradores a screm desenvolvidos. Através de um estudo das necessidades de programas de robôs ficou constatado que os próximos geradores deverão ser aqueles relacionados a Processamento de Sinais Digitais, Support Vector Machines e Algoritmos Genéticos (este último atualmente en desenvolvimento por má aluna de pós-graduaça do grupo de pescuisa).

Além disso, deve ser estudada a inter-relação entre esses geradores; como, por exemplo, o uso de geradores de redes nourais e algoritmos genćticos, associados ao uso de Eletrònica Evolutiva (a qual será comentada mais adiante nesse documento) para a geração dos chamados "cérebros artificiais"de robôs [100]. Fissa área de pesquisáa parece bastante promissora nos próximos anos e pode trazer avanços significativos para á área de robótica.

\subsubsection{Criação do Compilador}

Na construção do compilador do AlZCHITECT-R poderão ser estudadas técnicas inovadoras de gerenciamento de memória, paralclização de loops, alocação do registradores em arquiteturas reconfiguráveis, cxploração de paralelismo em nível de 
instrução em arquiteturas reconfiguráveis, influencia do tamanho das variáveis utilizadas tanto na área do hardware quanto do tempo de execuçäo do mesmo, entre inúneros outros fatores (principalmente aqueles ligados à compilação para arquiteturas reconfiguráveis, os quais foram pouco pesquisados até o presente momento).

Além disso, para o interfaceamento com os sensores e atuadores do robô, poderão ser desenvolvidas pesquisas sobre compilação para arquiteturas I)SPs (a qual é diferente da compilação para arquiteturas convencionais).

\subsubsection{Elctrônica Evolutiva}

Elctrônica Evolutiva [143: é a geraçẫo de circuitos de hardware através do uso de Algoritmos Evolutivos. Algoritmos Evolutivos é uma classe de algoritmos bascakdos nos princípios da evolução natural. Assinn sendo, os circuitos criados são, na verdade, cvoluídos. As principais vantagens desse método é que, assim cue os parâmetros são sctados, ole não necessita da interferência humana e são capazes de buscar soluçōes não-convencionais. Entretanto, o uso de Algoritmos Evolutivos torna o desenvolvimento mais lento do que através da maioria das outras técnicas itilizadas para a criaçào de circuitos eletrônicos.

O uso dessá ténica deve ser analisada como una forma potencial de criação de geradores do RPUs, visto gue bons resultados tem sido obtidos na geração de circuitos através do uso dessa técuica. Outro motivo (esse ajnda muito distante) é a possibilidade de que com a integração de geradores de RPUs para Algoritnos Evolutivos (cm especial, para Algoritmos Genéticos) possa ser introduzida a capacidade de o próprio robó evoluir o seu próprio hardware. Mais uma vez é importante salientar que essa possibiliclade ainda é bastante remota visto que cla depende de melhor desenvolvinento da tenologia de reconfiguraçâo dinânica, da tecnologia de Eletronica Evolutiva propriamente dita e da criação c uso da tecnologia de compilação dinânnica em computação reconfigurável. Contudo, isso poderia permitir o desenvolvimento de "cérebros artificiais" com capacidade de auto-evolução, o que seria uma evolução impressionante dentro do campo da robótica. 


\subsubsection{Reconfigurabilidade Dinâmica}

Reconfigurabilidade dinânica é a capacidade de Dispositivos Lógicos Progranáveis (PLDs), geralmente FPGAs, possucm em modificar a sua configuração; e, por conseguinte, o hardware sendo executado, para melhor se adequar a aplicação. Essà capacidade cria o que é comunente chanado de hardware virtual, ou seja, faz com que o chip do PLI) comporte inplementar mais hardware do que é comunente possível. Esse conceito é análogo ao conceito de memória virtual.

Muitas pesquisas tèm sido feitas sobre esse assunto. Contudo, tanto as ferramentas cono os recursos dos dispositivos ainda se encontram em etapas de desenvolvimento bastante preliminares.

Além disso, o uso de computação reconfigurávcl introduz um overhead no tempo de execução do circuito: o overhead de reconfiguração do circuito. Com o tamanho dos PLDs crescendo tão vertiginosanente (mais rápido do que o descuvolvinento observado nas memórias), esse tempo de reconfiguraçio tende a ser aumentado ao invés de diminuído.

Um recurso que pode ser usado, mas foi muito pouco estudado e encontra-se igualmente pouco descnvolvido, ć a cache de configurações. Tal cache poderia reduzir en muito o tempo de reconfiguração desses circuitos. Alén disso, para que o dispositivos suportasso aplicaçoes de tempo real com requisitos bastante apertados. seria necessário o uso de tócnicas de profetch dos dados de configuração, o que já é bastante complexo do ser utilizado mesmo en software onde o estudo do uso de tais téenicias encontrasse muito mais avançado.

Essas são tarefas difíceis, mas que, com certeza, terão que ser tratadas durante as fases de desenvolvimento futuro do ARCHITECT-R.

\subsubsection{Compilação Dinâmica}

Compilação dinâmica [31] [75] :48] envolve o conceito de se modificar o código executável de un programa em tempo de execusão de forma a se adequar melhor 
as características de execuçào atuais da aplicação ou de forma a se adequar a um ambiente pará o qual de näo foi criado inicialmente. Essse conceito possui algumas semelhanças com o conceito de reconfiguração de dinâmica e a possibilidade do uso conjunto de tais técnicas potencialmente pode ter un impacto bastante positivo no desempenho do circuito sendo executado. Contudo, o uso de tais técnicas nunca foi estudado até a presente data. Espera-se que em traballıos futuros do grupo de computação reconfigurável do ICLC/USP: a junçāo de tais técnicas possam ser estudadas e possivelnente implementadas (nesmo que seja apenas para o desbravamento da área), de forma a trazer algmma contribuição para a área.

No cntanto, laz-se necessírio destacar que cada mua dessas áreas já é bastante complexa por si só, c que a junção de ambas tende a exponencializar tais complexidarles.

\subsubsection{Extensão da Linguagem CES}

$\Lambda$ linguagen CES já possui inúmeros recursos para a construção de software para robótica, existem alguns ítens que podem ser melhorados/acrescentados. Un cxemplo disso é o suporte a DSP, o qual é muito utilizado para o processamento dos sinais recebidos pelos sensores e enviados para os atuadores, o qual é inexistente na linguagen CHS. Fssa extensão envolveria a inclusão de tipos de dados especiais para DSP (tais como núneros de ponto fixo e logarítmicos) e de funções especiais para tratamento de sinais (tais cono filtros e compressores/decomprossores de dados). A inclusão dessas funcionalidades poderia facilitar ainda mais a progranação dos robôs além de servir de novas fontes potenciais para otimização do lıardware.

Outras alteraçôes que podcriam melhorar a linguagen CES scriam as inchusões de novas funções de aprendizado (supervisionado ou não), alén da inchusão de funçòes particulares de robóticia, tais como navegação e mapeamento.

Outros recursos que poderian ser acrescontados são aqueles que permitan o suporte a aplicaçocs de tempo-real. 


\subsubsection{Construção do LEGUS System}

O LEGUS System é o coração do ARCHITECT-R e, por isso, todas as opçōes que possam vir a trazer melhorias a esse sistema devem estudadas e dentro do possível testadas e validadas.

As duas principais correntes para a criação do LEGUS são: sistemas inteligentes e algoritmos evolutivos. Essas duas opções são bastante antagônicos: uma defende o uso de busca leeurística enquanto a outra defende o uso de busca cega, mana exige'o máxino de conllecinnentos provindos de un especialista enquanto a outra exige o mínimo possível, o primeiro método é bastante rápido enquanto o outro é lento e assim por diante.

A principal vantagen do uso de um sistemas inteligentes é o grau de controle que o sistema $\Lambda$ RCHITECT-R possuiria solsre o lardware sendo gerado. Já o uso de algoritmos evolutivos não permite ao sistema cer muito controle solse o lardware sendo gerado, mas possui a capacidade de gerar circuitos bastante distintos (e potenciahmente mais eficientes) daqueles comumente criados por um projetista humana, o que não é possívcl com o uso de sistemas inteligentes.

Un fator que deve ser observado é que nem todos os geradores de RPUs necessitam utilizar o mesmo estilo. Na verdade, é até recomendável que cada gerador empregue un estilo próprio, de forma a explorar ao míximo as características intrínsecas a RPU sendo gerada. Também ć importante lembrar que os geradores não precisam utilizar un único método para a geração do hardware. Por exemplo, pretende-se estudar a utilizaçĩo tanto de un sistema especialista quanto de algoritmos cvolutivos (e até mesmo de sistemas híbridos) no gerador de RPUs para a criação de redes neurais (MLP ou não). 


\subsubsection{Criação de Robôs Miniatura para Jogos de Futebol de Robôs}

Inspirados pela conquista do Penta-Campeonato do Brasil, pesquisadores da área de robótica pretendem criar uma liga brasileira de futebol de robôs (FBFR - Fedcração Brasileira de Futebol de Robôs). A criação dessa liga serviria para criar uma maior integração entro os pesquisadorcs c como uma nneta para ser alcançada pelos pesquisadores.

Essc tipo de aplicarăo parece particularmente propício para a ferramenta ARCHITECT-R:

- O uso de PLDs daria una vantagen computacional (cm termos de descmpenho) bastante clevada quando comparada com os microcontroladores communente utilizados nesse tipo de aplicação;

- Daria uma maior liberdade quanto ao interfaceamento com os sensores/atuadores e protocolos de comunicação com os outros robôs e um possível host. o que possibilitaria um melhor uso dos recurso periféricos do robô;

- Tempo de programação menor, visto que esse tipo de robô, geralmente, é progranlado utilizando-se linguagens de baixo nível;

- Possibilidade de modificação rápida dos algoritmos do robô (inclusive en termos de hardwarc) para melhor se adeculur às estratégias utilizadas pelo time adversário;

- Possibilidade de nudança quase que incediata para a estratégia antiga caso uma mudança de estratégia näo resulte en resultados melhores, mas sim piores, através do uso de buffers de configuração;

- Possibilidade de reconfiguração (ou seja, re-uso) dos robôs utilizados, em especial, para tarelias bastante distintas mantendo a execução dos algoritmos utilizados en hardware. 
Alćm disso, os robôs serviriam como uma boa plataforma empírica para validaçà̃o das idéias propostas na ferramenta.

\subsection{Conclusão}

O projeto ARCIITLCT-R possui un potencial enorme para desenvolver inúmcras áreas da computação, cun especial a robólica e a computação reconfigurável. Só que para que isso se torne realidade será necessário profundos investinnentos, tanto de recursos financeiros quanto (e, principalmente) de recursos liumanos.

Muitais idéias já foram elaboradas nos últimos anos e agora ć o momento de começar a colocar em prática tais idéias c validá-las em experimentos reais.

A criação da uma parcela do sistema que permita á execução da ferramenta (mesmo que apenas num conjunto muito pequeno de exemplos) deve ser vista como a principal prioridade dos pescuisadores relacionados com o projeto.

A futura criação de um robô bastante simples com un chip FPG $\Lambda$ seria também colaboraria en muito para o andamento das pesquisas, visto que o mesmo constituiria un antbiente de validaçäo cmpírico bastante confiável e que potencializaria a possibilidade de publicaçoes relacionadas com a ferramenta dentro de ineios relacionados com a robótica.

O ARCHITECT-R pode vir a formar inúmeros profissionais em áreas carentes no país (tanto no campo de pesquisa como no campo industrial), tais como: compiladores, sistemas digitais, sistemas opcracionais de tempo-real, compilação dintâmica, computação reconfigurável, entre outras. Somente esse potencial para criação de mão-de-obra em áreas carentes no país já justificariam o descuvolvimento do projeto, mas somado com o potencial comercial, tecuológico e cicntífico, o tomam como o projeto mais promissor dentro do grupo de pesquisa de computação reconfigurável até o presente momento. 


\section{Referências Bibliográficas}

[1] Salant M.A . Introdução à Robótica. McGraw Hill, 1990.

[2] DeHon A. Reconfigurable Architectures for General-Purpose Computing. $\mathrm{PhD}$ thesis, MIT, 1996.

[3] Farabuschi P.; Desoli G.; Fisher J. A. Clustered instruction-level parallel processors. Technical Report HPL-98-204, HP-Labs, 1998.

[4] Gonçalves R. A. Proposta de uma ferramenta para o auxílio ao desenvolvimento de hardware. Technical report, ICMC-USP, 2000.

[5] Jones J. L.; Flynn A. M.; Seiger B. A. Mobrie Robots: Inspiralion to Implementation. A K Petcrs, 1999.

(6) Meystel A. Knowlcdge Based Nested Hierarchical Control, volume 2, pages 6.3-152. JAI Press, 1990.

[7] Moritz C. A.; Ycung D.; Agarwal A. Exploiting optimal cost-performance designs for raw microprocessors.

[8] Ran B. R.; Fischer ,. A. Instruction-level parallel processing; History, overview and porspective. Technical Report HPL-92-132, HP Labs, 1992. 
[9] Waingold E.; Taylor M. B.; Sarkar V.; Lee W.; Lee V.; Kim J.; Frank M.; Finch P.; Devablaktuni S.: Barna R.; Babb J.; Amarasinghe S.; $\Lambda$ garwal A. Baring it all to software: The raw machine.

[10] Waingold F.; Taylor M. B.; Srikrishna D.; Sakar V.; Lee W.; Lee V.; Kim J.; Frank M.; Finch P.: Barua R.; Babb J.; Amarasinghe S.; Agarwal A. Baring it all to software: Raw machines. IEEE Computer Magazine, 2000.

[11] Ye Z. A. A c compiler for a processor with a reconfigurable functional unit. Master's thesis, Northwest University, 1999.

[12: Altera. www.altera.com.

[13] Altera. Excalibur backgrounder. white paper, 2000.

[14] Altera. Excalibur devclopment kit. data, sheet, 2000.

[15] Altera. Nios soft core: Nios uart peripheral. data sheet, 2000.

[16] Altera. Nios softcore mbedded processor. data sheet, 2000.

[17] Altera. Apex 20k. data sheet, 2001.

[18] Altera. Apex 20kc. data shect, 2001.

[19] Altcra. Apex ii. data sheet, 2001.

[20] Altera. Nios cmbedded processor development board. data sheet, 2001.

[21; Altcra. Nios cmbedded processor: Parallel i/o modulc. data sheet, 2001.

22] Altera. Nios cmbedded processor: Timer peripheral. data sheet, 2001.

23] Altera. Stratix. Data Shect, Abril 2002.

[24] Altera. Stratix programmable logic device family. Data Sheet, 2002.

[25] Altera. Using plds for high-performance dsp applications. White Paper, 2002.

[26] Kathail V.; Schlansker M.; Rau B. Hpl playdoh architecture specification: Version 1.0, 1994.

[27] Nabbe B. A language for reconfigurable robots. Technical Report CMC-IRTR-98-32, CMU, 1998. 
[28] Parhami B. Computer Arithmetic: Algorithms and Hardware Designs. Oxford University Press, 2000.

[29] Taylor M. 13. Design decisions in the inplenentation of a raw architecture workstation. Master's thesis, Massachusetts Institute of Techmology, 1999.

[30] Taylor M. B. The raw prototype design docunent. Technical report, Massachusetts Institute of Technology, 2000).

[31] ; Duesterwald E.; Bancrjia S. Bala V. Transparent dynamic optimization: 'The design and implenentation of dynamo. Technical Report HPL-1999-78. HP, 1999.

[32 Klaus Bergner, Andreas Rausch, and Marc Sihling. Using uml for modeling a distributed java application. Technical Report TUM-I9735, Technische Univerität München, 1997.

[33] Arkin C. Behavior-Based Robotics. The MIT Press, 2000.

[34] Arkin R. C. 'Towards the unification of navigational planning and reactive control. AAAI Spring Symposium on Robot Navigation, 1989.

[35] Arkin R. C. Integrating behavioral, perceptual, and world knowledge in reactive navigation. IEEE Robotics and Autonomous Systems, 6:105-122, 1990.

[36] Budiu M.: Goldstein S. C. Fast compilation for pipelined reconfigurable fabric's. In ACM/SIGDA International Symposium on Field Programmable Gate. Arruys, pages 195 205. AC.M Press, 1999.

[37] Figuciredo M. A.; Gloster C. Implementation of a probabilistic neural network for multi-spectral innage classification on a fpga-based custom computing machine.

[38] Kotay K.; Rus 1).; Vona M.; McGray C. The self-reconfiguring robotic molecule. IEEE International Conference on Robotics and Automation, 1998. 
[39] João M. P. Cardoso. A novel algorithm combining temporal partitioning and sharing of functional units. In IEEE 9th Symposinm on Field-Programmable. Custom Computing Machines (FCCMOl), Mai 2001.

[40] Compiler and Architecture Research Group a.t Hewlett Packarcl. The sinulation and performance monitoring environment of trimaran.

[41] Accurate Automation Corporation. Accurate automation's neural network processor (nnp) on-line brochure. htip://www.accurateautomation.com/Products/nnp ${ }_{b}$ rochure.htm.

[42] Aho A. V; Sethi R.; Ullman J. D. Compilers: Principles, Techiniques and Tools. Arldison-Wesley Publishing Company, 1986.

[43] Cilctti M. D. Modeling, Synthesis and Rapid Prototyping with Verilog HDL. Prentice Hall, 1999.

[44] Pormeleau 1). Advances in Neural Information Processing Systems 3, chapter Rapidly adapting ncural networks for autononous navigation, pages 429-435. Morgan Kaufinann, 1991.

[45] Pormeleau D. Ncural Network: Perception for Mobile Robol Guidance. Kluwer Aca(lenic Publishers, 1993.

[46] Razdan R.; Brace K.; Smith M. D. Prisc software acceleration techniques. International Conference on Computer Design. 1994.

[47] Razdan R.; Smith M. D. A high-perfomance nicroarchitecture with hardwareprogrannable functional units. IEEE MICRO, 1991.

[48] Instituto de Computaçiono Unicamp. Guaraná. http://www.ic.unicanp.br/oliva/guarana/.

[49] DeHon. The density advantage of configurable computing. IEEE Computer Magazine, 2000 .

[50] Fischer F. Neural chip sand/1 for real time pattern recognition. 
[51] Gonçalves R. A.; Wolf D. F.: Coelho F. A. S.: Teixeira M. A.; Ribeiro A. A. L.; Marques E. Architect: Un sistema de computaçäo reconfigurável. In CORE2000 Workshop de Computaçäo Reconfiguránel, 2000.

52: Gonçalves R. A.; Wolf D. F.; Rodrigues M. I.; Osorio L. F.; Moraes P. A.; Genuário L. B.; Teixeira M. A.; Ribeiro A. A. L.; Romero R. A. F.; Marquess E. Architect-r: A system for reconfigurable robots design - an overview and initial results. IFIP VLSI-SOC, 2001.

[53] Pérez-Uribe A.; Sanches E. Fpga implementation of an adjustable-size neural nctwork. International Conference on Neural Networks, pages 29-31, 1996.

[54] Vemuri R. R.; Harr R. E. Configurable computing: 'Technology and applications. IEEE Computer Magazine, 2000.

[55] Zell A. et al. SNNS: Stuttgart Neural Network Simulator User's Guide v. 4.2. UNIVERSITY OF STUTTGART and UNIVERSITY OF TUBINGEN.

56] Faraboschi P.; Brown G.; Fisher J. A.; Desoli G.; Homewood F. Lx: A technology platform for custonizable vliw embeded procssing. International Symposium on Computer Architecture, 2000).

57] Nishiyama H.; Olıwada H.; Mizoguchi F. A multiagent robot language for communication and concurrency control.

[58] Romero R. A. F. Armosh: Aprendizado em robós móvcis via software e hardware. Technical report, ICMC-USP, 2000.

[59] Thrun S.; Fox 1).; W. Burgard W.; Dellacrt F. Robust monte carlo localization for mobile robots, 2000.

[60] Wakerly J. F. Digital Deseign Principles and Practices. Prentice Hall, 20000.

[61] Desoli G. Instruction assignument for chustered vliw dsp compilers: A new approach. Technical Report HPL-98-13, HP, 1998. 
[62] Molz R. F.; Engel P. M.; Moraes F. G. Uso de 1 m ambiente codesign para a implementaçäo de redes neurais. IV Congresso Brasileiro de Redes Neurais, pages $1318,1999$.

[633 Schreiber R.; Aditya S.; Ran B. R.; Kathail V.; Malılke S.; Mbrahann S.; Snider G. IHigh-level synthesis of nomprogrammable hardware accelerators. Iechnical Report IIPL-2000-31, IIP, 2000.

[64] Thomas G. ecos: An operating system for enbedded systems. Dr. Dobb's Journal, 2000.

[65] Vassiliadis S.; Zhang M.; Delagad(0-Frias J. G. Elementary function generators for neural-network emulators. IEEE Transactions on Neural Networks, 11(6):14381449, November 2000.

[66] GNU. Gcc online documentation. littp:/www.gnu.org/software/gec/ onlinedocs/.

[67] GNU. Using, maintaining and enhancing cobol for the gnu compiler collection (gcc).

[68] The Stanford SUIF Compiler Group. Suif compiler system. www.suif.stanford.edu.

[69] Hikawa $\mathrm{H}$. Implementation of a simplificd multi layer neural network with on-chip learning.

[70] McCartor H. Advances in Neural Information Processing Systems, chapter Back Propagation Implementation on the Adaptive Solutions CNAPS Neurocomputer Chip, pages 1028-1031. Morgan Kaufmam Pub, 3 edition, 1991.

[71] Villasenor J.; Mangione-Smith W. II. Configurable computing. Scientific American, june 1997.

[72] Red Hat. ecos. http://www.redlat.com/embedded/sechnologies/ecos/.

[73] Red Hat. ecos documentution. htt.p:/sources.redhat.com/ecos/docs.litml.

174] Foren I. Computer Arithmetic Algorithms. Prentice Hall, 1993.

[75] IBM. Daisy: Dynannically architected instruction set from yorktown. www.research.ibm.com/daisy. 
'76] Ashenden P. J. The VHDL Designers Guide to VHDL. Morgan Kaufmann, 1996.

[77. Beckett J. As you like it: New technology lets non-techics customize computers. www.hpl.hp.com/news/shackleford.litml.

[78] Brown S; Rose J. Architecture of fpgas and cplds: A tutorial.

[79] Callahan T. J.; Chong P.; Dellon A.; Wawrzynek J. Fasst module mapping and placemenc for clatapaths in fpgas.

[80] Callahan T. J; Hauser J. R.; Wawrzynck J. The garp architecture and c compiler. IEEE Computer Maga wine, 2000.

[81] Callahan T. J; Wawrzynek J. Instruction level parallelism for reconfigurable computing.

[82] Callaham T.; Wawrzynek J. Compiling e to a hybrid architecture.

[83] DeHon A.; Wawrzynck J. The case for reconfigurable processors.

[84] DeIIon A.; Wawrzynek J. Reconfigurable computing: What, why, and design antomation requirements? In Proceedings of the 1999 Design Automation Conference, pages 610-615, 1999.

[85] Gowdy J. Emergent Architectures: A Case Study for Outdoor Mobile Robots. PhD thesis, Carneggie Mellon Un iversity, 2000).

[86] Hauser J. R.; Wawrzynek J. Garp: A mips processor with a reconfigurable coprocessor.

[87] Paltor I. P.; Lilius J. Digital sound recorder: $\Lambda$ case study on designing embedded systems using uml notation. Technical report, Turku Centre for Computer Science, 1999.

[88] Rumelhart D. E.; Hinton G. E.; Willians R. J. Learning representations by backpropagation erros. Nature, 323:533-536, 1986.

89] Coffam K. Real World FPGA Design with Verilog. Prentice Hall, 2000.

[90] Compton K. Programming architectures for run-tine reconfigurable systems. Master's thesis, Northwestern University, 1999. 
[91. Gertz M: Stewart D. B; Khosla. P. K. An iconic programming language for sensorbased robots. SCIAR, 1992.

[92] ÜNSAL C.; Kiliç̧öte H.; Patton M. E.; Khosla P. K. Motion planning for a modular self-reconfiguring robotic system.

[93] Eldredge J. G.; Hutchigns B. L. Rran: A harelware implenentation of backpropagation algorithm using reconfigurable f $f_{1} g a$.

[94] Fldredge J. G.; Hutchings B. L. Density enhancement of a neural network using fpgas and run-time reconfiguration. Procedings of the IEEE Workshop on FPGAs for Custom Computing Machines, pages 180-188, 1994.

[95] Moore D. L. The SUlF Programmer Guide. Stanford University.

[96] Schlansker M.; Conte T. M.; Dehnert J.; Ebcioglu K.; Fang J. Z.; Thompson C. L. Compilers for instruction-level parallclism. IEEE Computer Magazine, 30(12):63 69, 1997.

[97] Wirthlin M. J.; Hutchings B. L. Disc: The dynamic instruction set computer.

[98] Wirthlin M. J.; Hutching: B. L. A dynamic instruction set computer. IEEE Workshop on FPGAs for Custom Computing Machines, 1995.

[99] Fitch R.; Rus D.; Vona M. A basis for self-repair robots using self-reconfiguring crystal modules: 2000.

[100' Garis H.; Korkin M. 'The cam-brain machine (cbm): An fpga-based hardware tool that evolves 1000 neuron-net circuit nuodule in seconds and updates a 75 nuillion ncuron artificial brain for real-time robot control.

[101] Lan M. An overview of the suif2 system.

[102] Molz R. F, Engel P. Mi; Moraes F. G.; Torres L.; Robert M. Estudo da viabilidade de inplenentação de un sistena de localização e reconhecinnento de objetos com o uso de mas implenentadas em fpgas. CORE, pages 226-235, 2000. 
[103: Moreno J. M; Cabestany J.; Cantó E.; Faura J.; Insenser J. M. Dynanically reconfigurable strategies for implenenting neural networks models in progranmable laardware. Conference on Mixed Design of Integrated Systems, pages $379384,1999$.

[104] Moreno J. M: Cabestany J.; Cantó E.; Faurá. J.; Insenser J. M. Éngineering Applicalions of Bio-Inspired Artificial Neural Networks, chapter The Role of Dynamically Reconfiguration for Implementing Noural Networks Models in Programmable Hardware, pages 85-94. Springer-Verlag, 1999.

[105] Rus D.; Vona M. Crystalline robots: Self-reconfiguration witl compressible unit modules.

[106] Rus D.; Vona M. Self-reconfiguration planning with compressible unit modules. IEEE International Conference on Robotics and Automation, 1999.

[107! Rus D; Vona M. A basis for self-reconfiguring robots using crystal modules. IEEE/RSJ International Conference on intelligent Robots and Systems, 2000.

[108] Rus D.; Vona M. A plysical implenentation of the self-reconfiguring crystalline robot. IEEE International Conference on Robotics and Automation. 2000.

[109] Skrbek M. Fast neural network inplenentation. Neural Network: World, (5):375. $391,1999$.

[110] Yim M. Locomotion with a Unit-Modular Reconfigurable Rokot. PlhD thesis, Universitu of Stanford, 1994.

[111: Model Technology hncorporated. ModelSim Command Reforence.

[112] Model 'Technology Incorporated. ModelSim Titorinl.

[113] Model Technology Incorporated. ModelSim User's Guide.

[114] Motorola. Semiconductor reuse standard: Documentation. 'lechnical Report IPMXDSRSDOCO0001 V3.0, Motorola CO.. 2001.

[115] Motorola. Seniconductor rense standard: Functional verification. Technical Report IPMXXSRSFVX00001 V3.0, Motorola CO., 2001. 
[116] Motorola. Semiconductor reuse standard: Ip interface. Technical Report IPMXDSRSIPI00001 V3.0, Motorola CO., 2001.

[117] Motorola. Semiconductor reuse standard: Vc design-for-test. Technical Report IPMXDSRSDFT00001 V3.0, Motorola CO., 2001.

[118. Ünsal C.; Khosla P. K. Mechatronic design of a modular self-reconfiguring robotic system. IEEE Conference on Robotics and Automation, 2000.

[119] Ünsal C.; Khosila P. K. Solutions for 3-d self-reconfiguration in a nodular robotic systen: implenentation and motion plaming. Proceedings of SPIE: Sensor Fusion and Decentralized Conlrol in Robotics Systems III: 4196:388-401, 20000.

[120] Banysad O. A visual programming cnvironment for autonomous robots. Master's thesis, Dalhousie University, 2000.

121] Cardoso J. M. P. Compilaçäo de Algoritmos em JAVA para Sistemas Computacionais Reconfiguráveis com Exploraçäo s Paralelismo ao Nível das Operaçöes. $\mathrm{l}$ 'hD thesis, UNIVERSIDADE TH́CNICA DE LISBOA, Outubro 2000.

[122] Cardoso J. M. P.: Vestias M. P. Architcetures and compilers to support reconfigurable computing. www. acm.org/crossroads/xrds5-3/rcconcept.html, january 2000.

[123] Hauck S.; Fry T. W.; Hosler M. M.; Kao J. P. The chinnaera reconfigurable functional unit. IEEE Sympostum on FPGAs for Custom Computing Machines, 1997.

[124] Nilsson H. P. Porting the ginu c compiler to the cris architecture. Technical report, Lund Instituion of T'echnologie, 1998.

[125j Ye Z. A.; Moshovos A.; Hauck S.; Banerjec P. Chimata: A high-performance architecture with a tightly-coupled reconfigurable functional unit.

[126] Ye Z. A.; Shenoy N.; Hanck S.; Bancrjee P. A c compiler for a processor with a reconfigurable functional unit.

[127] XEROX PARC. Polypod. littp:/www.parc.xcrox.coml/spl/projects/modrobots/ Polypod/polypod.htm. 
[128] Aditya S.; Kathail V.; Rau B. R. Elcor's machine description system: Version 3.0. Teclmical Report HPL-98-128, HP, 1998.

[129] Aditya. S.; Rau I3. R. Automatic arditecture synthesis annl compiler retargeting for vliw and epic processors. Technical Report HPL-1999-93, HP Labs: 2000.

[130. Brooks R. A robust layered control system for a mobile robot. IEEE Joumal of Robotics and Automation, 1(1):1-10, 1986

[131] J Brooks R. A hardware retargetable distributed layered architecture for nobile robot control. ICRA, 1987.

132] Brooks R. Intelligence without reason. Technical Report 1293, MIT, 1991.

[133] Chekuri C.; Motwani R.; Johnson R. Profile-driven instruction level parallel scheduling. Technical Report IIPL-96-16, HP Labs, 1996.

[134] Fischer J. A.; Raı B. R. Instruction-level parallel processing. 'Technical Report HPL-92-02, IIP Labs, 1992.

[135: Goldstein S. C.; Schnidt H.; Budiu N.; Cadambi S.; Moe M.; Taylor R. R. Piperench: A reconfigurable architecture and compiler. IEEE Computer Magazine, 2000 .

[136] Goldstein S. C.; Schnnit I1.; Moe M.; Budliu M.: Cadambi S.; Taylor R. R.; Lanfer R. Piperench: A coprocessor for strcanning multinedia acceleration. In ISCA, pages 28--39, 1999.

[137] Hauser J. R. The garp architecture, 1997.

[138] Manière E. C.: Simmons R. Architecture, the backbone of robotic systems. ICRA, 2000.

[139] Mano M. M.; Kime C. R. Logic and Computer Design Fundamentals. Prentice Hall, 2000.

[140] Murphy R. R. Introduction to AI Robotics. The MIT Press, 2000.

[141] Rau B. R. Dynanic scheduling techniques for vliw processors. Technical Report HPL-93-52, HP Labs, 1993. 
[142] Schlansker M. S.; Rau B. R. Epic: Explicitly parallel instruction computing. Computer Magazine, pages 37-45, 2000.

[113] Zcbulum R. S.; Pacheco M. A. C.; Vellasco M. M. B. R. Evolutionary Eletronics: Automatic: Design of Eletronic Circuits and Systems by Genetic Algortihms. CRC Press, 2001.

[144] HP CAR; IMPACT Group; ReaC'I-ILP. TRIMARAN - An Infrastructure for Research in Instruction-Level Parallelism. www.trimaran.org.

[145] Compton K.; Hauck S. Configurable computing: A survey of systems and software. Technical report, University of Washington, 1999.

[146. Compton K.; Hanck S. An introduction to reconfigurable computing. IEEE Computer, 2000.

[147] Dellaert F.; Seitz S. M.: Thorpe C. E.; Thrun S. Em, momc, and chain flipping for structure from motion with unknown correspondence. Machine Learning.

[148] Doty K. L.; Jantz S. Progo: A begimning language for programming autonomous mobile robots.

[149] Hauck S. The future of reconfigurable systems. 5th Canadian Conference on Field Programmable Devices, 1998.

[150] Haykin S. Neural Networks: A Comprchensine Foundation. MakMillan Publishing/IELF, Press, 1994.

[151] Muchinick S. Advanced Compiler Design and Implementation, volune 1. Morgan Kaufmam, 1997.

[152. Nelson K.; Hanck S. Mapping methods for the chimacra reconfigurable functional unit. Technical report, Northwest University, 1997.

[153] Palem K. V.; Talla S. Adaptive explicitly parallel instruction computing. Fourth Australasian Computer Architecture Conference, 1999.

[154] Rau B. R.: Kathail V.; Aditya S. Machine-description driven compilers for epic processors. Technical Report HPL-98-40, HP, 1998. 
[155] Rau B. R.; Kathail V.; Aditya S. Machinc-description driven compilers for epic processors. Technical Report HPL-1998-40, HP, 1998.

156] Ran B. R.: Schlansker M. S. Énbedded computer architecture and automation. Computer Magazine, pages 75 83, 2001.

157] Thrun S. Bayesian landmark learning for mobile robot localization. Machine Leaming, 33:41, 1998.

[158] Thrun S. $\Lambda$ framework for programming enbededed systens: Initial design and results. Tcchnical Report CMU-CS-98-112. Carnegie Mellon, 1998.

[159] Thrun S. Learning motric-topological maps for indoor mobile robot navigation. Artificial Intelligence, 1(99):21 71, 1998.

[160] Thrm S. Probabilistic algorithm in robotics. Technical Report CMU-CS-00-126, Carnegie Mellon, 2000.

161] Thrun S. Towards programming tools for robotics that integrate probabilistic conputation and lcarning. Technical report, Carnegie Mellon, 2000.

[162] Yalamanchili S. Introductory VHDL: From Simulation to Synthesis. Prentice Hall, 2001.

[163] Stanford Univeristy. The SUIF Interfaces Guide.

[164] Stanford Univeristy. The SUIF Program Representation Guide.

[165] Thrum S.; Fox D.; Burgard W. A probabilistic approach to concurrent mapping and localization for mobile robots. Autonomous Robots, 5:253-271, 1998. 